\begin{tabular}{|c|c|}
\hline $\begin{array}{c}\text { UnB } \\
\text { Universidade de Brasilia }\end{array}$ & $\begin{array}{c}\text { UnPB } \\
\text { Universidade Federal da } \\
\text { Paraíba }\end{array}$ \\
Programa Multiinstitucional e Inter-Regional de Pós-graduação em Ciências Contáneis do Rio \\
Grande do Norte
\end{tabular}

\title{
PROVISÃO PARA CRÉDITOS DE LIQUIDAÇÃO DUVIDOSA DE BANCOS E CICLOS ECONÔMICOS: O CASO BRASILEIRO
}

\section{ROBERTA LIRA CANECA}

Orientador: Prof. Dr. Paulo Roberto Barbosa Lustosa 
UNIVERSIDADE DE BRASÍLIA

UNIVERSIDADE FEDERAL DA PARAÍBA

UNIVERSIDADE FEDERAL DO RIO GRANDE DO NORTE

PROGRAMA MULTI-INSTITUCIONAL E INTER-REGIONAL DE PÓS-

GRADUAÇÃO EM CIÊNCIAS CONTÁBEIS

ROBERTA LIRA CANECA

PROVISÃO PARA CRÉDITOS DE LIQUIDAÇÃO DUVIDOSA DE BANCOS E CICLOS ECONÔMICOS: O CASO BRASILEIRO 
Prof. Dr. Ivan Marques de Toledo Camargo Reitor da Universidade de Brasília

Prof. Dra. Sonia Báo

Vice-reitora da Universidade de Brasília

Prof. Dr. Jaime Martins de Santana

Decano de Pesquisa e Pós-graduação

Prof. Dr. Roberto de Goes Ellery Júnior

Diretor da Faculdade de Economia, Administração, Contabilidade e Ciências Políticas

Prof. Dr. José Antônio França

Chefe do Departamento de Ciências Contábeis e Atuariais

Prof. Dr. Rodrigo de Souza Gonçalves

Coordenador Geral do Programa Multi-institucional e Inter-regional de Pós-graduação em Ciências Contábeis - UnB/UFPB/UFRN 
Tese apresentada ao Programa Multiinstitucional e Inter-regional de Pós-graduação em Ciências Contábeis - UnB/UFPB/UFRN, como requisito para a obtenção do título de Doutor em Ciências Contábeis

Orientador:

Prof. Dr. Paulo Roberto Barbosa Lustosa 
TERMO DE APROVAÇÃO

ROBERTA LIRA CANECA

\section{PROVISÃO PARA CRÉDITOS DE LIQUIDAÇÃO DUVIDOSA DE BANCOS E CICLOS ECONÔMICOS: O CASO BRASILEIRO}

Tese apresentada ao Programa Multi-institucional e Inter-regional de Pós-graduação em Ciências Contábeis UnB/UFPB/UFRN, como requisito para a obtenção do título de Doutor em Ciências Contábeis.

Banca Examinadora:

Prof. Dr. Paulo Roberto Barbosa Lustosa

Presidente da Banca

Prof. Dr. José Alves Dantas

Membro Examinador Interno

Prof. Otávio Ribeiro de Medeiros, PhD.

Membro Examinador Interno

Prof. Dr. José Elias Feres de Almeida

Membro Examinador Externo

Prof. Dr. Bruno Meirelles Salotti.

Membro Examinador Externo

Brasília, 31 de outubro de 2015 
Caneca, Roberta Lira

Provisão para créditos de liquidação duvidosa de bancos e ciclos econômicos: o caso brasileiro / Roberta Lira Caneca, Brasília: UnB, 2015.

XXX p.

Orientador: Prof. Dr. Paulo Roberto Barbosa Lustosa.

Tese (Doutorado) - Universidade de Brasília (UnB). Faculdade de Economia, Administração, Contabilidade e Ciências Políticas (FACE). Programa Multi-institucional e Inter-regional de Pósgraduação em Ciências Contábeis UnB/UFPB/UFRN.

1. Ciclos econômicos 2. Despesa com créditos de liquidação duvidosa 3. Perda incorrida 4. Perda esperada 5. Empréstimos bancários. 
Ao meu filho Gabriel, dedico este trabalho, com todo o meu amor. 


\section{AGRADECIMENTOS}

Primeiramente, à minha família: ao meu filho Gabriel, sem dúvida o mais sacrificado durante toda esta jornada e, ao mesmo tempo, grande companheiro e maior incentivador; à minha mãe, Madalena; a Biane, minha "mãe torta" e aos meus irmãos, pelo apoio, carinho e dedicação dispensados ao meu filho nos meus momentos de ausência; e ao meu Tio Toinho (in memorian), que sempre torceu pelo meu sucesso na profissão e na vida.

Aos meus colegas da Caixa Econômica Federal, particularmente aos meus ex-chefes e amigos Thiago Souza Silva, Ronald Fantoni, Selma Lopes Lusa e Juliana Grigol, que me permitiram cursar o doutorado e me incentivaram a fazê-lo, bem como aos gerentes Rafael Morais e Roberto Eduardo, pelo incentivo durante esta caminhada.

Aos meus colegas de trabalho e, em especial, às amigas que trabalham diretamente comigo, Ana Elen, Fabiana, Karen, Sandra e Vanessa, pela compreensão e apoio nos momentos em que estive ausente, e por suas colaborações, sem as quais não teria sido possível completar este trabalho.

Aos meus amigos e colegas de turma do doutorado, Adriana, Carlos, Ercilio, Gustavo, Jailson, Nair, Rossana e Valdemir, pela amizade e companheirismo ao longo de nossa convivência no doutorado, tornando prazerosos até os momentos mais difíceis e, sem dúvida, selando uma amizade para toda a vida.

Ao meu grande amigo e mentor, professor Luiz Carlos Miranda, pela amizade e apoio e por, certamente, ser um dos maiores torcedores pelo meu sucesso.

Aos professores do Programa Multi-institucional, pelos conhecimentos transmitidos, sobretudo aos professores Edilson Paulo e Otávio Medeiros pelas valiosas colaborações a esta pesquisa.

Ao meu orientador, Prof. Dr. Paulo Lustosa, pela orientação, paciência, incentivo e ajuda na construção deste trabalho de pesquisa e pela relação de amizade e parceria. Espero que esta seja longa e vitoriosa.

Aos membros da banca de defesa, professores José Alves Dantas, Otávio Medeiros, José Elias Feres e Bruno Salotti, pelas valiosas contribuições para a melhoria deste estudo.

Por fim, a todos que, de uma forma ou de outra, embora não mencionados individualmente, contribuíram de forma positiva para a execução deste trabalho. 
“As mãos que fazem valem mais que os lábios que rezam". Madre Teresa de Calcutá 


\section{RESUMO}

A crise financeira de 2008, iniciada nos Estados Unidos da América, teve, como uma de suas consequências, a indicação de que algumas práticas contábeis vigentes contribuíram para o seu agravamento. Dentre essas práticas, está o modelo de provisão para perdas com empréstimos, tanto o norte-americano como o emanado das normas internacionais de contabilidade do IASB, que consiste numa metodologia de perda incorrida. As normas brasileiras de contabilidade bancária ainda não convergiram completamente às normas internacionais de contabilidade. Nesse contexto, o modelo de provisão para créditos de liquidação duvidosa adotado pelos bancos brasileiros é determinado pelo Conselho Monetário Nacional, através de sua Resolução $\mathrm{N}^{\mathrm{o}}$ 2.682/99, e constitui-se em uma metodologia mista de perda incorrida e perda esperada. O Brasil, para lidar com os efeitos da crise do sistema financeiro internacional, ao contrário da tendência mundial, expandiu o crédito e promoveu um incentivo maior ao consumo. Uma das justificativas para tal movimento seria o fato de que o modelo de reconhecimento de perdas da Resolução CMN No 2.682/99 teria proporcionado que os bancos construíssem um colchão para absorver os impactos de uma eventual crise financeira. Esse trabalho teve por objetivo investigar a relação entre os ciclos econômicos do Brasil e a despesa com créditos de liquidação duvidosa (DPCLD) dos brasileiros. O propósito foi verificar como a DPCLD registrada pelos bancos, no Brasil, tem respondido às oscilações do ambiente macroeconômico brasileiro, considerando-se as discussões sobre qual seria o método mais adequado para a constituição de provisão para perdas com créditos, capaz de diminuir a pró-ciclicidade dos empréstimos bancários, os quais, de forma geral, tendem a exacerbar os ciclos econômicos. Apesar de estabelecer regras mínimas de constituição da PCLD, a Resolução CMN No 2.682/99 permite aos bancos brasileiros a constituição de provisões adicionais, caso julguem necessário. Neste trabalho, deduziu-se uma fórmula, e procedeu-se ao cálculo, do valor da DPCLD dos bancos brasileiros, com base nas regras mínimas de provisão da Resolução CMN No 2.682/99, ou seja, sem considerar as provisões adicionais; analisou-se, então, qual seria o comportamento dessa DPCLD, sem provisões adicionais, em relação aos ciclos econômicos do País. Adicionalmente, foram simulados valores da DPCLD dos bancos brasileiros, pelos métodos da perda incorrida e da perda esperada, segundo modelos teóricos de provisão propostos por Bouvatier e Lepetit (2012a); os valores obtidos para a DPCLD, pela aplicação dos modelos propostos pelos pesquisadores, também foram objetos de análise quanto ao seu comportamento frente às oscilações dos ciclos econômicos do Brasil. Para investigar a relação entre os ciclos econômicos do Brasil e a DPCLD dos bancos brasileiros, foi especificado um modelo econométrico que permitisse essa análise e, ainda, que permitisse identificar a metodologia de provisão predominante no modelo misto de provisão da Resolução CMN N ${ }^{o}$ 2.682/99, se da perda esperada ou da perda incorrida. No modelo especificado, foi adotada como proxy dos ciclos econômicos a variação percentual do PIB real. A pesquisa foi realizada com base nos bancos brasileiros, com uma amostra de estudo composta das informações financeiras trimestrais de 148 bancos atuantes no Brasil, no período entre o $1^{\circ}$ trimestre de 2001 e o $4^{\circ}$ trimestre de 2012. Os resultados desta pesquisa indicam uma relação negativa entre os ciclos econômicos do Brasil e a DPCLD registrada pelos bancos brasileiros, uma vez que estes provisionam menos em períodos de expansão e mais em períodos recessivos, ou seja, da forma como é constituída pelos bancos, a DPCLD não é capaz de conter a próciclicidade dos empréstimos bancários.

Palavras-chave: ciclos econômicos; despesa com créditos de liquidação duvidosa; perda incorrida; perda esperada; empréstimos bancários. 


\begin{abstract}
The recent world financial crisis which started in the US in 2008 and still affects the world economy has had as one of its consequences the indication that some of the prevailing accounting practices contributed to worsening the crisis. Among these practices are the models of loan loss provisions, both the American one and also the one emanating from IASB's international accounting norms, which is based on an incurred loss methodology. The Brazilian banking accounting norms have not yet converged entirely towards international accounting norms, and the model of provision for doubtful credits adopted by Brazilian banks established by the National Monetary Council by means of its Resolution CMN No 2.682/99 consists of a mixed methodology of incurred and expected losses. Brazil, attempting to deal with the effects of the financial crisis, followed an opposite path with respect to the rest of the world, with a strong domestic credit expansion and high incentives to consumption. One of the justifications for such movements was that the model of loss recognition of the Resolution CMN N $2.682 / 99$ would allow banks to build a cushion to absorb the impacts of an eventual financial crisis. The present study is aimed at investigating the relationship between business cycles and the constitution of expenses with doubtful credits accounted for by Brazilian banks. The goal is to verify how the expenses with doubtful credits accounted for by banks in Brazil have reacted to changes in the Brazilian macroeconomic environment having in mind the debate around which method of loss provision would be more appropriate to diminish the pro-cyclicality of bank loans which by and large tend to intensify the business cycles, both in expansion and recession periods as well. As the Resolution CMN N 2.682/99 despite establishing minimum rules for constituting provisions for doubtful credits allows banks to constitute additional provisions, we have estimated the value of the provision for doubtful credits and the expenses with its provision which would have been accounted for by the Brazilian banks if they did not have the option to constitute additional provisions. Additionally, expenses with the provision of doubtful debts of Brazilian banks were simulated according to theoretical provision models based on incurred and expected losses proposed by Bouvatier and Lepetit (2012). Relationships between simulated values of expenses with the provision of doubtful credits and Brazilian business cycles were also tested. To test the latter, an econometric model was specified to capture the mentioned relationship and also check the dominating methodology in the Brazilian model, if expected or incurred loss. In the specified model, percent changes in real GDP were used as a proxy for business cycles. In order to perform the research, a sample containing quarterly financial data of 148 banks operating in Brazil during the period from the 1st quarter of 2001 and the 4th quarter of 2012 were collected. Among other finds, the research results indicate a negative relationship between the business cycles and the expensed with the provision for doubtful credits accounted for by Brazilian banks, indicating that banks make less provisions in expansion periods and more in recession periods, which means that in the manner they are constituted by Brazilian banks, the expenses with the provision for doubtful credits are not capable of restraining the procyclicality of bank loans.
\end{abstract}

Keywords: Business cycles; Expenses with dobtful credits; Incurred loss; Expected loss; Bank loans. 


\section{LISTA DE QUADROS}

Quadro 1 - Origem das informações necessárias à pesquisa ................................................42

Quadro 2 - DPCLD de acordo com a hipótese da pesquisa a ser testada................................56

Quadro 3 - Sinais esperados das variáveis independentes do modelo .....................................59

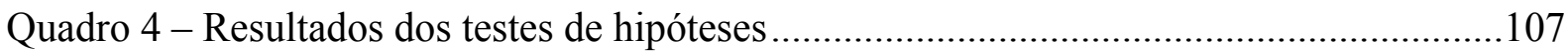




\section{LISTA DE TABELAS}

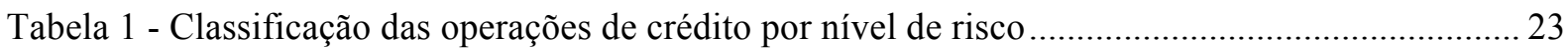

Tabela 2 - Estatísticas descritivas da PCLD trimestral segregada por nível de risco de crédito ............ 66

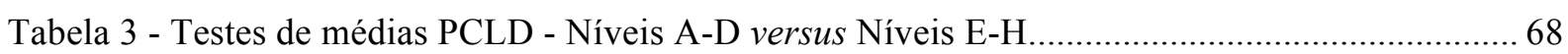

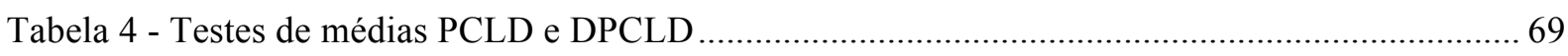

Tabela 5 - Testes de médias DPCLD calculada versus Bouvatier e Lepetit (2012a) ............................ 71

Tabela 6 - Painéis para análise modelos derivados da equação 13 ....................................................... 74

Tabela 7 - Testes ADF-Fisher e PP-Fisher - DPCLD informada e calculada ......................................... 76

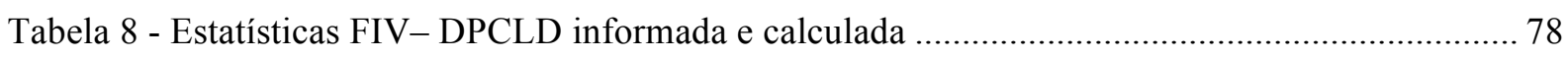

Tabela 9 - Matriz de correlação de Pearson - DPCLD informada e calculada ...................................... 79

Tabela 10 - Testes ADF-Fisher e PP-Fisher - Perda esperada e incorrida .............................................. 83

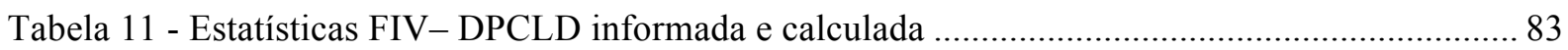

Tabela 12 - Matriz de correlação de Pearson - DPCLD - perda incorrida e perda esperada................. 84

Tabela 13 - Composição de variância das variáveis do modelo ............................................................. 89

Tabela 14 - Composição das variáveis do modelo - Bouvatier e Lepetit (2012a) ................................ 90

Tabela 15 - Regressões com erros-padrão robutos clusterizados ..................................................... 91

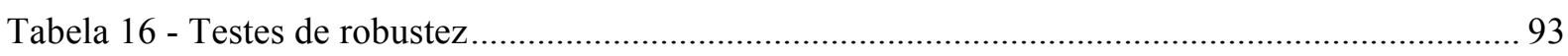

Tabela 17 - Regressões com erros-padrão robustos clusterizados ....................................................... 96 


\section{LISTA DE SIGLAS E ABREVIATURAS}

BACEN: Banco Central do Brasil

BRGAAP: Normas Brasileiras de Contabilidade para Instituições Financeiras

CDO: $\quad$ Collateralized Debt Obligation

CMN: Conselho Monetário Nacional

DPCLD: Despesa com provisão para créditos de liquidação duvidosa

FED: $\quad$ Federal Reserve

FHA: $\quad$ Federal Housing Administration

FOMC: $\quad$ Federal Open Market Comittee

FSB: $\quad$ Financial Stability Board

G10: $\quad$ Grupo dos 10

G20: $\quad$ Grupo dos 20

IAS: $\quad$ International Accounting Standard

IASB: $\quad$ International Accounting Standards Board

IFRS: $\quad$ International Financial Reporting Standards

IFT: $\quad$ Informações Financeiras Trimestrais

LIBOR: $\quad$ London Interbank Offered Rate

NASDAQ: $\quad$ National Association of Securities Dealers Automated Quotations

PCLD: $\quad$ Provisão para créditos de liquidação duvidosa

SIV: $\quad$ Structured Investment Vehicles 


\section{SUMÁRIO}

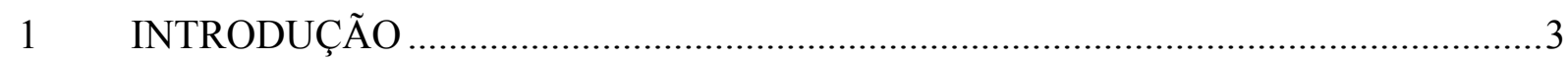

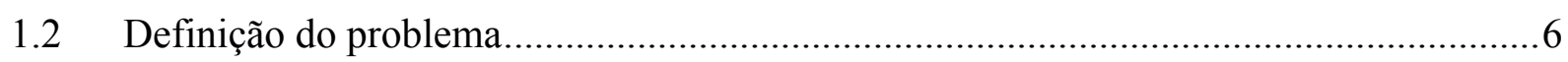

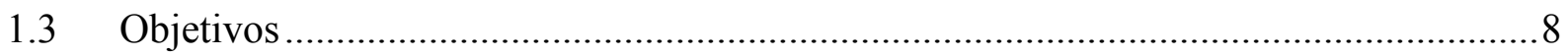

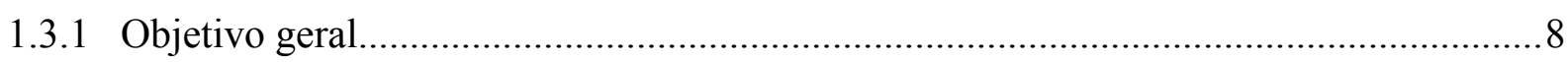

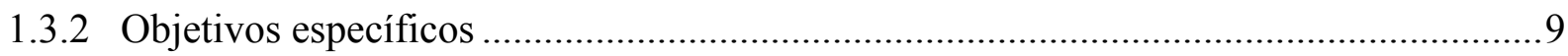

1.4 Relevância e caráter inovador da pesquisa .................................................................

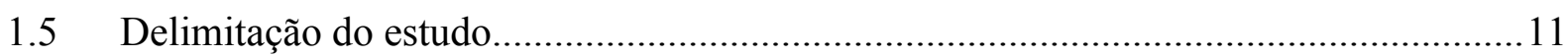

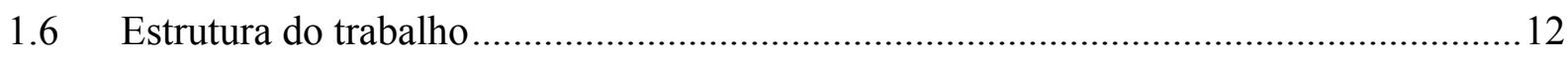

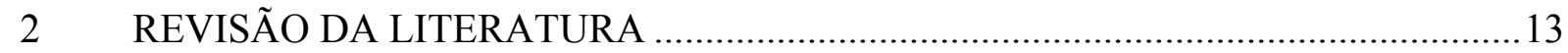

2.1 A crise financeira internacional de 2008 e seus desdobramentos .................................13

2.2 Os reflexos da crise financeira internacional de 2008 no Brasil....................................18

2.3 O ambiente regulatório contábil internacional: IAS 39 - Financial Instruments: Recognition and Measurement e IFRS 9 - Financial Instruments ...........20

2.4 O ambiente regulatório bancário brasileiro e a metodologia de cálculo da provisão para créditos de liquidação duvidosa segundo a Resolução CMN No 2.682/99 ............22

2.5 Os modelos de perdas estimadas com créditos de liquidação duvidosa ........................24

2.6 "Estado da arte" das pesquisas relacionadas ao tema de estudo..................................25

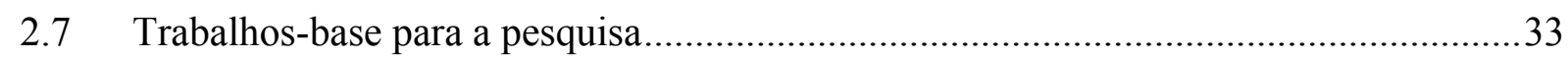

2.7.1 A pesquisa de Beatty e Liao (2011) ...............................................................................33

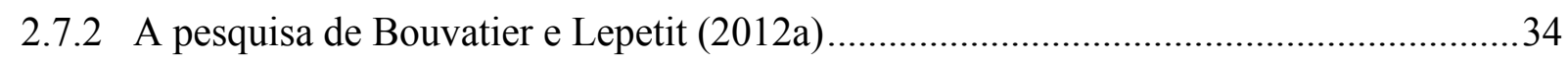

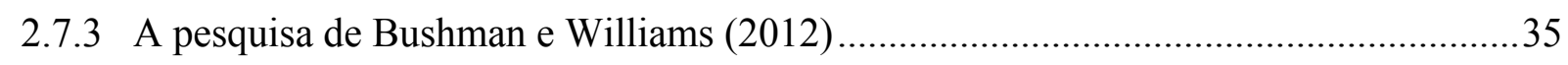

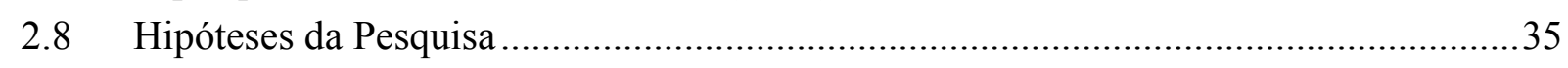

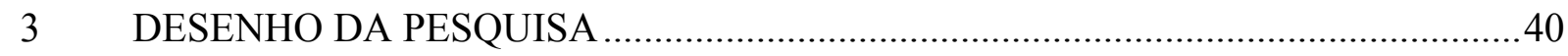

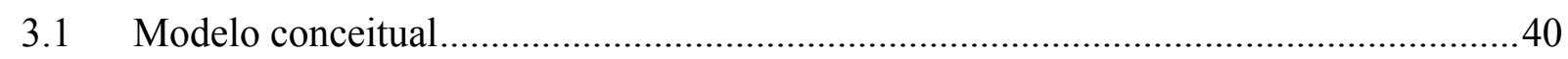

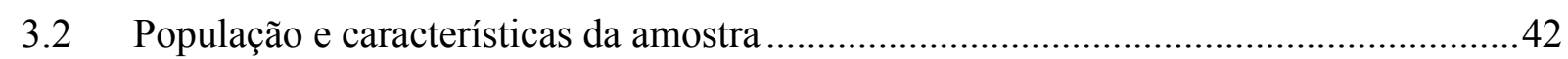

3.3 Processo de coleta dos dados e constituição da amostra.................................................4

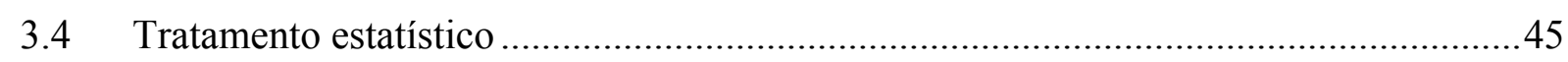

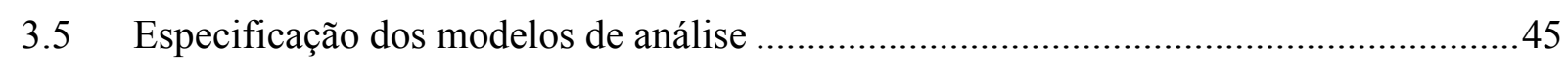

3.5.1 Especificação do modelo para cálculo da PCLD e da DPCLD, de acordo com a Resolução CMN N ${ }^{0}$ 2.682/99 ...........................................................................46

3.5.2 Modelos de estimação da DPCLD não discricionária ................................................49

3.5.2.1 Cálculo da fração média dos empréstimos em atraso, cobertos pela PCLD do

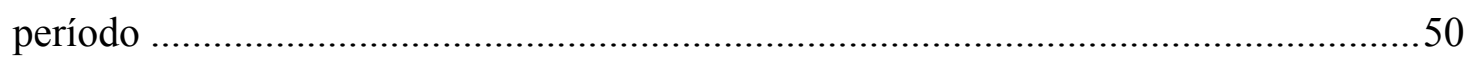

3.5.2.2 Cálculo da proporção média de empréstimos em atraso no período, em relação ao

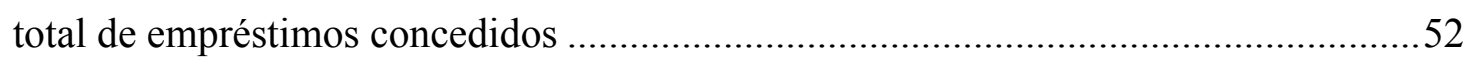

3.5.2.3 Cálculo da fração de empréstimos em atraso pelo método da perda incorrida.............53

3.5.3 Análise da relação entre a despesa com créditos de liquidação duvidosa dos bancos brasileiros e os ciclos econômicos do Brasil.......................................................56 
4.1 Análise da composição da provisão para créditos de liquidação duvidosa dos bancos brasileiros

4.2 A provisão para créditos de liquidação duvidosa calculada conforme a Resolução $\mathrm{CMN} \mathrm{N}^{\mathrm{o}} 2.682 / 99$ e os valores efetivamente registrados pelos bancos

4.3 A despesa com provisão para créditos de liquidação duvidosa de acordo com os modelos teóricos de Bouvatier e Lepetit (2012a)....

4.4 Análise da relação entre os ciclos econômicos do Brasil e a DPCLD dos bancos brasileiros.

4.4.1 Estruturação dos modelos de análise: testes de estacionariedade, de risco de multicolinearidade e adequação das variáveis dos modelos

4.4.1.1 Modelo de análise da relação entre os ciclos econômicos do Brasil e a DPCLD registrada pelos bancos brasileiros

4.4.1.2 Modelo de análise da relação entre os ciclos econômicos do Brasil da DPCLD calculada de acordo com as regras da Resolução CMN No 2.682/99

4.4.1.3 Modelo de análise da relação entre os ciclos econômidos do Brasil e a DPCLD pela perda esperada, segundo Bouvatier e Lepetit (2012a)

4.4.1.4 Modelo de análise da relação entre os ciclos econômicos do Brasil e a DPCLD pela perda incorrida, segundo Bouvatier e Lepetit (2012a)

4.4.2 Análise dos modelos estimados para investigar a relação entre os ciclos econômicos do Brasil e a DPCLD dos bancos brasileiros

4.4.2.1 Análise das tabelas de composição de variâncias das variáveis do painel.

4.4.2.2 Análise das significâncias dos modelos e testes de robustez

4.4.3 Análises das regressões dos modelos de dados em painel que investigam as relações entre os ciclos econômicos do Brasil e a DPCLD dos bancos brasileiros ......95

4.4.3.1 Análise da relação entre os ciclos econômicos do Brasil e a DPCLD efetivamente registrada pelos bancos brasileiros

4.4.3.2 Análise da relação entre os ciclos econômicos do Brasil e a DPCLD calculada de acordo com as regras mínimas de provisão da Resolução CMN No 2.682/99 100

4.4.3.3 Análise da relação entre os ciclos econômicos do Brasil e a DPCLD pela perda esperada, de Bouvatier e Lepetit (2012a).

4.4.3.4 Análise da relação entre os ciclos econômicos do Brasil e a DPCLD pela perda incorrida, de Bouvatier e Lepetit (2012a) ....................................................... 104

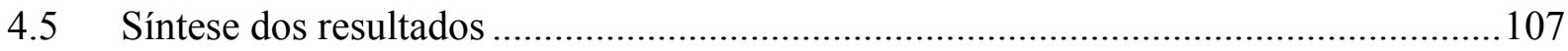

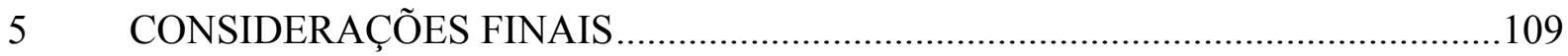

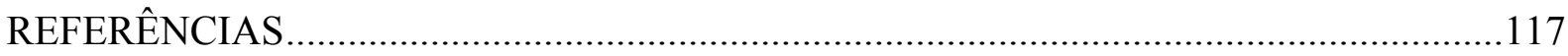

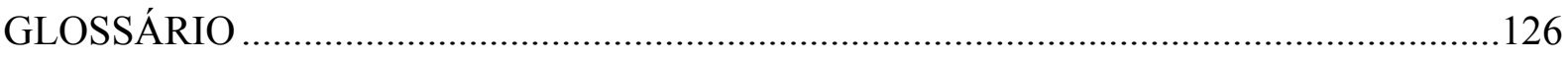

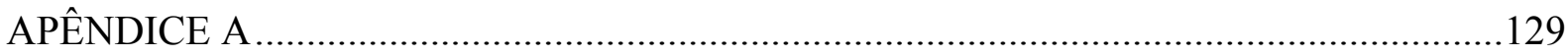

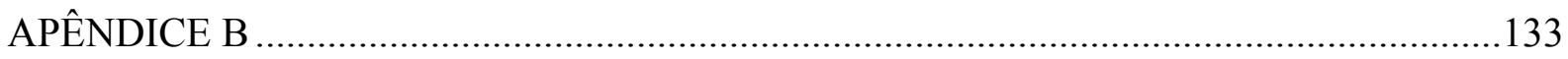




\section{INTRODUÇÃO}

As sucessivas crises financeiras, que tiveram início em 2008 nos Estados Unidos da América, propagaram-se pela União Europeia e, oito anos depois, ainda causam reflexos na economia mundial, mais uma vez suscitaram discussões sobre a adequação das metodologias contábeis praticadas para auxiliar na proteção dos mercados.

O Financial Stability Board (FSB, 2009) apontou como uma das causas da crise do sistema financeiro de 2008 o modelo de perda incorrida para o reconhecimento de perdas com instrumentos financeiros e instou o International Accounting Standards Board (IASB) a acelerar o processo de revisão da International Accounting Standard (IAS) 39 - Financial Instruments: Recognition and Measurement (IASB, 2008), bem como o processo de convergência entre as normas contábeis do IASB e do Financial Accounting Standards Board (FASB).

Conforme o modelo de reconhecimento de perdas através de instrumentos financeiros da IAS 39 (IASB, 2008), ainda em vigor $^{1}$, principalmente nos países da União Europeia, uma perda somente deve ser reconhecida quando houver evidência objetiva de que os fluxos futuros de caixa esperados não fluirão para a entidade em sua totalidade. Dessa forma, os bancos só reconheceriam perdas com empréstimos após a ocorrência destas.

Uma das consequências dos períodos de crise dos mercados financeiros é o aumento da inadimplência, o que obriga os bancos a reconhecerem mais perdas e, em decorrência, enfrentar problemas de capital regulatório. Com restrições de capital, os bancos passam a dispor de menos recursos para emprestar.

Beatty e Liao (2011) conduziram pesquisa sobre a associação entre a metodologia de reconhecimento de perdas, capital regulatório e operações de crédito de instituições financeiras americanas em períodos de recessão. Os pesquisadores concluíram que o atraso no reconhecimento de perdas incorridas, somado a restrições de capital regulatório em tempos de recessão, favorece a pró-ciclicidade dos empréstimos bancários.

\footnotetext{
${ }^{1}$ Em julho de 2014, o processo de substituição da IAS 39 pela IFRS 9 foi concluído; entretanto, sua adoção é mandatória apenas a partir de $1^{\circ}$ de janeiro de 2018 .
} 
Conforme Bushman e Williams (2012), pró-ciclicidade refere-se ao exagero de tendências cíclicas na atividade econômica agregada, amplificando as flutuações dos ciclos econômicos. Os mesmos autores afirmam que, quando o saldo constituído para perdas estimadas com créditos de liquidação duvidosa não é suficiente para absorver perdas com créditos em períodos de recessão, o maior reconhecimento de perdas com empréstimos faz com que os bancos enfrentem problemas de liquidez, forçando-os a reduzir o nível de empréstimos, o que acaba por agravar a crise.

De acordo com FSB (2009), em períodos de retrações econômicas, um sistema financeiro enfraquecido não tem como absorver mais perdas sem causar uma retração ainda maior.

Por outro lado, além da qualidade do crédito e do capital regulatório, verifica-se a existência de outros fatores que influenciam a propensão dos bancos a emprestar, pois estes passaram de uma posição de simples intermediários para verdadeiros influenciadores do nível de crescimento econômico de determinado país.

Segundo a visão tradicional do pensamento econômico, mercados financeiros são simples "escravos da indústria"; entretanto, recentes pesquisas em economia têm sugerido exatamente o contrário, pois os intermediários financeiros acabam por desempenhar um papel central na determinação dos padrões de negócios e crescimento de um país, definindo as organizações que vão sobreviver ou perecer, quais empreendedores controlarão ou não as organizações e os tipos de investimentos que podem ser feitos ou não, e que novos produtos serão introduzidos (KING; LEVINE, 1993a).

Infere-se que uma das formas do sistema bancário gerenciar tanto o nível de crédito como fomentar o setor da indústria seja o gerenciamento do nível de provisão ${ }^{2}$ para perdas com créditos de liquidação duvidosa (PCLD). Esse mecanismo é influenciado por vários fatores, dentre os quais os principais são a análise de risco de crédito e o capital regulatório, além da qualidade da carteira de crédito.

\footnotetext{
${ }^{2}$ O termo "provisão", em contabilidade, é definido como um passivo de prazo ou valor incerto (CPC, 2009; IASB, 2009) e, por isso, tem sido considerado inadequado para representar contas redutoras do ativo (IUDÍCIBUS et al., 2013). Entretanto, o Plano Contábil das Instituições do Sistema Financeiro Nacional (COSIF), criado pelo BACEN com a edição da Circular 1.273, em 29 de dezembro de 1987, adota o termo "provisão" para representar as perdas estimadas com empréstimos. Por se tratar de uma pesquisa com Bancos Brasileiros, no presente trabalho é adotada a expressão "provisão para créditos de liquidação duvidosa", em consonância com o COSIF.
} 
O Brasil, para lidar com os efeitos da crise do sistema financeiro internacional, optou por uma orientação contrária à dos outros países, com a expansão do crédito e o incentivo maior ao consumo. Uma das justificativas apresentadas pelo Banco Central do Brasil (BACEN) para tal movimento é que o modelo de reconhecimento de perdas da Resolução $\mathrm{N}^{\mathrm{o}} 2.682$, de 21 de dezembro de 1999, do Conselho Monetário Nacional (Resolução CMN No 2.682/99), atualmente adotado pelas instituições financeiras atuantes no Brasil, permitiu que estas construíssem um colchão para absorver os impactos de uma eventual crise financeira.

O modelo de PCLD, segundo a Resolução CMN N 2.682/99, é um misto de perda esperada e perda incorrida. No momento da concessão do crédito é constituída uma PCLD de acordo com a classificação de risco de crédito do tomador e da operação. Essa classificação é periodicamente revisada ao longo da duração do empréstimo e, caso necessário, provisões adicionais são efetuadas, a depender do comportamento do tomador e da carteira de empréstimos.

Entretanto, modelos de provisão que consideram perdas futuras esperadas com empréstimos, apesar de contribuírem para a diminuição da pró-ciclicidade dos empréstimos, permitem maior discricionariedade por parte das instituições financeiras, podendo dificultar a fiscalização por parte dos reguladores bancários e criar ambiente favorável ao gerenciamento de resultados através da despesa com créditos de liquidação duvidosa (BUSHMAN; WILLIAMS, 2012).

Bouvatier e Lepetit (2012) estudaram a relação entre diferentes metodologias de cálculo da despesa com créditos de liquidação duvidosa (DPCLD) e ciclos econômicos. Em seu trabalho, os pesquisadores desenvolveram modelos teóricos, segundo eles não discricionários, para cálculo da DPCLD pelos métodos da perda incorrida e da perda esperada. Os achados de Bouvatier e Lepetit (2012) foram que a DPCLD pela perda incorrida favorece a próciclicidade dos empréstimos, ao passo que a DPCLD pela perda esperada contribui para a diminuição da pró-ciclicidade dos empréstimos e, dessa forma, não contribui para o agravamento das crises.

Como, no Brasil, o Sistema Financeiro é fortemente regulado pelo CMN que, através da sua Resolução $\mathrm{N}^{\mathrm{o}}$ 2.682/99, estabelece uma metodologia mista de cálculo da DPCLD a ser registrada pelas instituições financeiras que atuam no Brasil, esta pesquisa investiga a relação 
entre os ciclos econômicos do Brasil e a DPCLD reconhecida pelas instituições financeiras atuantes no país.

Além da Resolução CMN No 2.682/99, determinante da metodologia de cálculo da DPCLD para os bancos em atividade no Brasil, este trabalho baseia-se nos seguintes estudos, de:

a) Beatty e Liao (2011), que estudaram como os retardos no reconhecimento de perdas com empréstimos pelos bancos afetam sua propensão a emprestar, especialmente em tempos de crise;

b) Bushman e Williams (2012), que pesquisaram os elementos que constituem a DPCLD registrada em 27 países e discutem as metodologias de cálculo de provisão para perdas com créditos (perda incorrida e perda esperada); e

c) Bouvatier e Lepetit (2012a), que desenvolveram modelos teóricos não discricionários para cálculo da DPCLD, pelos métodos da perda incorrida e perda esperada, aplicáveis a instituições financeiras, e testaram suas relações com os ciclos econômicos.

Esses trabalhos serviram de base para a construção dos modelos que testam as hipóteses levantadas para responder ao problema central desta pesquisa: investigar a relação entre os ciclos econômicos do Brasil e a DPCLD dos bancos brasileiros.

\subsection{Definição do problema}

A propensão dos bancos a emprestar é influenciada por vários fatores, tanto legais como estratégicos, tais como adequação de capital regulatório, qualidade da carteira de crédito e decisões sobre o setor da indústria a ser impulsionado.

As peculiaridades das instituições financeiras, notadamente o fato de atuarem em um ambiente com elevado potencial de risco sistêmico, que pode ocasionar danosos impactos à sociedade, resultam na necessidade de um sistema de regulação específico e rigoroso. No entanto, esse sistema de regulação não impede que elas desenvolvam mecanismos próprios e diferenciados umas das outras de gerenciar suas decisões de crédito as quais podem influenciar os rumos do setor produtivo e os ciclos econômicos dos países onde atuam. 
Segundo Beatty e Liao (2011), instituições que retardam o reconhecimento de perdas com créditos, isto é, possuem modelos de provisão ex-post, são menos propensas a emprestar em períodos de crise financeira devido às restrições de capital regulatório, favorecendo a próciclicidade dos empréstimos.

Por outro lado, modelos de provisão ex-ante, considerando perdas futuras esperadas com empréstimos, apesar de diminuírem a pró-ciclicidade dos empréstimos, podem criar um ambiente favorável a práticas discricionárias de gerenciamento de resultados e, dessa forma, desvirtuar o objetivo da PCLD, o qual é a prevenção contra perdas com créditos (BUSHMAN; WILLIAMS, 2012).

Como o nível de crédito exerce influência e é influenciado pelos ciclos econômicos (ROCHA; NAKANE, 2007) e o reconhecimento de perdas estimadas restringe a oferta de crédito pelas instituições que adotam modelos de provisão ex-post, infere-se que a DPCLD possua uma influência indireta na propensão dos bancos a emprestar. Estudos atestam que modelos de provisão ex-ante são anticíclicos e que modelos de provisão ex-post são pró-cíclicos (BOUVATIER; LEPETIT, 2012; BUSHMAN; WILLIAMS, 2012).

Considerando que estudos econômicos atestam que o nível de concessão de créditos afeta o crescimento econômico (BECK; LEVINE; LOAYZA, 2000; KING; LEVINE, 1993a, 1993b, 1993c; MATOS, 2002; SILVA; PORTO JÚNIOR, 2006; ROCHA; NAKANE, 2007; ROUSSEAU; WACHTEL, 1998) e que os bancos brasileiros, através da Resolução CMN N ${ }^{\circ}$ 2.682/99, adotam um modelo misto de provisão para perdas com créditos de liquidação duvidosa, o problema central desta pesquisa consiste em investigar a relação entre os ciclos econômicos do Brasil e a despesa com créditos de liquidação duvidosa dos bancos brasileiros. De modo adjacente, este trabalho também investiga o caráter dominante do modelo misto de provisão para créditos de liquidação duvidosa, emanado da Resolução CMN $\mathrm{N}^{\mathrm{o}} 2.682 / 99$, se é de perda incorrida ou de perda esperada.

A resposta ao problema central da pesquisa se dá através de análises empíricas do modelo de provisão para cálculo da DPCLD dos bancos brasileiros, bem como da relação entre a DPCLD e as oscilações dos ciclos econômicos do Brasil, sendo conduzida em três etapas:

a) dedução do modelo de cálculo do valor da DPCLD, considerando-se as regras mínimas de provisão contidas na Resolução CMN No 2.682/99, livre de elementos discricionários, ou seja, sem considerar a constituição de provisões adicionais permitida aos bancos 
brasileiros pela referida Resolução. Essa etapa objetiva a comparação dos valores da DPCLD efetivamente registrada pelos bancos brasileiros àqueles calculados de acordo com as regras mínimas de constituição da Resolução CMN No 2.682/99;

b) aplicação empírica dos modelos teóricos desenvolvidos por Bouvatier e Lepetit (2012a) para estimação da DPCLD pelos métodos da perda incorrida e da perda esperada, livres de elementos discricionários, segundo os próprios pesquisadores; e

c) investigação da relação entre os ciclos econômicos do Brasil e a DPCLD registrada pelos bancos brasileiros. Para tanto, é proposto um modelo de dados em painel, que permita verificar essa relação e, de modo adjacente, se a DPCLD registrada pelos bancos brasileiros possui mais características de perda esperada ou de perda incorrida.

Os resultados da pesquisa são confrontados com as teorias vigentes acerca da relação entre as metodologias de cálculo da DPCLD, os aspectos motivadores da sua constituição e sua relação com os ciclos econômicos do Brasil, de modo a verificar se a DPCLD constituída pelos brancos brasileiros é capaz de favorecer a anticiclicidade dos empréstimos. ${ }^{3}$

\subsection{Objetivos}

\subsubsection{Objetivo geral}

Este trabalho tem como objetivo geral verificar a relação entre os ciclos econômicos do Brasil e a provisão para perdas com créditos de liquidação duvidosa constituída pelos bancos brasileiros.

\footnotetext{
${ }^{3}$ Este trabalho não tem o propósito de desenvolver modelos econométricos de previsão do comportamento da DPCLD frente aos ciclos econômicos, mas tão somente o de verificar a relação existente entre a DPCLD registrada pelos bancos brasileiros e as oscilações dos ciclos econômicos.
} 


\subsubsection{Objetivos específicos}

Para alcançar o objetivo geral, são estabelecidos os seguintes objetivos específicos:

a) analisar o nível de discricionariedade da despesa com provisão para créditos de liquidação duvidosa registrada pelos bancos brasileiros, em relação às regras mínimas de provisão contidas na Resolução CMN N² 2.682/99;

b) identificar qual a metodologia predominante no modelo misto de provisão para créditos de liquidação duvidosa da Resolução CMN No 2.682/99, se da perda incorrida ou da perda esperada;

c) investigar a relação entre os ciclos econômicos do País e a despesa com provisão para perdas com créditos de liquidação duvidosa registrada pelos bancos brasileiros;

d) investigar qual seria a relação entre os ciclos econômicos do País e a despesa com provisão para créditos de liquidação duvidosa, calculada considerando-se apenas as regras mínimas de provisão contidas na Resolução CMN N 2.682/99;

e) validar os dois modelos teóricos propostos por Bouvatier e Lepetit (2012a), para cálculo da despesa com provisão para créditos de liquidação duvidosa pelos métodos da perda incorrida e da perda esperada, mediante a aplicação dos valores encontrados ao modelo que verifica a relação entre os ciclos econômicos e a despesa com créditos de liquidação duvidosa dos bancos brasileiros.

\subsection{Relevância e caráter inovador da pesquisa}

O trabalho justifica-se pela atualidade, importância e controvérsia do tema não apenas no Brasil, mas em nível global, diante das sucessivas crises financeiras que têm dominado o cenário internacional, evidenciando riscos potenciais de uma crise sistêmica. E a contabilidade, devido aos seus critérios de avaliação e reconhecimentos de instrumentos financeiros, tem sido apontada como uma das responsáveis pelo agravamento da crise. 
Esta pesquisa também busca verificar se a decisão por uma política contábil mais austera imposta aos bancos comerciais brasileiros pelo CMN, através da Resolução No 2.682/99, bem como sua resistência à adoção das normas internacionais de contabilidade do IASB de forma completa, no curto prazo, tem efetivamente contribuído para que os bancos brasileiros sejam menos sensíveis às crises do sistema financeiro internacional, evitando a pró-ciclicidade da concessão de crédito pelos bancos comerciais brasileiros e, por conseguinte, favorecendo o crescimento econômico do país.

O estudo ainda contribui com a discussão sobre os métodos de PCLD da perda incorrida e da perda esperada, uma vez que modelos de provisão ex-ante podem diminuir a pró-ciclicidade dos empréstimos, entretanto, também, segundo Bushman e Williams (2012), podem propiciar um ambiente favorável a práticas discricionárias de gerenciamento de resultados por parte dos bancos na constituição dessas provisões.

Enfim, este trabalho se justifica pelo fato de a contabilidade ter a sua importância cada vez mais reconhecida, tanto no ambiente internacional como no Brasil, pois, cada vez mais, percebe-se que mecanismos de mensuração contábil inadequados podem acarretar não apenas decisões impróprias, mas contribuir para os riscos de uma crise sistêmica.

Destacam-se algumas contribuições deste trabalho de pesquisa para o avanço da literatura contábil relacionada ao tema, como:

a) o cálculo da despesa com créditos de liquidação duvidosa estritamente baseado nas regras mínimas de provisão contidas na Resolução CMN No 2.682/99, considerada livre de elementos discricionários, e a determinação de sua característica predominante, se de perda incorrida ou de perda esperada;

b) a verificação que um modelo de provisão com características predominantemente ex-post pode ser eficiente na proteção contra perdas com créditos e manter uma relação positiva com os ciclos econômicos, capaz de auxiliar a tomada de medidas anticíclicas do mercado de empréstimos bancários, evitando o agravamento de crises;

c) a constatação que, por mais que um sistema bancário possua mecanismos capazes de protegê-lo contra perdas com créditos de liquidação duvidosa e de garantir medidas anticíclicas, o uso de práticas discricionárias por parte dos participantes do sistema 
bancário, se não controlado de alguma forma, pode desvirtuar os mecanismos de proteção criados pelo regulador bancário.

\subsection{Delimitação do estudo}

Esta pesquisa tem por base os bancos brasileiros comerciais, múltiplos e a Caixa Econômica Federal, doravante denominados simplesmente bancos brasileiros. O intervalo de tempo selecionado para estudo abrange desde o $1^{\circ}$ trimestre de 2001 até o $4^{\circ}$ trimestre de 2012 , e foi escolhido devido a dois fatores:

a) por ser posterior ao início da vigência da Resolução CMN Nº 2.682/99; e

b) por abranger o período de disponibilidade das Informações Financeiras Trimestrais (IFT) no sítio do BACEN, que são a principal fonte de consulta dos dados contábeis necessários à consecução desta pesquisa ${ }^{4}$.

De acordo com informações do sítio do BACEN (2012), em 31 de dezembro de 2012 existiam 161 bancos comerciais em atividade no Brasil.

Como proxy para a verificação dos ciclos econômicos no Brasil no período analisado, utilizase o Produto Interno Bruto a valores constantes (PIB real), cujos dados encontram-se disponíveis no sítio do Instituto de Pesquisa Econômica Aplicada (IPEA) ${ }^{5}$.

\footnotetext{
${ }^{4}$ O BACEN dispensou os bancos da elaboração e remessa das IFT a partir, do $1^{\circ}$ trimestre de 2013, inclusive, através da Circular 3.630, de 19 de fevereiro de 2013. Com isso, algumas informações trimestrais utilizadas nesta pesquisa tornaram-se indisponíveis a partir do ano de 2013, ou por não serem de publicação obrigatória nas demonstrações contábeis intermediárias $\left(1^{\circ}\right.$ e $3^{\circ}$ trimestres $)$ das instituições financeiras, ou devido ao fato de os bancos não seguirem um padrão na disponibilização das informações nos seus balanços, fato que levaria à necessidade de manipulação de dados e ao consequente aumento do risco de incorreções. Com o objetivo de não comprometer a consistência dos dados através de manipulações excessivas e dada a amplitude do intervalo temporal da pesquisa, a qual abrange 48 trimestres (do $1^{\circ}$ trimestre de 2001 ao $4^{\circ}$ trimestre de 2012), considerase que a ausência dos dados referentes aos quatro trimestres do ano de 2013 não compromete os resultados.

${ }^{5}$ Base de dados macroeconômicos do Instituto de Pesquisa Econômica Aplicada - IPEA (www.ipeadata.gov.br).
} 


\subsection{Estrutura do trabalho}

O presente trabalho possui cinco capítulos, sendo o primeiro, o capítulo introdutório, sobre a contextualização e seus objetivos.

O capítulo 2 abrange a revisão da literatura, contemplando: uma discussão sobre a crise financeira de 2008, seus reflexos internacionais e no Brasil; o ambiente regulatório contábil internacional; o ambiente regulatório bancário brasileiro; algumas considerações sobre as metodologias da perda incorrida e da perda esperada; o "estado da arte" das pesquisas relacionadas à provisão para créditos de liquidação duvidosa; a descrição dos trabalhos que serviram de base para este estudo; e a discussão das hipóteses da pesquisa.

No capítulo 3, há o desenho da pesquisa, no qual são apresentados o modelo conceitual deste trabalho, a população e características da amostra, a descrição do processo de coleta dos dados empíricos, a descrição do tratamento estatístico e a estruturação dos modelos de análise.

Os resultados da pesquisa estão no capítulo 4, juntamente com os testes de robustez dos modelos estimados e as análises dos achados, além da discussão das hipóteses da pesquisa.

No capítulo 5 expõem-se as considerações finais, a partir de um apanhado de todo o processo da pesquisa, da discussão das hipóteses, da resposta ao problema central da pesquisa, das limitações do estudo e, por fim, a sugestão para trabalhos futuros. 


\section{REVISÃO DA LITERATURA}

Neste capítulo é realizada uma revisão da literatura, em que são abordados os seguintes assuntos: a crise financeira internacional de 2008 e seus desdobramentos; os reflexos da crise financeira de 2008 no Brasil; o ambiente regulatório contábil internacional; o ambiente regulatório bancário brasileiro; o "estado da arte" das pesquisas relacionadas ao tema em estudo; a apresentação dos trabalhos de Bouvatier e Lepetit (2012a), Bushman e Williams (2012) e Beatty e Liao (2011); e a construção das hipóteses da pesquisa.

\subsection{A crise financeira internacional de 2008 e seus desdobramentos}

Apesar de ter eclodido em setembro de 2008, com a falência do Banco Lehman Brothers, pode-se considerar que a crise financeira internacional, também conhecida como crise dos subprime, já vinha configurando-se, nos Estados Unidos, desde o início dos anos 2000. Após a crise das ações de tecnologia e do atentado ao World Trade Center em 11 de setembro de 2001, o banco central norte-americano (Federal Reserve - FED) iniciou uma política de contínua redução de taxas de juros, que durou até 2004, como medida anticíclica para atenuar os efeitos dessas crises (MOREIRA; SOARES, 2010).

White (2008) comenta que a taxa anual de fundos federais norte-americanos iniciou o ano de 2001 em 6,25\% e terminou em 1,75\% ao ano; continuou a ser reduzida nos anos de 2002 e 2003 , quando chegou ao piso de $1,00 \%$, no qual permaneceu por mais um ano, até 2004 . De acordo com White (2008), nesse período de dois anos e meio, a taxa de juros real da economia foi negativa, o que significa que a taxa de juros nominal era menor do que a inflação do período. Em termos de poder de compra, entre 2001 e 2004, o tomador não estava pagando, mas ganhando em proporção ao que havia tomado emprestado (WHITE, 2008).

De acordo com Roubini e Mihn (2011), mesmo quando a economia norte-americana passou a dar sinais de recuperação, o FED continuou sua política de redução de juros e no momento em que, finalmente, decidiu retomar o aumento da taxa de juros, fez isso de maneira muito lenta e previsível, com aumentos de 25 pontos-base a cada seis semanas, por ocasião das reuniões do 
Federal Open Market Committee (FOMC). "This policy kept rates too low for too long and normalized them too late and too slowly" (ROUBINI; MIHN, 2011, p.73).

De acordo com Moreira e Soares (2010), as taxas de juros reduzidas praticadas pelo FED, somadas a inovações financeiras, tais como derivativos e securitizações, que surgiram no Estados Unidos e foram copiadas por reguladores bancários de outros países (inclusive pelo Brasil), contribuíram para a formação da bolha no mercado de ativos, culminando na crise financeira mundial de 2008, considerada a maior desde a Grande Depressão de 1929.

A bolha de demanda atingiu fortemente o mercado imobiliário. Alimentada pelo crédito hipotecário, a demanda empurrou para cima o preço dos imóveis existentes e encorajou a construção de novas habitações em terrenos não urbanizados (WHITE, 2008).

Moreira e Soares (2010) ponderam que, ainda que as condições de crédito do mercado norteamericano fossem favorecidas pela disponibilidade de crédito e pela política monetária expansionista, se o mercado de crédito imobiliário ainda fosse caracterizado pelo tradicional "originar e manter em carteira" com o mesmo banco que originou os empréstimos mantendoos em carteira até que fossem liquidados vinte ou trinta anos após a concessão, os bancos seriam seletivos na concessão de créditos, no esforço mitigar riscos de inadimplência. Entretanto, com o surgimento dos derivativos e securitizadores no mercado imobiliário, o tradicional "originar e manter" cedeu lugar ao "originar e distribuir", ou seja, a instituição originária do crédito não mais o mantinha em carteira até o seu vencimento, mas o repassava, na forma de recebíveis, a outros investidores (MOREIRA; SOARES, 2010).

A possibilidade de a instituição originar o crédito e poder repassá-lo produzia dois efeitos imediatos:

a) a transferência do risco para o investidor; e

b) a liquidez da instituição originadora do crédito, que manteria recursos para conceder mais créditos.

Nesse cenário, quanto mais concessões fossem efetuadas, mais recursos a instituição originadora obteria pela venda dos seus recebíveis imobiliários e, assim, mais recursos teria para conceder novos créditos e repassá-los, gerando um ciclo vicioso e criando um ambiente

\footnotetext{
${ }^{6}$ Tradução livre: "Esta política manteve as taxas muito baixas por muito tempo e as normalizou muito tarde e lentamente".
} 
propício para as instituições concessoras serem menos seletivas na aprovação de empréstimos, financiando projetos cada vez mais arriscados.

De acordo com Roubini e Mihn (2011), a chave para o entendimento da situação é o risco moral (moral hazard), o qual consiste na disposição de alguém assumir riscos excessivos, que normalmente seriam evitados, apenas por saber que terceiros vão arcar com quaisquer consequências negativas em seu lugar.

\begin{abstract}
Como a instituição financeira que originou o empréstimo não seria responsável por sua arrecadação ao longo da hipoteca, ela teria incentivos para conceder empréstimos independentemente do risco representado pelo seu tomador. Sua função era conceder empréstimos, formar carteiras e transferir essas carteiras para outros investidores. $\mathrm{O}$ descasamento entre a criação e o recebimento do crédito aumentou sobremaneira o risco. (MOREIRA; SOARES, 2010, p. 18).
\end{abstract}

A Administração Federal de Habitação (Federal Housing Administration - FHA), que antes determinava ao tomador de empréstimo imobiliário o pagamento de uma entrada equivalente a $20 \%$ do valor do imóvel financiado com recursos próprios, em 2004 passou a exigir do tomador apenas 3\% de recursos próprios, o que significava financiar $97 \%$ do valor do imóvel (WHITE, 2008). Com isso, cresce o volume de concessão de hipotecas subprime, que são caracterizadas por: concessões com valor de entrada reduzido, ou sem entrada, a tomadores sem histórico de crédito, ou mesmo com passado de inadimplência e sem a documentação completa; concessão de empréstimos com valores de prestações acima da capacidade de pagamento do tomador; taxas de juros baixas que, por serem pós-fixadas, cresciam após os primeiros anos do financiamento (WHITE, 2008; MOREIRA; SALES, 2010).

Segundo Torres Filho (2008, p. 3), "a participação dos subprime no total das novas hipotecas passou de 8,6\% em 2001 para 20,1\% em 2006". De acordo com o mesmo autor, durante esse período, as operações de crédito imobiliário eram contratadas, geralmente, pelo prazo de 30 anos e envolviam dois regimes de pagamento, conhecidos como do tipo " $2 / 28$ " e " $3 / 27$ ": nos dois ou três primeiros anos, as taxas de juros e as prestações eram fixas e relativamente baixas; nos 27 ou 28 anos seguintes, as taxas de juros e as prestações eram mais elevadas e ajustadas periodicamente, com base em uma taxa de mercado, geralmente a LIBOR.

Quando o período de prestações mais baixas chegava ao final, os tomadores de subprime geralmente enfrentavam dificuldades para continuar a honrar suas dívidas e renegociavamnas, substituindo-as por novas hipotecas do tipo " $2 / 28$ ' ou ' $3 / 27$ ”, porém com taxas de juros mais elevadas; entretanto, como o mercado de imóveis estava aquecido, geralmente as novas 
hipotecas eram de valores mais elevados e os tomadores conseguiam ainda embolsar a diferença em dinheiro, ainda que precisassem pagar elevadas comissões cobradas pelos agentes financeiros em razão das renegociações (TORRES FILHO, 2008).

Sob a dos financiadores das operações de crédito imobiliário, as atividades de "originar e distribuir" seguiam, basicamente, de acordo com Torres Filho (2008), o seguinte fluxo:

a) os contratos de financiamento imobiliário (hipotecas) eram transferidos para um único fundo de investimento, denominado mortage pool, o qual, por sua vez, emitia tranches agrupadas por classes de risco, de modo que, quanto maior o risco da tranche, maior o seu retorno;

b) os bancos dividiam as tranches em três classes de risco:

- menor risco: tranches classificadas como AAA, AA e A, que eram comercializadas diretamente com investidores;

- risco médio: tranches classificadas como $\mathrm{BBB}, \mathrm{BB}$ e $\mathrm{B}$, que eram transferidas para um fundo CDO (collateralized debt obligation), mais diversificado, que agrupava outros títulos de dívida, derivativos e investimentos imobiliários, de modo a se obter uma carteira com risco superior ao dos títulos que a originaram;

- risco extremo: tranches denominadas equity (capital) ou toxic waste (lixo tóxico), que eram transferidas para sociedades de propósito específico, denominadas structured investments vehicles (SIV), criadas pelas instituições financeiras especialmente para receber essas tranches e transformá-las em commercial papers (títulos de curto prazo utilizados para remunerar aplicações de caixa de empresas);

c) em caso de inadimplência, as perdas eram, inicialmente, suportadas pelas tranches que carregavam maior risco (toxic waste); caso os prejuízos fossem superiores ao montante da classe de maior risco, passavam a consumir as tranches da classe de risco seguinte.

Como se pode verificar, enquanto o mercado imobiliário estava em expansão, e os tomadores de créditos imobiliários subprime tinham condições de redirecionar suas dívidas mediante o refinanciamento de suas hipotecas, havia um ambiente de falsa estabilidade, no qual todos pareciam lucrar. 
[...] Os Estados Unidos são efetivamente caracterizados por um histórico de cumprimento de seus compromissos financeiros. Também são caracterizados pela robustez de suas instituições. [...] Além do risco, os investidores observam outra variável - o retorno. No período de 2003 a 2006, que compreende o auge do mercado imobiliário, as taxas de retorno oferecidas pelo mercado norte-americano eram superiores às oferecidas em outros mercados. Baixo risco associado à maior rentabilidade tornou os Estados Unidos um ainda maior absorvedor de poupança líquida de países como a Alemanha, China e Japão. (MOREIRA; SOARES, 2010, p. $13)$.

Entretanto, conforme Torres Filho (2008), a partir de 2005, após a venda de imóveis residenciais atingir seu ápice, com mais de 8,2 milhões de unidades comercializadas naquele ano, o mercado imobiliário começou a arrefecer e, no final do ano de 2006, os preços dos imóveis passaram a diminuir. Com a desvalorização no valor dos imóveis, os tomadores de empréstimos subprime não conseguiam renovar suas hipotecas e, em consequência, a inadimplência começou a aumentar, comprometendo não apenas as tranches equity, mas também os CDO e, dada a falta de informações sobre as perdas em curso, os investidores apressaram-se para resgatar suas aplicações em fundos imobiliários e não mais renovaram suas aplicações em comercial papers. Era o início da crise financeira internacional, cujo marco é a falência do banco Lehman Brothers, em setembro de 2008, e que afetou severamente os países europeus.

De acordo com Moreira e Soares (2010), a crise de 2008 não foi meramente transmitida dos Estados Unidos para os demais países, mas provocou um efeito denominado wake-up effect, segundo o qual a crise iniciada em um país faz com que os investidores passem a questionar os fundamentos econômicos de outros países, onde a crise também se instala caso sejam percebidos sinais de desequilíbrio.

O FSB (2009), ao examinar os fatores que contribuem para a pró-ciclicidade do sistema financeiro e, por conseguinte, foram agravantes da crise internacional de 2008, identificou três áreas prioritárias para ação política: o regime de capital; as práticas de provisão para perdas; e a interação entre valorização e alavancagem.

Particularmente quanto às práticas de provisão para perdas, vigentes nos Estados Unidos, Europa e outros países que convergiram às normas internacionais de contabilidade do IASB, o FSB (2009) avalia que o reconhecimento precoce de perdas com crédito poderia ter atenuado movimentos cíclicos da crise financeira de 2008. 
Under the current accounting requirements of an incurred loss model, a provision for loan losses is recognised only when a loss impairment event or events have taken place that are likely to result in non-payment of a loan in the future. Identification of the loss event is a difficult and subjective process that results in a range of practice and, potentially, a failure to fully recognise existing credit losses earlier in the credit cycle. Earlier identification of credit losses is consistent both with financial statement users' needs for transparency regarding changes in credit trends and with prudential objectives of safety and soundness ${ }^{7}$ (FSB, 2009, p. 4).

O FSB (2009) advertiu que o FASB e IASB reconsiderassem o modelo de perda incorrida e analisassem abordagens alternativas para mensuração e reconhecimento de perdas com empréstimos que incorporassem uma maior gama de informação de crédito. Em decorrência das recomendações do FSB, o IASB resolveu acelerar o processo de substituição da IAS 39 pela IFRS 9 e um grupo de trabalho conjunto foi formado entre FASB e IASB, com o objetivo de convergir as normas estadunidenses com normas internacionais de contabilidade.

\subsection{Os reflexos da crise financeira internacional de 2008 no Brasil}

Segundo Mesquita e Torós (2010), a postura conservadora do Regulador Bancário Brasileiro fez com que o país entrasse mais tarde e saísse mais cedo da crise financeira mundial de 2008, sem consequências mais graves tanto para o mercado quanto para a sociedade como um todo. Entretanto, pode-se afirmar que o esforço do governo brasileiro foi considerável para conter os efeitos da crise de 2008, com medidas anticíclicas que, aparentemente, tiveram um efeito pernicioso sobre a situação econômica do País, como o aumento da dívida pública, elevação das despesas de caráter permanente e redução da arrecadação.

Lopes (2009) enumera os seguintes meios de propagação da crise financeira mundial de 2008, também identificados no Brasil:

\footnotetext{
${ }^{7}$ Tradução livre: "De acordo com os requisitos contábeis atuais de um modelo de perda incorrida, uma provisão para créditos de liquidação duvidosa é reconhecida somente quando um evento de perda ou eventos que ocorreram são suscetíveis a resultar em falta de pagamento de um empréstimo no futuro. A identificação de um evento de perda é um processo difícil e subjetivo, o qual resulta em uma série de práticas e, potencialmente, em uma falha no reconhecimento pleno das perdas no início do ciclo de crédito. A identificação precoce de perdas com créditos é consistente, tanto com as necessidades dos usuários de demonstrações financeiras por transparência em relação a mudanças nas tendências de crédito, como com os objetivos prudenciais de segurança e solidez".
} 
a) contração do crédito em decorrência do processo de redução da alavancagem do sistema financeiro mundial;

b) destruição de riqueza, como resultado da queda nos preços dos ativos financeiros;

c) deterioração das expectativas com relação à evolução da atividade econômica, influenciando decisões de gastos de empresas e famílias; e

d) redução no volume de exportações e do comércio mundial.

Para amenizar esses efeitos, o Brasil tomou medidas anticíclicas, no âmbito fiscal, creditício e monetário, favorecendo o aumento do consumo. De acordo com Moreira e Soares (2010), as medidas fiscais ocorreram, principalmente, pela redução do IPI sobre alguns setores específicos, tais como eletrodomésticos da linha branca, bens de capital e materiais de construção; a política creditícia foi capitaneada principalmente pelos bancos públicos, que supriram a falta de crédito privado e irrigaram setores da economia como o da construção civil e automobilístico; no âmbito monetário, houve a redução da taxa básica de juros economia que, por sua vez, refletiu nas taxas de juros nominal e real.

Entretanto, conforme Moreira e Soares (2010), as medidas anticíclicas adotadas pelo governo brasileiro contribuíram para o aumento do consumo e do produto agregado durante o período da crise de 2008, mas não foram suficientes para aumentar o nível de investimentos. De acordo com os pesquisadores, o elevado grau de incerteza no período de crise pode ter sido crucial para que os empresários adotassem uma postura mais cautelosa e conservadora, suspendendo tanto investimentos em andamento, como cancelando novos projetos.

Atualmente, passados sete anos desde a eclosão da crise financeira internacional de 2008, confirma-se o previsto por Moreira e Soares (2010) em sua pesquisa: as medidas adotadas para contenção da crise financeira de 2008 no Brasil, em longo prazo, teriam efeito pernicioso, com a elevação das despesas, principalmente as de caráter permanente, como de salários e previdências, bem como a redução da arrecadação, que demandariam esforços de ajuste fiscal e retirariam recursos necessários ao investimento privado. 


\subsection{O ambiente regulatório contábil internacional: IAS 39 - Financial Instruments: Recognition and Measurement e IFRS 9 - Financial Instruments}

Conforme mencionado anteriormente, um dos desdobramentos da crise financeira internacional de 2008 foi a aceleração do processo de substituição da IAS 39 pela IFRS 9. Segundo as regras de reconhecimento de perdas com créditos contidas na IAS 39 (IASB, 2008), uma provisão para perdas com créditos só pode ser reconhecida quando há evidência objetiva da ocorrência do evento de perda. A IAS 39 (IASB, 2008) relaciona as seguintes situações indicativas de um evento de perda:

a) dificuldade financeira significativa do tomador do crédito;

b) quebra de contrato, como descumprimento ou atraso nos pagamentos de juros ou de capital;

c) o emprestador ou financiador, por razões econômicas ou legais relacionadas com as dificuldades financeiras do tomador do empréstimo ou do financiamento, oferece ao tomador uma concessão que, de outra forma, não disponibilizaria;

d) é provável de o devedor entre em processo de falência ou reorganização financeira;

e) desaparecimento de mercado ativo para o ativo financeiro, devido a dificuldades financeiras;

f) dados observáveis que indicam decréscimo mensurável nos fluxos de caixa futuros estimados do grupo de ativos financeiros, desde o reconhecimento inicial desses ativos, embora o decréscimo não possa ser identificado com os ativos financeiros individuais do grupo.

Dessa forma, pode-se afirmar que o reconhecimento de perdas com créditos, segundo as regras contidas na IAS 39 (IASB, 2008), não deve ocorrer antes que o problema já esteja instalado. Dentre outras regras de reconhecimento e mensuração de ativos financeiros contidas na IAS 39 (IASB, 2008), também objeto de críticas pelo FSB, está o reconhecimento de perdas com créditos pela metodologia da perda incorrida. 
A IAS 39 (IASB, 2008), desde sua criação, foi muito criticada tanto pelos usuários como pela academia, devido à diversidade de assuntos e à sua complexidade, sendo considerada uma norma de difícil entendimento. Por esse motivo, o IASB já possuía um projeto de substituição da IAS 39, sendo acelerado pelos desdobramentos da crise financeira de 2008. O processo de substituição da IAS 39 pela IFRS 9 teve início no ano de 2009 e foi efetuado em três fases:

a) Fase 1: classificação e mensuração;

b) Fase 2: Metodologia de impairment;

c) Fase 3: Hedge accounting.

A cada fase concluída eram publicadas novas versões da IFRS 9, bem como da IAS 39, com a remoção, do seu escopo, dos temas revisados e transferidos para a IFRS 9.

No mês de julho de 2014 foi concluído o processo de substituição da IAS 39 pela IFRS 9 Financial Instruments, que modificou substancialmente a metodologia de provisão para perdas com créditos, a qual passa a ter características de perda esperada. A adoção das novas regras de provisão contidas na IFRS 9 (IASB, 2014) são mandatórias a partir de $1^{\circ}$ janeiro de 2018, mas sua adoção pode ser antecipada.

O novo modelo de provisão para perdas com créditos da norma internacional IFRS 9 (IASB, 2014) requer que a entidade reconheça perdas futuras esperadas considerando o tempo de vida da operação de crédito e que o valor provisionado seja atualizado na data do levantamento do balanço da empresa, de modo a refletir eventuais mudanças no risco de crédito do instrumento financeiro.

Cabe salientar que, apesar das normas internacionais do IASB ainda não terem sido recepcionadas, na sua totalidade, pelo BACEN, para fins de convergência das normas brasileiras de contabilidade das instituições financeiras, conhecidas como BRGAAP, o Conselho Monetário Nacional, através da sua Resolução N ${ }^{0} 3.786$, de 24 de setembro de 2009, determinou que as demonstrações contábeis consolidadas das instituições financeiras constituídas na forma de companhia aberta ou que sejam obrigadas a constituir comitê de auditoria em IFRS sejam elaboradas e divulgadas, anualmente, conforme os pronunciamentos internacionais emitidos pelo IASB. 


\subsection{O ambiente regulatório bancário brasileiro e a metodologia de cálculo da provisão para créditos de liquidação duvidosa segundo a Resolução CMN N².682/99}

O Conselho Monetário Nacional (CMN) é o órgão superior do Sistema Financeiro Nacional e tem a responsabilidade de formular a política da moeda e do crédito, objetivando a estabilidade da moeda e o desenvolvimento econômico e social do Brasil. Foi criado pela Lei $\mathrm{n}^{\mathrm{o}}$ 4.595, de 31 de dezembro de 1964 e instituído em 31 de março de 1965. Atualmente, o CMN é composto pelo Ministro de Estado da Fazenda (presidente do Conselho), pelo Ministro de Estado do Planejamento, Orçamento e Gestão e pelo Presidente do Banco Central do Brasil.

Os membros do CMN reúnem-se, pelo menos, uma vez por mês para deliberarem sobre assuntos de sua competência. As normas aprovadas pelo CMN são regulamentadas por meio de Resoluções, divulgadas no Diário Oficial da União e no sítio do $\mathrm{BACEN}^{8}$.

O método de cálculo para constituição da PCLD dos bancos brasileiros, determinado pelo CMN através da Resolução $\mathrm{N}^{\mathrm{o}} 2.682 / 99$, pode ser considerado misto, pois apresenta características inerentes às duas metodologias de provisão, perda esperada e perda incorrida, ao estabelecer que provisões para perdas futuras sejam registradas no momento da contratação do empréstimo e que, ao longo deste, sejam feitas reclassificações de risco em função de atrasos verificados.

A referida Resolução determina que as instituições financeiras e demais instituições autorizadas a funcionar pelo BACEN classifiquem as operações de crédito em ordem crescente de risco, do nível 'AA' ao ' $\mathrm{H}$ '. A classificação no nível de risco é de responsabilidade da instituição detentora do crédito e deve ser efetuada com critérios consistentes e verificáveis, com informações tanto internas quanto externas, e contemplar os seguintes aspectos:

a) em relação ao devedor e garantidores: situação econômico-financeira, grau de endividamento, capacidade de geração de resultados, fluxo de caixa, administração e qualidade de controles, pontualidade e atrasos nos pagamentos, contingências, setor de atividade econômica, limite de crédito;

\footnotetext{
${ }^{8}$ Sítio do BACEN: www.bcb.gov.br.
} 
b) em relação à operação: natureza e finalidade da operação, características das garantias quanto à suficiência e liquidez e o valor da operação.

A constituição da PCLD deve ser feita mensalmente de acordo com os níveis de classificação de risco das operações e conforme o percentual determinado no artigo $6^{\circ}$ da Resolução CMN $\mathrm{N}^{\mathrm{o}} 2.682 / 99$, evidenciado na tabela 1 .

Tabela 1 - Classificação das operações de crédito por nível de risco

\begin{tabular}{crrr}
\hline & & \multicolumn{2}{c}{ Risco por faixa de atraso } \\
\cline { 3 - 4 } Risco & Provisão & PR $\leq 36$ meses & PR $>36$ meses* \\
\hline AA & $0,0 \%$ & & \\
A & $0,5 \%$ & & \\
B & $1,0 \%$ & $15-30$ & $30-60$ \\
C & $3,0 \%$ & $30-60$ & $61-120$ \\
D & $10,0 \%$ & $61-90$ & $121-180$ \\
E & $30,0 \%$ & $91-120$ & $181-240$ \\
F & $50,0 \%$ & $121-150$ & $241-300$ \\
G & $70,0 \%$ & $151-180$ & $301-360$ \\
H & $100,0 \%$ & Acima de 180 & Acima de 360 \\
\hline
\end{tabular}

*De acordo com o parágrafo $1^{\circ}$ do art. $4^{\circ}$ da Resolução CMN N ${ }^{\circ} 2.682 / 99$, para compromissos acima de 36 meses, o prazo de migração do nível de risco conta em dobro. PR: prazo remanescente da operação de crédito. As faixas de atraso são medidas em dias.

A classificação da operação de crédito no nível 'AA' significa ser uma operação livre de riscos, enquanto a operação classificada no nível ' $H$ ' deve ser $100 \%$ provisionada e, dentro de, no máximo, seis meses, baixada do balanço e lançada a prejuízo.

Desse modo, diferentemente do que preceitua a IAS 39 (IASB, 2008), a metodologia de reconhecimento de perdas com operações de crédito, adotada pelos bancos brasileiros através Resolução CMN No 2.682/99, é apoiada em expectativas de perdas futuras, sendo estas ainda complementadas em caso de ocorrência de atrasos nos pagamentos pelos tomadores.

Os resultados obtidos com o modelo proposto neste trabalho de pesquisa para verificar a relação entre os ciclos econômicos e a DPCLD registrada pelos bancos brasileiros possibilita verificar, empiricamente, se a DPCLD registrada pelos bancos brasileiros é capaz de manter os níveis de créditos bancários em períodos recessivos. 


\subsection{Os modelos de perdas estimadas com créditos de liquidação duvidosa}

Vários estudos atestam que o retardo no reconhecimento de perdas esperadas exacerba os ciclos econômicos e defendem que a adoção de modelos de provisão mais forward looking diminuiria a pró-ciclicidade dos empréstimos e, assim, permitiria que o nível destes fosse menos suscetível aos ciclos econômicos, de modo a não contribuir para o agravamento de crises. Dentre tais estudos, evidenciam-se os trabalhos de Bikker e Metzemakers (2005), Zicchino (2005), Repullo e Suarez (2008), Drumond (2009), Beatty e Liao (2011), Bouvatier e Lepetit, (2008, 2012a, 2012b), Bouvatier, Lepetit e Strobel (2012) e Bushman e Williams (2012).

Por outro lado, a adoção de modelos de provisão mais forward looking é também criticada por muitos pesquisadores, pois tais modelos poderiam favorecer o uso de práticas discricionárias para gerenciamento de resultados e suavização de lucros, podendo desvirtuar o real objetivo da DPCLD, o qual consiste em prevenção contra perdas futuras esperadas com operações de crédito. Dentre esses pesquisadores, destacam-se Greenawalt e Sinkey (1988), Kanagaretnam, Lobo e Mathieu (2003), Fonseca e Gonzales (2008), Bushman e Williams (2012) e El Sood (2012).

O modelo de provisão para créditos de liquidação duvidosa adotado pelos bancos brasileiros, advindo da Resolução CMN No 2.682/99, consiste em uma metodologia mista, com características tanto de um modelo de perda incorrida como de perda esperada.

Apesar de possuir regras claras para a constituição da provisão para créditos de liquidação duvidosa, a própria Resolução CMN No 2.682/99 deixa espaço para a adoção de práticas discricionárias pelos bancos brasileiros, pois estes são incentivados a fazerem provisões adicionais que julgarem necessárias e, além disso, cada banco desenvolve seu próprio modelo interno de avaliação de risco de crédito, conforme determina a referida Resolução. Assim, infere-se que a DPCLD registrada pelos bancos brasileiros possui componentes discricionários, que podem ou não estar relacionados à prevenção contra perdas futuras com empréstimos.

O problema central da presente pesquisa consiste em verificar a relação entre a DPCLD, segundo a Resolução $\mathrm{CMN} \mathrm{N}^{\mathrm{0}} 2.682 / 99$, e os ciclos econômicos do Brasil, e, como 
consequência, se a DPCLD registrada pelos bancos brasileiros tem sido, de fato, capaz de conter os ciclos econômicos do País, independentemente da sua característica predominante (perda incorrida ou perda esperada) ou mesmo da presença ou não de componentes discricionários.

\section{6 "Estado da arte" das pesquisas relacionadas ao tema de estudo}

Apresenta-se a seguir o "estado da arte" das pesquisas relacionadas à provisão para créditos de liquidação duvidosa. Primeiramente, é exposto um conjunto de pesquisas internacionais sobre o tema de estudo. Na sequência são relatados estudos de autores nacionais que analisaram a despesa com créditos de liquidação duvidosa no Brasil e como esta responde às oscilações dos ciclos econômicos.

Kim e Kross (1998) investigaram a existência de mudanças de comportamentos dos bancos após alterações ocorridas no requerimento de capital de bancos estadunidenses, o qual passou de 4\% para 8\%, no ano de 1989 . Os pesquisadores averiguaram se a mudança no índice de capital regulatório dos bancos está associada a uma redução na constituição de provisões para perdas ou a um aumento do montante de empréstimos baixados como prejuízo. Segundo os autores (1998), a partir de 1989 a provisão para perdas com créditos foi substancialmente excluída do cálculo do capital regulatório, de modo que o reconhecimento de provisões para perdas com créditos, que anteriormente possuía um efeito positivo sobre esse índice, passou a impactá-lo negativamente. Já as baixas de empréstimos como prejuízo continuaram a influenciar negativamente o cálculo do capital regulatório, de modo semelhante ao período anterior a 1989, fato que, de acordo com Kim e Kross (1998), desmotivou o gerenciamento de capital através da minimização de baixas de empréstimos.

A amostra de estudo selecionada por Kim e Kross (1998) é composta por 193 conglomerados bancários, listados no arquivo anual do Compustat (140 conglomerados) e no NASDAQ (53 conglomerados), e resultou em um número máximo de 1.544 observações no período total considerado para estudo, dividido em dois intervalos de tempo: de 1985 a 1988, ou seja, anterior às mudanças no cálculo do capital regulatório; e de 1990 a 1992, posterior às mudanças de 1989. Os pesquisadores constataram que, após as mudanças ocorridas no cálculo 
do capital regulatório, os bancos estadunidenses com baixos índices de capital reduziram as constituições de provisões para perdas e aumentaram as baixas de empréstimos como prejuízo.

Ahmed, Takeda e Thomas (1999) investigaram a relação entre provisão para perdas com créditos, gerenciamento de resultados e gerenciamento de capital. Para tanto, os autores utilizaram uma amostra de 113 conglomerados bancários, cujos relatórios constam do arquivo Y-9 do Federal Reserve, no período compreendido entre os anos de 1986 e 1995. Os autores constataram que, de forma semelhante aos achados de Kim e Kross (1998), a provisão para perdas com créditos é muito utilizada no gerenciamento de capital, predominantemente a partir de 1990, ou seja, após as alterações ocorridas nas regras de requerimento de capital regulatório em 1989. Entretanto, não encontraram evidências da utilização de provisões para perdas no gerenciamento de resultados.

Cavallo e Majnoni (2001) examinaram se os bancos constituem provisões para perdas com créditos ruins em períodos de expansão, utilizando uma amostra de 1.176 bancos comerciais de grande porte, com dados disponibilizados no Bankscope, sendo 372 não pertencentes a países integrantes do G-10, analisados no período de 1988 a 1999. A amostra abrange bancos comerciais de 36 países, com todos os continentes representados (Américas, Europa, Ásia, África e Oceania). Para os bancos integrantes do G-10, os autores identificaram evidências robustas de associação positiva entre a provisão para perdas e o resultado antes do reconhecimento da despesa com provisão para perdas com créditos. Por outro lado, Cavallo e Majnoni (2001) verificaram que os bancos da amostra, não participantes do G-10, provisionam pouco em períodos de expansão e muito em períodos recessivos, contribuindo para a pró-ciclicidade dos empréstimos.

Laeven e Majnoni (2003) encontraram evidências empíricas de que muitos bancos, em escala mundial, retardam os reconhecimentos de perdas com empréstimos, a tal ponto de só o fazerem quando o período recessivo já está instalado, o que acaba por exacerbar os impactos das crises. Os pesquisadores estudaram uma amostra de 1.419 bancos de 45 países, inclusive do Brasil, com dados disponibilizados no Bankscope, no período compreendido entre 1988 e 1999. Os achados indicam uma relação negativa entre a variação do PIB dos países da amostra e a provisão para perdas com empréstimos. Laeven e Majnoni (2003) também encontraram evidências da utilização das provisões para perdas no gerenciamento de resultados. 
Kanagaretnam, Lobo e Mathieu (2003) investigaram incentivos gerenciais para a suavização de resultados através de provisões para perdas com créditos, por meio de uma amostra com 91 bancos estadunidenses, cumulativamente, com as seguintes características: ter ativos totais superiores a US\$ 300 milhões; serem publicamente listados e com observações trimestrais no período de 1987 a 2000. Os pesquisadores encontraram que bancos com bom desempenho corrente, mas que esperam pior desempenho futuro, tendem a "guardar" lucros no presente, através do aumento da provisão para perdas com créditos, para "gastá-los" no futuro. Já os bancos com baixo desempenho corrente, mas com expectativa de melhoria futura, tendem a "tomar empréstimos" da provisão para perdas com créditos, ou seja, provisionam menos no presente e aumentam suas provisões no futuro.

Bikker e Metzemakers (2005) investigaram a relação entre os ciclos econômicos e a despesa com provisão para perdas com créditos, a partir de uma amostra com bancos de 29 países participantes da Organização para a Cooperação e Desenvolvimento Econômico (OCDE), ao longo da década de 1990. Os pesquisadores encontraram uma relação negativa entre os ciclos econômicos e as despesas com provisões para perdas, indicando que os bancos aumentam significativamente o nível de provisão em períodos recessivos. Adicionalmente, constataram que os bancos se utilizam da despesa com provisão para perdas para o gerenciamento de resultados.

Bouvatier e Lepetit (2008) estudaram como um sistema de provisão para créditos de liquidação duvidosa pode afetar a ciclicidade dos empréstimos bancários. Para tanto, analisaram uma amostra de 186 bancos de 15 países europeus, com dados disponibilizados no Bankscope, no período de 1992 a 1994. Os pesquisadores concluíram que as despesas com créditos de liquidação duvidosa constituídas com o objetivo de cobrir perdas futuras esperadas aumentam as flutuações dos créditos. Por outro lado, Bouvatier e Lepetit (2008) acharam que as despesas com créditos de liquidação duvidosa, constituídas com o objetivo de gerenciamento de resultados, não afetam as flutuações dos créditos.

Fonseca e Gonzáles (2008) investigaram os fatores determinantes da suavização de lucros através da provisão para perdas com créditos, através da utilização de um banco de dados em painel contendo 3.221 observações anuais sobre bancos de 40 países, com todos os continentes representados (Américas, Europa, Ásia, África e Oceania). Os pesquisadores encontraram diferentes padrões de suavização de lucros e que esta depende da proteção ao 
investidor, do nível de disclosure, da regulação e supervisão bancárias, além da estrutura e do desenvolvimento financeiro do país.

Betancourt e Baril (2009), em seu trabalho teórico, refletiram se o método de provisão para perdas com créditos de liquidação duvidosa pela perda incorrida agravou a crise financeira de 2008 e contribuiu para instabilidade das instituições financeiras. Os pesquisadores fizeram considerações os métodos da perda incorrida, da perda esperada e da provisão dinâmica, também conhecida como "provisão estatística", adotada pelos bancos espanhóis e concluíram que, qualquer metodologia de provisão para perdas com créditos, seja de perda incorrida ou perda esperada, está sujeita ao uso de práticas discricionárias de gerenciamentos e manipulações.

Entretanto, na opinião de Betancourt e Baril (2009), os modelos de provisão pela perda incorrida apresentam a dificuldade de determinar quando, de fato, um evento de perda ocorreu. Os autores ponderam que ambas as metodologias de provisão fornecem informações sobre a qualidade da carteira de créditos, entretanto, o modelo da perda esperada fornece informações mais úteis para investidores e credores na estimação de fluxos de caixa futuros.

Kanagaretnam, Lim e Lobo (2010) estudaram a relação entre a reputação do auditor e a prática de gerenciamento de resultados através da provisão para créditos de liquidação duvidosa, pelo aumento da DPCLD quando os lucros acrescem. A amostra de estudo compreendeu instituições bancárias de 29 países, cadastradas no banco de dados do Bankscope, entre os anos de 1993 e 2006. Os pesquisadores encontraram que o tanto o tipo do auditor como a sua expertise coíbem o gerenciamento de resultados através da despesa para créditos de liquidação duvidosa.

Fora do eixo Estados Unidos e Europa, Taktak, Zouari e Boudriga (2010) investigaram se bancos islâmicos fazem uso das provisões para perdas com créditos para gerenciar resultados. De acordo com os pesquisadores, o ambiente em que os bancos islâmicos atuam possui algumas peculiaridades, tais como:

a) os Shari'a proíbem operações especulativas, negociações com instrumentos derivativos e investimentos em setores ou produtos tais como tabaco, álcool e suínos;

b) os bancos são proibidos de receberem juros decorrentes de transações financeiras e comerciais; 
c) os bancos são governados por princípios islâmicos, denominados shari'a, que têm por base o compartilhamento dos riscos pelos investidores;

d) os reguladores contábeis encorajam o uso da provisão dinâmica; por isso, os bancos islâmicos costumam constituir provisões para perdas futuras;

e) os bancos islâmicos são encorajados a constituírem reservas de compensação de lucros e reservas de riscos de investimentos, com o objetivo de manter estáveis os retornos sobre os investimentos dos depositantes.

Em sua pesquisa com bancos islâmicos, Taktak et. al. (2010) utilizaram uma amostra de 66 bancos, de 19 nacionalidades diferentes, durante o período de 2001 a 2006. Os autores encontraram que os bancos islâmicos fazem uso de suavização de lucros, mas não por meio da provisão para créditos de liquidação duvidosa e, sim, através de constituição de reservas de compensação de lucros e reservas de riscos de investimentos.

Alali e Jaggi (2011) investigaram a existência de relação entre lucros e gerenciamento de capital pelos bancos comerciais estadunidenses, em uma amostra de 11.315 bancos, entre os anos de 1991 e 2008. Os pesquisadores verificaram que bancos de maior porte fazem mais uso do gerenciamento de resultados através das provisões para perdas com empréstimos do que os de menor porte. Alali e Jaggi (2011) também encontraram que bancos que possuem ativos de maior risco utilizam a despesa com provisão para perdas com créditos para gerenciar resultados e capital. Acharam, ainda, um nível maior de gerenciamento de lucros através da provisão para perdas com créditos durante o período da crise financeira de 2008, em relação ao período pré-crise.

El Sood (2012) investigou a relação entre a suavização de resultados e a provisão para perdas com empréstimos dos bancos estadunidenses no período anterior e posterior à crise financeira de 2008. Para tanto, utilizou uma amostra de 878 conglomerados bancários, cujos relatórios constam do arquivo Y-9 do Federal Reserve, analisada entre o período compreendido entre os anos de 2001 e 2009. O pesquisador encontrou que os bancos intensificaram o uso da provisão para perdas com créditos no período compreendido entre 2007 e 2009, justamente quando se instalou a crise financeira, e que os bancos se utilizam dessa prática para suavizar o aumento dos lucros em períodos de crise. 
Bouvatier e Lepetit (2012b) pesquisaram os efeitos da provisão para perdas com créditos sobre o nível de empréstimos bancários. Na sua pesquisa, os autores consideraram amostras de bancos de cinco regiões geográficas: Europa (1.636 bancos), Estados Unidos (9.421 bancos), Japão (689 bancos), sul e sudeste asiático (245 bancos) e América Latina (632 bancos), entre os anos de 1995 e 2008. Os pesquisadores encontraram que as práticas de provisão para perdas com créditos pelo método da perda incorrida exacerbam a próciclicidade dos empréstimos e, ainda, que esse impacto é sensivelmente maior em países emergentes.

Como se observa, há uma variedade de trabalhos acadêmicos internacionais sobre a provisão para créditos de liquidação duvidosa e como esta se relaciona com os ciclos econômicos, sua utilização para práticas discricionárias de gerenciamento de resultados, gerenciamento de capitais, inclusive a relação entre a reputação do auditor e a discricionariedade da provisão para créditos de liquidação duvidosa praticada pelos bancos.

No entanto, no Brasil, não foram encontrados muitos trabalhos empíricos que estudem o comportamento da despesa com provisão para créditos de liquidação duvidosa dos bancos brasileiros. A seguir são apresentados os trabalhos de Dantas, Lustosa e Medeiros (2012) e Araújo (2014), que efetuaram pesquisas empíricas, com bancos brasileiros, sobre a constituição das despesas para créditos de liquidação duvidosa e suas relações com os ciclos econômicos, bem como a utilização da DPCLD como instrumento de práticas discricionárias de gerenciamento de resultados e de capital.

Dantas, Lustosa e Medeiros (2012) estimaram um modelo ampliado para avaliação da discricionariedade nos bancos brasileiros, cuja variável dependente é a despesa com provisão para créditos de liquidação duvidosa. O modelo proposto foi testado a partir de uma amostra com 204 bancos comerciais, múltiplos e caixas econômicas, no período compreendido entre 2001 e 2010, em bases trimestrais. Dentre outros achados, os pesquisadores encontraram relações estatisticamente significativas entre o PIB e a DPCLD dos bancos brasileiros, indicando que em períodos de expansão os bancos brasileiros tendem a constituir menos provisões para perdas com créditos de liquidação duvidosa.

Araújo (2014) estudou a ciclicidade da provisão para créditos de liquidação duvidosa em bancos, que envolveu a avaliação dos modelos de provisão pela perda esperada, perda incorrida e a provisão dinâmica. O pesquisador estimou um modelo econométrico, aplicado 
para análise da relação entre a DPCLD e os ciclos econômicos de três países: Reino Unido, Espanha e Brasil. A aplicação do modelo em diferentes ambientes permitiu que Araújo (2014) verificasse a relação entre a DPCLD e os ciclos econômicos, segundo três metodologias distintas de provisão para perdas:

a) método da perda incorrida (Reino Unido);

b) método da perda esperada (Espanha); e

c) método misto de provisão (Brasil).

A amostra de estudo, selecionada por Araújo (2014) em sua pesquisa, tem a seguinte composição:

a) noventa e oito instituições financeiras brasileiras (demonstrações contábeis individuais ou consolidadas), analisadas no período de 2001 a 2012, em bases semestrais;

b) cinquenta e oito instituições financeiras espanholas, analisadas no período de 2001 a 2012, em bases semestrais;

c) quarenta e cinco bancos do Reino Unido, analisados no período entre 2001 e 2012, em bases anuais.

Araújo (2014) encontrou que, apesar de as três metodologias de provisão para perdas com créditos possuírem características distintas, quando testadas nos bancos das amostras dos três países, indicaram uma relação negativa entre a variação do PIB e a despesa com créditos de liquidação duvidosa, denotando que os bancos provisionam menos em períodos de expansão e mais em períodos recessivos, independentemente da metodologia de provisão para perdas com créditos adotada.

O presente trabalho também investiga a relação entre a DPCLD registrada pelos bancos brasileiros e as variações dos ciclos econômicos; entretanto, há diferenças em relação ao trabalho de Araújo (2014) nos seguintes termos:

a) a amostra de bancos brasileiros para esta pesquisa é composta das demonstrações financeiras individuais dos bancos brasileiros (múltiplos, comerciais e Caixa Econômica Federal), em base trimestral, no período compreendido entre 2001 e 2012; 
b) nesta pesquisa, o modelo estimado para estudo da relação entre a DPCLD registrada pelos bancos brasileiros e os ciclos econômicos envolve algumas variáveis de controle para capturar, empiricamente, além da relação entre a DPCLD e a variação do PIB, a metodologia predominante no modelo misto de provisão adotado no Brasil, se a perda incorrida ou a perda esperada;

c) neste trabalho, é deduzida uma fórmula para cálculo do valor da DPCLD dos bancos brasileiros de acordo com as regras mínimas de provisão da Resolução CMN No 2.682/99, sem considerar as provisões adicionais cuja constituição é facultada aos bancos, ou seja, calcula-se empiricamente a parcela do valor da DPCLD dos bancos brasileiros, livre dos elementos discricionários contidos nas provisões adicionais; essa DPCLD, livre de elementos discricionários, é aplicada ao modelo estimado com o objetivo de se verificar qual seria a relação entre a DPCLD estimada de acordo com as regras mínimas de provisão da Resolução $\mathrm{CMN} \mathrm{N}^{0} 2.682 / 99$ e as variações dos ciclos econômicos brasileiros;

d) este estudo ainda aplica, empiricamente, dois modelos teóricos de provisão estimados por Bouvatier e Lepetit (2012a); segundo os pesquisadores, esses dois métodos representariam, individualmente, modelos puros de perda incorrida e de perda esperada. Os resultados também são aplicados ao modelo estimado para verificar a relação entre a DPCLD e os ciclos econômicos, de forma a averiguar qual seria o seu comportamento e se os métodos teóricos estimados por Bouvatier e Lepetit (2012a) se sustentam quando aplicados ao caso brasileiro, isto é, se atendem aos conceitos de perda incorrida e de perda esperada.

Verifica-se, portanto, que este trabalho difere da pesquisa de Araújo (2012) devido ao fato de possuir objetivos distintos e proporcionar achados também diferenciados. Entretanto, os achados desta pesquisa permitem, em certa medida, comparações com os achados de Araújo (2012) naquilo que se refere à relação entre a DPCLD registrada pelos bancos brasileiros e as variações dos ciclos econômicos, bem como com referência a algumas variáveis de controle comuns aos modelos estimados em ambos os trabalhos. 


\subsection{Trabalhos-base para a pesquisa}

Apresentam-se a seguir os trabalhos de Beatty e Liao (2011), Bouvatier e Lepetit (2012a), Bushman e Williams (2012). As teorias desses estudos serviram de ponto de partida para a consecução desta pesquisa.

\subsubsection{A pesquisa de Beatty e Liao (2011)}

Beatty e Liao (2011) conduziram uma pesquisa sobre a influência de atrasos no reconhecimento de perdas com créditos sobre propensão dos bancos norte-americanos a emprestar em tempos de recessão internacional. Os pesquisadores verificaram que bancos que costumam retardar reconhecimento de perdas esperadas com operações de crédito são mais dependentes do capital regulatório e esse fato, em tempos de crises, ou períodos recessivos, faz com que esses bancos fiquem menos propensos à concessão de crédito, pois enfrentam problemas de liquidez.

A partir das constatações de Beatty e Liao (2011), pode-se inferir que um modelo de provisão para perdas mais conservador, que antecipe eventos desfavoráveis de perda, possa ser benéfico ao sistema bancário, pois os bancos norte-americanos que adotam uma política de reconhecimento de perdas mais conservadora, ainda que ex-post, enfrentam menos problemas de dependência do capital regulatório e de liquidez em períodos recessivos, embora ainda haja certa pró-ciclicidade nas concessões de empréstimos bancários nesses períodos.

Assim, a partir dos resultados da pesquisa de Beatty e Liao (2011), considerou-se relevante investigar o comportamento da DPCLD dos bancos brasileiros frente às oscilações dos ciclos econômicos do País, haja vista a política adotada pelo regulador brasileiro, que consiste numa metodologia mista de reconhecimento de perdas com créditos de liquidação duvidosa. 


\subsubsection{A pesquisa de Bouvatier e Lepetit (2012a)}

Bouvatier e Lepetit (2012a) discutiram modelos teóricos para cálculos da DPCLD segundo três metodologias:

a) de perda incorrida;

b) de perda esperada; e

c) de buffer de capital.

A partir dos modelos teóricos de DPCLD deduzidos, os pesquisadores estimaram outros modelos para cálculo da taxa de juros ótima sobre empréstimos e a relação entre o ciclo econômico e o mercado de empréstimos, segundo cada um dos modelos teóricos de provisão.

Bouvatier e Lepetit (2012a) construíram as três proposições seguintes, que foram por eles confirmadas, a partir da calibragem de seus modelos teóricos:

a) a DPCLD pelo método da perda incorrida amplifica o efeito do ciclo econômico sobre o mercado de empréstimos e a magnitude desse efeito depende do impacto do ciclo econômico sobre a PCLD;

b) as regras de DPCLD pelo modelo da perda esperada não amplificam o efeito do ciclo econômico sobre o mercado de empréstimos;

c) o uso de um colchão para cobrir perdas com empréstimos compensa o efeito do ciclo econômico sobre as provisões; entretanto, esse método pode implicar uma alta flutuação do capital dos bancos.

O presente trabalho de pesquisa testa empiricamente os modelos de DPCLD desenvolvidos por Bouvatier e Lepetit (2012a) e compara os resultados com as DPCLD dos bancos brasileiros. 


\subsubsection{A pesquisa de Bushman e Williams (2012)}

Bushman e Williams (2012) estudaram os elementos que constituem a DPCLD registrada em 27 países e verificaram que os bancos que utilizam a DPCLD mais para o gerenciamento de resultados do que para prevenção contra perdas esperadas com empréstimos, ainda que adotem uma metodologia de perda esperada, estão mais expostos ao risco e às oscilações dos ciclos econômicos.

Os achados de Bushman e Williams (2012) reforçam os resultados da pesquisa de Bouvatier e Lepetit (2008), que verificaram que as despesas com créditos de liquidação duvidosa constituídas com o objetivo de gerenciamento de resultados não afetam as flutuações dos créditos. Dessa maneira, provisões adicionais constituídas com outro objetivo que não o de proteger contra perdas com créditos não conseguem diminuir a característica pró-cíclica dos empréstimos bancários, por não terem sido constituídas para esse fim.

Corrobora-se com o pensamento de Bushman e Williams (2012) os quais ponderam que, mais importante do que a adoção do modelo de provisão para perda com créditos adotado, de perda esperada, perda incorrida ou misto, é que o método seja capaz de cumprir o seu papel de prevenção contra perdas estimadas com empréstimos e que, consequentemente, apresente uma característica anticíclica, que garanta a liquidez do sistema financeiro e não contribua para o agravamento das crises.

\subsection{Hipóteses da Pesquisa}

As hipóteses são formuladas pelo pesquisador a partir de suas conjecturas sobre determinado fenômeno, ou em função de informações teóricas (MARTINS; THEÓPHILO, 2007). Com o objetivo de responder ao problema levantado neste trabalho de pesquisa, foi estabelecido um conjunto de hipóteses, testadas a partir de modelos estatísticos estimados para esse fim.

A Resolução CMN N 2.682/99 fornece a metodologia de cálculo da provisão para créditos de liquidação duvidosa dos bancos brasileiros, a ser constituída mensalmente considerando-se o 
montante da carteira de empréstimos, adimplentes e aqueles em situação de atraso ainda não baixados, segundo a classificação de risco da operação de crédito.

A metodologia de cálculo da DPCLD para os bancos brasileiros, emanada da Resolução CMN No 2.682/99, pode ser considerada mista, pois, de acordo com a referida Resolução, no momento da concessão do crédito os bancos brasileiros devem fazer provisões iniciais baseadas no rating de entrada do tomador (perda esperada). Essas provisões devem ser ajustadas em função do seu comportamento ao longo da vida do contrato (perda incorrida).

Diversos estudos, como os de Beatty e Liao (2011), Bouvatier e Lepetit (2012a) e Bushman e Williams (2012), indicam que o método da perda incorrida exacerba os ciclos econômicos e acaba por agravar os períodos de crise, a exemplo do ocorrido com a crise financeira mundial de 2008, originada nos Estados Unidos da América.

Se o modelo misto de provisão para créditos de liquidação duvidosa adotado pelos bancos brasileiros, por meio da Resolução CMN N $\mathrm{N}^{\mathrm{2}}$ 2.682/99, é capaz de fazer com que essas instituições constituam PCLD em níveis suficientes para manter o nível de concessão de créditos em períodos recessivos, é provável que o componente anticíclico prepondere na composição da DPCLD brasileira, favorecendo, dessa forma, medidas anticíclicas para a concessão de empréstimos. Daí decorre a primeira hipótese de pesquisa:

Hipótese 1: $\mathrm{O}$ componente de perda esperada da despesa com provisão para créditos de liquidação duvidosa dos bancos brasileiros é preponderante na composição dessa provisão.

Alguns autores afirmam que o nível de crescimento de um país é diretamente proporcional ao nível de desenvolvimento do seu sistema bancário, principalmente de crédito, sendo os bancos os verdadeiros responsáveis pelo nível de crescimento de um país (KING; LEVINE, 1993a, 1993b, 1993c; ROUSSEAU; WACHTEL, 1998; BECK; LEVINE; LOAYZA, 2000; MATOS, 2002; SILVA; PORTO JÚNIOR, 2006; ROCHA; NAKANE, 2007). Portanto, é de se esperar que uma crise financeira afete a liquidez do sistema bancário e, por conseguinte, provoque uma queda no nível de empréstimos e agrave um período recessivo.

Estudos também indicam que a provisão para créditos de liquidação duvidosa calculada pelo método da perda incorrida exacerba os ciclos econômicos, uma vez que se empresta mais e se provisiona menos em épocas de expansão econômica e, por outro lado, em tempos de recessão, quando a inadimplência aumenta, assim como aumenta a procura por créditos, os 
bancos enfrentam restrições devido ao capital regulatório e terminam por agravar as crises (BIKKER; METZEMAKERS, 2005; ZICCHINO, 2005; REPULLO; SUAREZ, 2008; BOUVATIER; LEPETIT, 2008, 2012a, 2012b; DRUMOND, 2009; BEATTY; LIAO, 2011; BOUVATIER; LEPETIT; STROBEL, 2014; BUSHMAN; WILLIAMS, 2012).

Por outro lado, alguns pesquisadores, como Greenawalt e Sinkey (1998), Kanagaretnam, Lobo e Mathieu (2003), Fonseca e Gonzales (2008), El Sood (2012) e Bushman e Williams (2012), alertam para as consequências da adoção de modelos de provisão pelo método da perda esperada, pois este pode favorecer a criação de um ambiente propício a práticas discricionárias de gerenciamento de resultados.

Entretanto, segundo outros autores, práticas discricionárias de gerenciamento de resultados podem ser benéficas, podendo ser uma resposta a deficiências na regulamentação contábil para determinados eventos ou transações econômicas, bem como uma forma de comunicação para o mercado de previsões sobre o desempenho futuro da firma (PAULO, 2007; SCOTT, 2009).

Liu, Ryan e Wahlen (1997) estudaram a PCLD de uma amostra de 104 bancos norteamericanos no período de 1984 a 1991 e constataram que aumentos discricionários na DPCLD, observados para bancos cujas carteiras de créditos apresentam alto risco de inadimplência, são bem vistos pelo mercado. De acordo com Scott (2009), esses achados de Liu, Ryan e Wahlen (1997) sugerem que os bancos at risk, ao gerenciarem os seus resultados, convencem o mercado do seu esforço para resolver seus problemas e que poderão melhorar o seu desempenho futuro.

A Resolução CMN N 2.682/99 fornece a metodologia de cálculo da provisão para créditos de liquidação duvidosa dos bancos brasileiros, que deve ser constituída mensalmente considerando-se o montante da carteira de empréstimos, adimplentes e aqueles em situação de atraso ainda não baixados, segundo a classificação de risco da operação de crédito.

Entretanto, a própria Resolução CMN N $2.682 / 99$ permite o uso de práticas discricionárias pelos bancos brasileiros na constituição da PCLD, ao permitir que cada banco desenvolva seus próprios modelos internos de avaliação de risco de crédito e, ainda, ao determinar que a classificação do nível do risco seja de responsabilidade da instituição detentora do crédito, amparada por informações internas e externas. A referida Norma recomenda, ainda, que os bancos registrem provisões adicionais consideradas necessárias para precaução contra 
possíveis perdas, sem exigir, no entanto, que sejam evidenciadas as origens dessas provisões adicionais.

O objetivo é investigar se a DPCLD registrada pelos bancos brasileiros possui, de fato, comportamento anticíclico e, por conseguinte, propicia aos bancos a manutenção da liquidez e condições de emprestar em tempos de crise, quando a procura por créditos aumenta e, assim, sejam capazes de atenuar os períodos de crise financeira.

Nesta pesquisa, são estimados modelos para cálculo da despesa com créditos de liquidação duvidosa com base nas regras mínimas de provisão da Resolução CMN No 2.682/99, ou seja, não se consideram os aspectos discricionários de provisões adicionais, no intuito de verificar se existe diferença significativa entre a DPCLD calculada de acordo com as regras mínimas de provisão da Resolução CMN No 2.682/99 e aquela efetivamente registrada pelos bancos brasileiros.

Com base em toda essa discussão, sobre o método de provisão para perdas com créditos mais adequado para conter as crises, e partindo do pressuposto de que o modelo misto de PCLD adotado pelos bancos brasileiros, por meio da Resolução CMN No 2.682/99, é eficiente no enfrentamento de crises (MESQUITA; TORÓS, 2010), é desenvolvido um modelo para verificar a relação entre a DPCLD dos bancos brasileiros e os ciclos econômicos do País. Formula-se, então, a segunda hipótese da pesquisa, testada de duas formas:

Hipótese 2A: A despesa com provisão para créditos de liquidação duvidosa registrada pelos bancos brasileiros é anticíclica.

Hipótese 2B: A despesa com provisão para créditos de liquidação duvidosa dos bancos brasileiros, calculada com base nas regras mínimas de provisão da Resolução $\mathrm{CMN} \mathrm{N}^{\mathrm{o}}$ $2.682 / 99$, é anticíclica.

Considera-se que a construção de um modelo de provisão para créditos de liquidação duvidosa que cumpra o seu papel de prevenção contra perdas e, por conseguinte, mantenha a regularidade no nível de concessão de empréstimos, de forma que não haja exacerbação dos ciclos econômicos, esteja muito além da discussão sobre a metodologia utilizada para cálculo da provisão ou mesmo do gerenciamento de resultados (BUSHMAN; WILLIAMS, 2012). Por isso, são aplicados, ao mesmo modelo que testa a Hipótese 2, valores simulados da DPCLD para os bancos brasileiros, obtidos conforme: 
a) a DPCLD não discricionária, calculada a partir da aplicação empírica do modelo teórico desenvolvido por Bouvatier e Lepetit (2012a) para cálculo da DPCLD pelo método da perda esperada;

b) a DPCLD não discricionária, determinada a partir da aplicação empírica do modelo teórico desenvolvido por Bouvatier e Lepetit (2012a), para cálculo da DPCLD pelo método da perda incorrida.

Formula-se, então, a terceira hipótese da pesquisa, a ser testada de duas formas:

Hipótese 3A: A despesa com provisão para créditos de liquidação duvidosa dos bancos brasileiros, estimada a partir do modelo teórico de Bouvatier e Lepetit (2012a), pelo método da perda esperada, não tem relação com os ciclos econômicos.

Hipótese 3B: A despesa com provisão para créditos de liquidação duvidosa dos bancos brasileiros, estimada a partir do modelo teórico de Bouvatier e Lepetit (2012a), pelo método da perda incorrida, é pró-cíclica. 


\section{DESENHO DA PESQUISA}

Este capítulo é composto de cinco seções: na primeira, é apresentado o modelo conceitual desenvolvido para explorar a questão e as hipóteses da pesquisa; na segunda seção, apresentase a população de estudo e as características da amostra; na terceira, há o relato do processo de coleta de dados e constituição da amostra; na quarta seção, discute-se o tratamento estatístico dos modelos; e na quinta seção, apresenta-se a estruturação dos modelos de análise.

\subsection{Modelo conceitual}

De acordo com Miranda (1997), o modelo conceitual consiste no desenho de um modelo de pesquisa, a definição conceitual dos construtos primários e a proposição de hipóteses, baseados na revisão da literatura. O modelo conceitual busca evidenciar as supostas relações entre os fatores-chave ou construtos a serem estudados, cujas justificativas podem vir de várias fontes, como a própria investigação prévia, teorias provisórias, bem como as estabelecidas em trabalhos teóricos ou empíricos encontrados na literatura (RAVITCH; RIGGAN, 2011). A figura 1 evidencia o modelo de pesquisa representativo deste trabalho.

A crise financeira mundial de 2008 teve, como um de seus desdobramentos, a mudança na metodologia de reconhecimento de perdas com instrumentos financeiros, de um modelo de perda incorrida para um de perda esperada, com a substituição da norma internacional IAS 39 pela IFRS 9. O Regulador Bancário Brasileiro não acolheu a IAS 39 por considerar o modelo de perda incorrida inadequado para aplicação em bancos, pois favoreceria a pró-ciclicidade dos empréstimos, e manteve as regras de provisão emanadas da Resolução CMN No 2.682/99.

Toda essa conjuntura motivou o estudo das características da provisão para créditos de liquidação duvidosa da Resolução CMN No 2.682/99 e sua relação com os ciclos econômicos do Brasil. Para tanto foi estimado um modelo econométrico que captura a relação entre a variação dos ciclos econômicos e as despesas com créditos de liquidação duvidosa dos bancos brasileiros e que, de forma adjacente, permite verificar a metodologia predominante do modelo de provisão da Resolução $\mathrm{CMN} \mathrm{N}^{\mathrm{o}}$ 2.682/99. Para a estimação do modelo 
econométrico, foram utilizados como base trabalhos anteriores relacionados ao tema, particularmente as pesquisas de Beatty e Liao (2011) e Bushman e Williams (2012).

Ao modelo estimado, além dos valores da DPCLD efetivamente registrada pelos bancos brasileiros, foram aplicados valores simulados da DPCLD para os bancos brasileiros, calculados de três formas distintas:

a) com base nas regras mínimas de provisão da Resolução CMN Nº 2.682/99;

b) aplicação do modelo teórico de Bouvatier e Lepetit (2012a), para cálculo da DPCLD pelo método da perda incorrida;

c) aplicação do modelo teórico de Bouvatier e Lepetit (2012a), para cálculo da DPCLD pelo método da perda esperada.

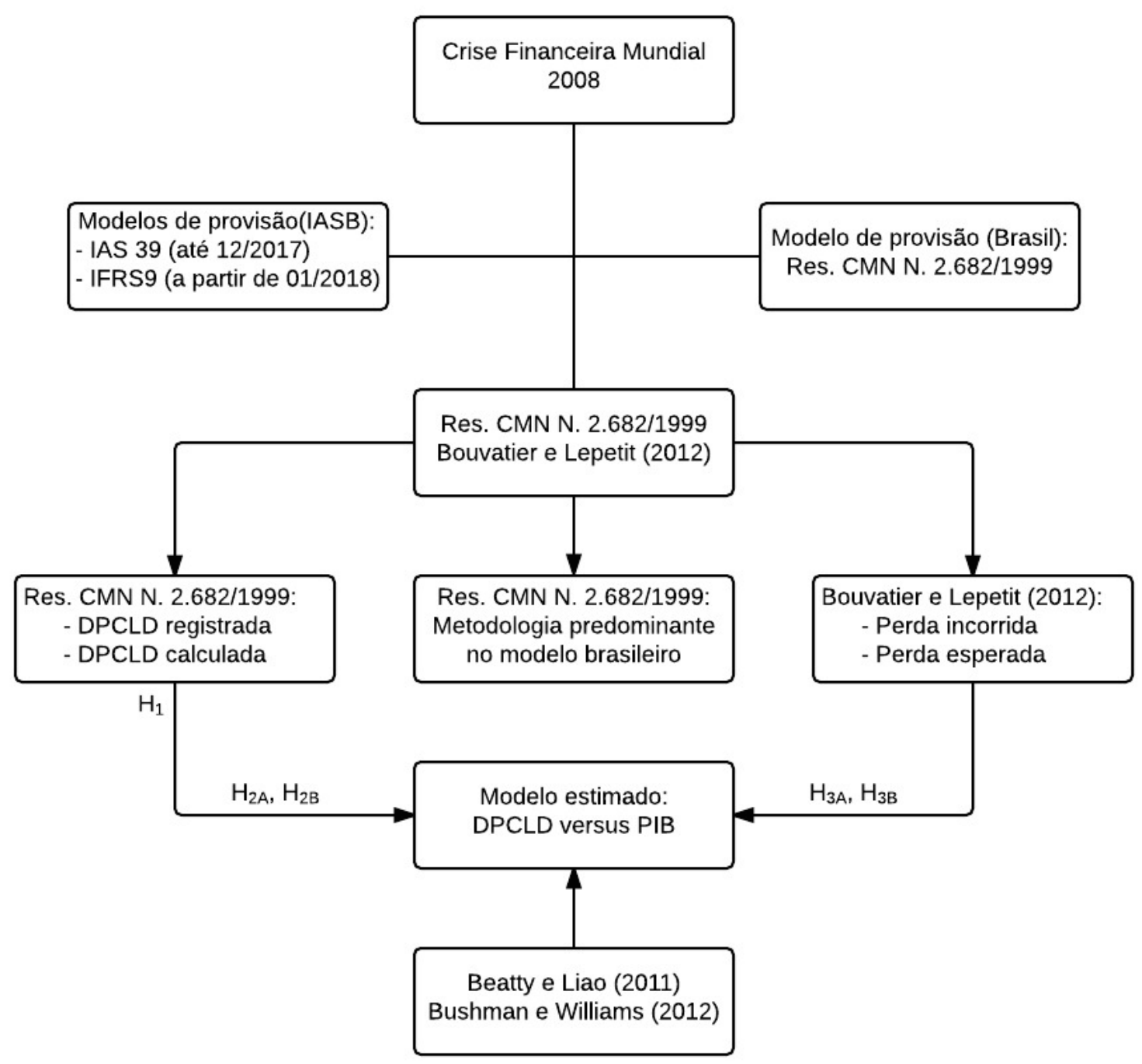

Figura 1 - Modelo da Pesquisa 


\subsection{População e características da amostra}

A população do estudo é composta pelos 161 bancos brasileiros comerciais, múltiplos e Caixa Econômica Federal, em atividade no Brasil em 31/12/2012. A amostra é formada pelos bancos que possuam carteira e empréstimos e tenham suas Informações Financeiras Trimestrais - IFT individuais publicadas no sítio do BACEN, no período considerado para estudo.

O período investigado abrange desde o $1^{\circ}$ trimestre de 2001 até o $4^{\circ}$ trimestre de 2012 e foi determinado com base em dois fatores:

a) ser posterior ao início da vigência da Resolução CMN Nº 2.682/99; e

b) período da disponibilidade das IFT no sítio do BACEN, a principal fonte de consulta e garimpagem dos dados contábeis necessários à consecução desta pesquisa.

As demais informações necessárias à construção das variáveis dos modelos estudados, tanto contábeis como macroeconômicas, foram obtidas nos sítios do BACEN, IPEADATA e no trabalho de Souza Júnior (2013). O quadro 2 resume as informações utilizadas nesta pesquisa e as respectivas fontes de obtenção.

Quadro 1 - Origem das informações necessárias à pesquisa

\begin{tabular}{|c|c|}
\hline Informação & Fonte \\
\hline $\begin{array}{l}\text { Saldos dos empréstimos, segregados em } \\
\text { adimplentes e inadimplentes }\end{array}$ & $\begin{array}{l}\text { IFT No } 7019 \text { - Operações de crédito - } \\
\text { vencimento }\end{array}$ \\
\hline Baixas da PCLD por prejuízo $^{(a)}$ & IFT No 7020 - Operações de Crédito - Fluxo \\
\hline Saldo das Operações de Crédito & $\begin{array}{l}\text { IFT No } 7022 \text { - Créditos Concedidos por Nível de } \\
\text { Risco }\end{array}$ \\
\hline $\begin{array}{l}\text { DPCLD efetivamente registrada e resultado } \\
\text { antes da tributação sobre o lucro e participações }\end{array}$ & IFT No 7023 - Demonstração do Resultado \\
\hline $\begin{array}{l}\text { Saldos das contas patrimoniais: ativo total, } \\
\text { PCLD, patrimônio líquido }\end{array}$ & IFT No 7002 - Balanço Patrimonial \\
\hline PIB & IPEADATA (2014) \\
\hline Hiato do Produto & Souza Jr. (2013) \\
\hline
\end{tabular}

Nota: (a) A informação das baixas da PCLD por prejuízo contida nas notas explicativas dos divulgadas pelos bancos nem sempre coincide com aquela apresentada na IFT No 7020 (BACEN); nesta pesquisa, optou-se por utilizar a informação contida na referida IFT. 
A constituição da amostra ocorreu de forma intencional, pelo critério da conveniência, por serem selecionados apenas os bancos que possuem IFT publicadas no sítio do BACEN no período considerado, fato que, além de facilitar o acesso aos dados também garante a uniformidade das informações, pois tem como base uma única fonte de pesquisa. O método de escolha da amostra para estudo não compromete a essência do trabalho, pois, amostragem válida é aquela que possibilita abranger a totalidade do problema investigado em suas múltiplas dimensões (SILVA, 2003).

\subsection{Processo de coleta dos dados e constituição da amostra}

Dos 161 bancos comerciais e múltiplos e Caixa Econômica Federal, em atividade no Brasil em 31/12/2012, treze foram excluídos da amostra pelos seguintes motivos:

a) dois bancos apresentaram dados de carteira de créditos durante apenas 4 trimestres e, ainda assim, todos classificados no nível de risco "AA", rating livre de risco e sem necessidade de constituição de provisão para créditos de liquidação duvidosa;

b) onze bancos não apresentaram saldos de empréstimos durante o período considerado para estudo.

Desse modo, a amostra de estudo é composta de 148 bancos comerciais e múltiplos e Caixa Econômica Federal, que possuem carteiras de crédito e constituem provisão para créditos de liquidação duvidosa.

As informações contábeis necessárias ao cálculo da PCLD e da DPCLD, de acordo com as regras de provisões mínimas contidas na Resolução CMN No $2.682 / 99$, foram coletadas dos documentos das IFT elencados anteriormente no quadro 1. A coleta dos dados e determinação das variáveis contábeis foi feita de forma manual, diretamente do sítio do Banco Central do Brasil, pois essa instituição não dispunha de arquivos em bancos de dados com informações necessárias à pesquisa. Os dados foram coletados e construídos da seguinte forma: 
a) os dados brutos para formação do banco de dados, referentes a cada um dos 148 bancos da amostra desta pesquisa foram copiados para o Excel, de forma manual, diretamente das respectivas IFT, para cada um dos 48 trimestres selecionados para estudo:

- os saldos das carteiras de empréstimos dos bancos da amostra, segregados por níveis de risco, foram coletados do documento IFT No 7022, linha "total";

- os saldos das operações de créditos segregados em situação normal (até 15 dias de atraso) e anormal (atrasos acima de 15 dias) foram extraídos do documento IFT $\mathrm{N}^{\mathrm{o}}$ 7019, linha "total";

- os valores das operações de crédito baixadas e levadas a prejuízo foram obtidos do documento IFT No 7070, linha "total";

- os saldos das operações de crédito, classificadas por níveis de risco e por situação de atraso (adimplentes e inadimplentes), foram retirados do documento IFT $\mathrm{N}^{\mathrm{o}}$ 7014;

b) os dados referentes à DPCLD efetivamente registrada pelos bancos brasileiros e ao lucro antes da tributação e participações constam no documento IFT N 7023 - Demonstração do Resultado; nesse caso, foi necessário copiar as demonstrações de forma completa e utilizar macros para capturar os valores de interesse para a pesquisa;

c) as informações referentes às contas patrimoniais (PCLD, ativo total e patrimônio líquido) constam no documento IFT No 7002 - Balanço Patrimonial; para obtenção desses dados também foi preciso copiar as demonstrações de forma completa e utilizar macros para capturar os valores de interesse para a pesquisa.

Como se pode notar, o processo de coleta e formação do banco de dados foi trabalhoso e demandou um tempo considerável para a sua conclusão (aproximadamente um ano no total). O banco de dados geral desta pesquisa resultou em uma planilha em Excel com 7.104 linhas e 22 colunas (sendo duas colunas referentes aos nomes dos bancos e aos CNPJ das instituições). Uma vez coletados os dados brutos necessários, procedeu-se à formação do banco de dados utilizados neste trabalho de pesquisa. 


\subsection{Tratamento estatístico}

A partir das hipóteses construídas para responder o problema da pesquisa, são estimados modelos para investigar os fatores (variáveis) que influenciam cada situação apresentada. Para a análise dos relacionamentos entre as variáveis estudadas são utilizados testes de médias, técnicas de análises de regressão múltipla e análise de dados em painel.

Os painéis construídos a partir dos modelos estimados nesta pesquisa são desbalanceados, uma vez que nem todos os bancos da amostra apresentam dados para todo o período pesquisado, devido à descontinuidade de alguns por processos de combinação de negócios ou liquidação, bem como a entrada de novos bancos ao longo do período considerado para estudo.

Os procedimentos e testes de robustez para controle de eventuais problemas que pudessem surgir na aplicação dos modelos estimados, tais como presença de raízes unitárias, multicolinearidade, heterocedasticidade e autocorrelação nos resíduos, entre outros, encontram-se detalhados no próximo capítulo.

\subsection{Especificação dos modelos de análise}

Nesta seção estão descritos os instrumentos de análise, empregados para teste das hipóteses e resposta ao problema da pesquisa. São utilizados, basicamente, dois instrumentos de análise:

a) equação deduzida para cálculo da despesa com créditos de liquidação duvidosa, segundo as regras mínimas de provisão contidas na Resolução CMN No 2.682/99;

- os valores calculados a partir da equação deduzida proporcionam uma análise da composição mista da DPCLD brasileira, bem como a sua comparação com a DPCLD efetivamente registrada pelos bancos brasileiros; 
- a Hipótese 1 da pesquisa é testada através da comparação entre os valores da DCLD registrados pelos bancos e os valores da DPCLD calculados segundo as regras mínimas da Resolução CMN No 2.682/99;

b) modelo de dados em painel construído a partir de estudos anteriores, com o objetivo de verificar a relação entre os ciclos econômicos do Brasil e a despesa com provisão para créditos de liquidação duvidosa dos bancos brasileiros; a partir desse modelo são testadas as Hipóteses 2A e 2B da pesquisa.

Além dos instrumentos de análise acima descritos, são avaliados empiricamente os modelos teóricos, não discricionários, deduzidos por Bouvatier e Lepetit (2012a) para cálculo da DPCLD pelos métodos da perda incorrida e da perda esperada. Os resultados obtidos com o cálculo empírico dos modelos teóricos deduzidos por Bouvatier e Lepetit (2012a) são aplicados ao modelo de dados em painel construído para verificar a relação entre os ciclos econômicos do Brasil e a DPCLD dos bancos brasileiros, para que sejam testadas as Hipóteses 3A e 3B da pesquisa.

\subsubsection{Especificação do modelo para cálculo da PCLD e da DPCLD, de acordo com a Resolução CMN N² 2.682/99}

A partir das orientações contidas na Resolução CMN N $2.682 / 99$ e das informações divulgadas em notas explicativas dos bancos brasileiros sobre o fluxo da PCLD no período, são estimados os modelos de cálculo da PCLD e da DPCLD, segregados por nível de classificação de risco, estritamente com base na referida Resolução.

O montante da PCLD calculado estritamente com base na Resolução CMN N 2.682/99 é obtido pelo valor total das operações de crédito em estoque, ponderadas pelas respectivas classificações de risco. A equação 1 evidencia o modelo representativo do cálculo da PCLD baseado estritamente nas regras contidas na Resolução CMN No 2.682/99:

$$
\begin{aligned}
P C L D_{i, t}= & 0,005 A_{i t}+0,01 B_{i t}+0,03 C_{i t}+0,10 D_{i t}+0,30 E_{i t}+0,50 F_{i t} \\
& +0,70 G_{i t}+1,00 H_{i t}
\end{aligned}
$$


onde:

$P C L D_{i, t}: \quad$ o saldo do estoque da provisão para créditos de liquidação duvidosa;

$A$ a $H: \quad$ os saldos de empréstimos, segregados por níveis de risco.

Outra forma de se obter o saldo da PCLD de um determinado período é a partir do fluxo da provisão ao longo desse tempo. De acordo com a Resolução CMN No 2.682/99, a variação da PCLD no período deriva de provisões decorrentes de novos empréstimos concedidos, baixas por amortizações, reclassificações de riscos das operações em andamento e baixas por lançamentos de operações em prejuízo. Desse modo, pode-se obter o saldo da PCLD da seguinte forma:

$$
P C L D_{i, t}=P C L D_{i, t-1}+c P C L D_{i, t}-b P C L D_{i, t}-P R J_{i, t}
$$

onde:

$P C L D_{i, t}: \quad$ saldo da PCLD do banco $i$ no período $t$;

$P C L D_{i, t-1}: \quad$ saldo da PCLD do banco $i$ no período anterior $(t-1)$;

$c P C L D_{i, t}$ : valor total da PCLD do banco $i$ constituída durante o período $t$, decorrente de novas concessões ou de reclassificações de risco;

$b P C L D_{i, t}$ : valor total das reversões de PCLD do banco $i$ no período $t$, decorrente de amortizações ou reclassificações de risco;

$P R J_{i, t}$ total das baixas para prejuízo de operações de crédito inadimplentes do banco $i$ no período $t$.

Ainda a partir do disposto na Resolução CMN No 2.682/99, bem como da análise das notas explicativas dos bancos brasileiros, verifica-se que a DPCLD de um banco para cobrir determinado período $\left(D P C L D_{i, t}\right)$ é registrada pelo valor líquido entre a constituição e a baixa da PCLD nesse período, ou seja:

$$
\operatorname{DPCLD} D_{i, t}=c P C L D_{i, t}-b P C L D_{i, t}
$$

Pode-se, então, substituir a equação 3 na equação 2 e reescrevê-la da seguinte forma: 


$$
P C L D_{i, t}=P C L D_{i, t-1}+D P C L D_{i, t}-P R J_{i, t}
$$

Deduz-se, então, que a DPCLD de um banco em certo período é dada por:

$$
\operatorname{DPCLD}_{i, t}=P C L D_{i, t}-P C L D_{i, t-1}+P R J_{i, t}
$$

Assim, conclui-se que a DPCLD de um banco, referente a certo período, pode ser calculada pela variação da PCLD ao longo do período considerado, mais o montante dos empréstimos lançados a prejuízo, conforme a equação 4 :

$$
D P C L D_{i, t}=\triangle P C L D_{i, t}+P R J_{i, t}
$$

onde:

$D P C L D_{i, t}: \quad$ despesa com créditos de liquidação duvidosa do banco $i$ no período $t$; $\triangle P C L D_{i, t}: \quad$ variação do saldo da PCLD do banco $i$ no período $t$; $P R J_{i, t}: \quad$ total das baixas para prejuízo de operações de crédito do banco $i$ no período $t$.

A partir da equação 4 é possível construir um modelo para o cálculo da DPCLD que evidencie a composição da referida despesa por classificação de nível de risco, conforme mostra a equação 5:

$$
\operatorname{DPCLD}_{i, t}=\Delta A_{i, t}+\Delta B_{i, t}+\Delta C_{i, t}^{N}+\Delta D_{i, t}+\Delta E_{i, t}+\Delta F_{i, t}+\Delta G_{i, t}+\Delta H_{i, t}+P R J_{i, t}
$$

onde:

$D P C L D_{i, t} \quad$ despesa com PCLD do banco $i$ no período $t$;

$\Delta A_{i, t}-\Delta H_{i, t}$ : variação da PCLD do banco $i$ no período $t$, por classificação de nível de risco, do $\mathrm{A}$ ao $\mathrm{H}$;

$P R J_{i, t}: \quad$ total das baixas para prejuízo de operações de crédito do banco $i$ ao longo do período $t$.

Entretanto, apesar de ser possível estimar o valor da PCLD e da DPCLD para os bancos brasileiros estritamente com base na Resolução CMN No 2.682/99, ainda assim obtém-se um 
resultado com certo grau de discricionariedade, pois a classificação dos empréstimos pelos respectivos níveis de risco é feita com base em fatores subjetivos (conjuntura econômica, experiência passada, avaliação de risco do tomador e garantidor, entre outros) e cada banco utiliza seus próprios modelos internos nessas avaliações.

Com o objetivo de se estimar uma DPCLD para os bancos brasileiros livre de elementos discricionários, são calculados empiricamente os modelos teóricos desenvolvidos por Bouvatier e Lepetit (2012a) para determinação da DPCLD pelos modelos de perda incorrida e perda esperada, com adaptações de algumas premissas, de modo a proporcionar resultados mais adequados à realidade dos bancos brasileiros, cujas regras contábeis são diferentes das normas europeias.

\subsubsection{Modelos de estimação da DPCLD não discricionária}

De acordo com Bouvatier e Lepetit (2012a), por definição, a DPCLD do período, segundo o método da perda incorrida, consiste na fração média de empréstimos em atraso cobertos pelas provisões para perdas com empréstimos durante o período, de modo que o modelo teórico para o seu cálculo está representado pela equação 6:

$$
\operatorname{DPCLD} D_{i, t}=I_{m, i t} E_{i, t} I\left(y_{t}\right)_{i, t}
$$

onde:

$D P C L D_{i, t}: \quad$ despesa com provisão para créditos de liquidação duvidosa do banco $i$ no período $t$;

$I_{m, i, t}$ fração média dos empréstimos em atraso do banco $i$, cobertos pela PCLD durante o período considerado;

$E_{i, t}: \quad$ montante de empréstimos concedidos pelo banco $i$ no período $t$;

$I\left(y_{t}\right)_{i, t}$ : fração de empréstimos em atraso ponderada por variáveis de curto prazo relacionadas ao ciclo econômico.

Por outro lado, na determinação da DPCLD segundo o método de perda esperada, as variações do ciclo econômico deixam de ser relevantes para o cálculo da DPCLD e o seu 
valor é suavizado em torno da fração média dos empréstimos em atraso (BOUVATIER; LEPETIT, 2012a). O modelo teórico deduzido é expresso na equação 7:

$$
\operatorname{DPCLD} D_{i, t}=I_{m, i, t} E_{i, t} I_{0, i, t}
$$

onde:

$D P C L D_{i, t}: \quad$ despesa com créditos de liquidação duvidosa do banco $i$ no período $t$;

$I_{m, i, t}$ fração média dos empréstimos em atraso do banco $i$, cobertos pela PCLD durante o período considerado;

$E_{i, t}: \quad$ montante de empréstimos concedidos pelo banco $i$ no período $t$

$I_{0, i, t}$ proporção de empréstimos em atraso do banco $i$ no período considerado, em relação ao volume de empréstimos concedidos.

Através da equação 7, verifica-se que o cálculo da DPCLD pelo modelo de perda esperada para o período corrente considera tão somente dados internos do banco, relacionados ao comportamento da carteira de empréstimos, quais sejam: o histórico da proporção de empréstimos em atraso cobertos pela PCLD $\left(I_{m}\right)$; o histórico da proporção de empréstimos em atraso em relação ao volume de empréstimos concedidos $\left(I_{0}\right)$; e o volume de empréstimos do período corrente $\left(E_{i, t}\right)$.

Apesar de as variáveis contidas nas equações 6 e 7 serem as mesmas consideradas por Bouvatier e Lepetit (2012a), as premissas adotadas para a aplicação dos modelos neste trabalho foram adaptadas com o objetivo de melhor refletir a realidade brasileira.

\subsubsection{Cálculo da fração média dos empréstimos em atraso, cobertos pela PCLD do período}

A fórmula para cálculo da fração média dos empréstimos em atraso cobertos pela PCLD durante determinado período, adaptada de Bouvatier e Lepetit (2012a), está evidenciada na equação 8: 


$$
I_{m, i, t}=\frac{\overline{\sum_{t-6}^{t} D P C L D_{l, t}}}{\overline{\sum_{t-6}^{t} I_{l, t}}}
$$

onde:

$I_{m, i, t}$ : fração média dos empréstimos em atraso do banco $i$ cobertos pela PCLD durante o período considerado;

$\overline{\sum_{t-6}^{t} D P C L D_{l, t}}:$ somatório das despesas médias com PCLD, calculadas trimestralmente com base no ciclo do atraso;

$\overline{\sum_{t-6}^{t} I_{l, t}}$ : somatório dos saldos médios dos empréstimos em atraso, calculados trimestralmente com base no ciclo de atraso.

O parâmetro " $I_{m, i, t}$ " é determinado trimestralmente e tem como base o ciclo do atraso, aqui definido como o período de 18 meses (ou seis trimestres), compreendido entre o primeiro dia de atraso de uma operação de crédito com prazo igual ou maior que 36 meses e a data do seu lançamento a prejuízo, ou seja, o tempo máximo que uma operação de crédito inadimplente pode permanecer no Balanço, de acordo com a Resolução CMN No 2.682/999.

A despesa média com PCLD, calculada em base trimestral, é obtida pela média móvel da DPCLD dos seis trimestres imediatamente anteriores, ou seja, do intervalo que abrange o ciclo de atraso. Os valores considerados para determinação da despesa média trimestral com PCLD são aqueles calculados estritamente de acordo com a Resolução CMN No 2.682/99, obtidos pela aplicação da equação 5 (ver seção 3.5.1), de forma a se evitar, ao máximo, a discricionariedade.

O saldo médio trimestral dos empréstimos em atraso, a exemplo da despesa média com PCLD, é obtido pela média móvel ponderada dos saldos dos empréstimos em atraso nos seis trimestres imediatamente anteriores, ou seja, no intervalo que abrange o ciclo do atraso. $\mathrm{O}$ valor trimestral dos empréstimos em atraso é determinado pelo montante dos empréstimos em curso anormal com níveis de rating entre " $\mathrm{D}$ " e " $\mathrm{H}$ ", e que apresentem atraso igual ou superior a 60 dias, de forma a convergir com Bouvatier e Lepetit (2012a), que consideram

\footnotetext{
${ }^{9}$ De acordo com a Resolução CMN No 2.682/99, “a operação classificada como de risco nível H deve ser transferida para conta de compensação, com o correspondente débito em provisão, após decorridos seis meses da sua classificação nesse nível de risco, não sendo admitido o registro em período inferior" (art. $7^{\circ}$ ). Por outro lado, ainda conforme a mesma Resolução, o prazo máximo de atraso para uma operação de crédito de longo prazo ser classificada como de nível H é 360 dias, ou um ano comercial. Dessa forma, o ciclo do atraso compreende o prazo máximo de 12 meses para uma operação de crédito inadimplente atingir o nível $\mathrm{H}$, mais o prazo máximo de 6 meses que essa mesma operação deve permanecer no nível H, antes de ser lançada em prejuízo, totalizando 18 meses, ou 6 trimestres.
} 
como empréstimos em atraso aqueles para os quais nenhuma receita é reconhecida. No Brasil, em obediência à Resolução CMN No 2.682/99, as receitas de empréstimos deixam de ser apropriadas a partir do $60^{\circ}$ dia de atraso, o que denota um nível de rating mínimo igual a " $\mathrm{D}$ " para essas operações ${ }^{10}$.

\subsubsection{Cálculo da proporção média de empréstimos em atraso no período, em relação ao total de empréstimos concedidos}

A fórmula para cálculo da proporção média dos empréstimos em atraso no período, em relação ao total de empréstimos concedidos, adaptada de Bouvatier e Lepetit (2012a), é representada pela equação 9:

$$
I_{0, i, t}=\frac{\overline{\sum_{t-6}^{t} I_{l, t}}}{\overline{\sum_{t-6}^{t} E_{l, t}}}
$$

onde:

$I_{0, i, t}: \quad$ proporção média de empréstimos em atraso do banco $i$ no período, em relação ao total de empréstimos concedidos;

$\sum_{t-6}^{t} \overline{I_{l, t}}: \quad$ somatório dos saldos médios dos empréstimos em atraso do banco $i$, calculados trimestralmente com base no ciclo de atraso.

$\sum_{t-6}^{t} \overline{E_{l, t}}$ : somatório dos saldos médios dos empréstimos concedidos pelo banco $i$, calculados trimestralmente com base no ciclo de atraso.

De modo similar ao parâmetro " $I_{m, i, t}$ ", o parâmetro " $I_{0, i, t}$ " é determinado trimestralmente e tem como base o ciclo do atraso, que é o tempo máximo que uma operação de crédito inadimplente pode permanecer no Balanço, segundo a Resolução CMN No 2.682/99. O parâmetro " $I_{0, i, t}$ " é calculado pela razão entre o saldo médio dos empréstimos em atraso (seis últimos trimestres) e o saldo médio dos empréstimos concedidos no mesmo período.

\footnotetext{
${ }^{10}$ Neste trabalho também é testado o total dos empréstimos em curso anormal no período, de modo a se verificar a existência de diferenças significativas nos resultados obtidos, caso seja considerado o total de empréstimos vencidos.
} 
O saldo médio trimestral dos empréstimos concedidos é obtido pela média móvel ponderada dos saldos totais dos empréstimos, tanto em curso normal como anormal, nos seis trimestres imediatamente anteriores, ou seja, no intervalo que abrange o ciclo de atraso. A metodologia de cálculo dos saldos médios dos empréstimos já foi abordada nesta seção (ver equação 8).

\subsubsection{Cálculo da fração de empréstimos em atraso pelo método da perda incorrida}

Para o cálculo da DPCLD não discricionária pelo método da perda incorrida, a fração dos empréstimos em atraso é ponderada por variáveis de curto prazo relacionadas ao ciclo econômico. A fórmula de cálculo da DPCLD pelo método da perda incorrida, adaptada de Bouvatier e Lepetit (2012a), está representada pela equação 10:

$$
I\left(y_{t}\right)_{i, t}=I_{0}\left(\frac{y_{t}}{y}\right)^{-w} \cdot z_{t}
$$

onde:

$I\left(y_{t}\right)_{i, t}$ : fração de empréstimos em atraso ponderada por variáveis de curto prazo relacionadas ao ciclo econômico;

$I_{0, i, t}$ : proporção média de empréstimos em atraso no período, em relação ao total de empréstimos concedidos;

$y_{t} / y: \quad$ hiato do produto;

$w$ : elasticidade dos empréstimos em atraso em relação ao hiato do produto;

$z_{t}$ : choques inesperados no nível de empréstimos em atraso (variável de média $1 \mathrm{e}$ desvio padrão, $\left.\sigma_{\mathrm{z}}\right)$.

De acordo com Cusinato, Minella e Porto Junior (2011), a definição usual do hiato do produto é a diferença entre o produto real (PIB real) e o produto potencial (PIB potencial) que, em termos práticos, obtido usualmente por meio de métodos de extração de tendência e calculado como o desvio entre o produto e a tendência.

Se o produto real é menor que o produto potencial $\left[\left(y_{t} / y\right)<1\right]$, a economia opera em um nível inferior ao esperado, o que denota um movimento de retração e, portanto, a fração de empréstimos em atraso $\left[I\left(y_{t}\right)\right]$ tende a aumentar; com isso, a DPCLD também aumenta. Por 
outro lado, se o produto real é maior que o produto potencial $\left[\left(y_{t} / y\right)>1\right]$, a economia está em movimento de expansão, no qual o nível de empréstimos em atraso $\left[I\left(y_{t}\right)\right]$ tende a diminuir, provocando uma diminuição da DPCLD no período.

Dessa maneira, verifica-se que, no modelo de perda incorrida, o nível da DPCLD não está relacionado ao valor total da fração média dos empréstimos em atraso $\left(I_{0, i, t}\right)$, mas a este total ponderado pelos ciclos econômicos no curto prazo e pelos choques $\left(\mathrm{z}_{\mathrm{t}}\right)$.

O hiato do produto $\left(y_{t} / y\right)$ afeta a situação financeira das firmas e das famílias e, desse modo, é inversamente proporcional ao nível dos empréstimos em atraso $\left[I\left(y_{t}\right)\right]$; entretanto, os choques $\left(\mathrm{z}_{\mathrm{t}}\right)$ chamam a atenção para o fato de que o nível de empréstimos em atraso não é totalmente previsível, mesmo quando o hiato do produto é conhecido (BOUVATIER; LEPETIT, 2012a).

Os valores trimestrais do hiato do produto utilizados nesta pesquisa são baseados nos cálculos efetuados por Souza Júnior (2013). Para obtenção do hiato do produto trimestral, Souza Junior (2013) utilizou o PIB real com ajuste sazonal e estimou o PIB potencial pelo Filtro de Hodrick - Prescott (HP), um dos principais métodos utilizados, considerado de simples aplicação, além de ser um dos métodos adotados pelo BACEN para determinação do produto potencial da economia brasileira (BARBOSA FILHO, 2009; SOUZA JÚNIOR, 2009; SUMMA; LUCAS, 2010; CUSINATO; MINELLA; PORTO JÚNIOR, 2011).

Os choques $\left(\mathrm{z}_{\mathrm{t}}\right)$, segundo Bouvatier e Lepetit (2012a), representam quaisquer outros fatores que podem influenciar o nível de empréstimos em atraso, além dos ciclos econômicos. Houve contato por e-mail com os pesquisadores, em dezembro de 2012, na tentativa de se obterem maiores orientações sobre como estimar tais choques, entretanto, a resposta obtida não foi suficiente para esclarecer a dúvida, de maneira que, nesta pesquisa, decidiu-se atribuir o valor "1" para os choques, que são o seu valor médio.

Para calibrar a elasticidade dos empréstimos em atraso em relação ao hiato do produto (w), Bouvatier e Lepetit (2012a) estimaram uma equação em painel, na qual a variável dependente é a proporção dos empréstimos em atraso em relação ao total de empréstimos, e as variáveis independentes são a variável dependente defasada e o hiato do produto. O modelo adaptado de Bouvatier e Lepetit (2012a) é representado pela equação 11: 


$$
I_{0(i, t)}=\rho_{1} I_{0(t-1)}+\lambda_{1}\left(y_{t} / y\right)+\varepsilon_{i, t}
$$

onde:

$I_{0(i, t)}$ : proporção média de empréstimos em atraso no período, em relação ao total de empréstimos concedidos;

$I_{0(t-1)}$ : proporção média de empréstimos em atraso no período anterior, em relação ao total de empréstimos concedidos;

$\left(y_{t} / y\right): \quad$ hiato do produto;

$\rho_{1}$ : $\quad$ coeficiente que captura a influência da proporção média de empréstimos em atraso, ponderada pelo total dos empréstimos concedidos, no período anterior, sobre essa mesma proporção no período atual;

$\lambda_{1}$ : coeficiente que captura a influência do hiato do produto sobre a proporção média de empréstimos em atraso, ponderada pelo total dos empréstimos concedidos no período;

$\varepsilon_{i, t}: \quad$ termo de erro da equação.

A partir da equação 11, infere-se que um hiato do produto negativo, ou seja, o produto real menor que o produto potencial, indica um processo recessivo e, dessa maneira, espera-se que a proporção de empréstimos em atraso aumente em relação ao período anterior $\left(\lambda_{1}>0\right)$. Por outro lado, um hiato do produto positivo indica um processo em expansão e, assim, espera-se que o nível de empréstimos em atraso seja menor $\left(\lambda_{1}<0\right)$.

Determinados os coeficientes " $\rho_{l}$ " $e$ “ $\lambda_{l}$ ”, estima-se então a elasticidade dos empréstimos em atraso, em relação ao hiato do produto, a partir da equação 12 :

$$
\lambda_{1}=\left(1-\rho_{1}\right) w \therefore w=\frac{\lambda_{1}}{1-\rho_{1}}
$$

onde:

$w$ : elasticidade dos empréstimos em atraso em relação ao hiato do produto;

$\rho_{1}$ : coeficiente que captura a influência da proporção média de empréstimos em atraso, ponderada pelo total dos empréstimos concedidos, no período anterior, sobre essa mesma proporção no período atual;

$\lambda_{1}$ : coeficiente que captura a influência do hiato do produto sobre a proporção média de empréstimos em atraso, ponderada pelo total dos empréstimos concedidos no período. 
Corrobora-se com Bouvatier e Lepetit (2012a) quanto aos modelos teóricos desenvolvidos pelos pesquisadores serem livres de discricionariedade, uma vez que foram construídos a partir de dados concretos, como o montante de empréstimos concedidos e os atrasos efetivamente verificados, estando, desse modo, livres de julgamentos subjetivos, já que tais julgamentos influenciaram na decisão de conceder e de quanto emprestar, mas não na operação de crédito já em curso.

\subsubsection{Análise da relação entre a despesa com créditos de liquidação duvidosa dos bancos brasileiros e os ciclos econômicos do Brasil}

Com o objetivo de verificar a relação entre os ciclos econômicos do Brasil e a DPCLD dos bancos brasileiros, estimou-se um modelo em painel cuja construção teve como ponto de partida estudos anteriores, constantes no referencial teórico desta pesquisa, com adaptação de algumas variáveis explicativas, no intuito de se obter maior aderência às regras brasileiras para cálculo da DPCLD, ditadas pela Resolução CMN No 2.682/99, e ao ambiente macroeconômico do Brasil.

A partir do modelo proposto são testadas as Hipóteses 2A, 2B, 3A e 3B da pesquisa. A DPCLD é a variável dependente do modelo e assume diferentes valores, de acordo com a hipótese testada, conforme evidenciado no quadro 2 :

Quadro 2 - DPCLD de acordo com a hipótese da pesquisa a ser testada

\begin{tabular}{|c|l|}
\hline Hipótese & \multicolumn{1}{|c|}{ Valor assumido pela DPCLD } \\
\hline $\mathrm{H}_{2 \mathrm{~A}}$ & Valor efetivamente registrado pelos bancos brasileiros. \\
\hline $\mathrm{H}_{2 \mathrm{~B}}$ & $\begin{array}{l}\text { Valor calculado segundo as regras mínimas de provisão da Resolução CMN No } \\
2.682 / 99 .\end{array}$ \\
\hline $\mathrm{H}_{3 \mathrm{~A}}$ & $\begin{array}{l}\text { Valor obtido pela aplicação do modelo teórico da perda esperada, estimado por } \\
\text { Bouvatier e Lepetit (2012a) }\end{array}$ \\
\hline $\mathrm{H}_{3 \mathrm{~B}}$ & $\begin{array}{l}\text { Valor obtido pela aplicação do modelo teórico da perda incorrida, estimado por } \\
\text { Bouvatier e Lepetit (2012a) }\end{array}$ \\
\hline
\end{tabular}


O modelo teórico estimado para análise da relação entre os ciclos econômicos do Brasil e a DPCLD dos bancos brasileiros é representado pela equação $13^{11}$ :

$$
\begin{aligned}
D_{P C L D}, t & =\beta_{0}+\beta_{1} \Delta \% P I B_{t}+\beta_{2} C A P_{i, t}+\beta_{3} L n A T_{i, t-1}+\beta_{4} L A I M P_{i, t} \\
& +\beta_{5} \Delta E M P_{i, t}+\beta_{6} \Delta I N A D_{i, t-2}+\beta_{7} \Delta I N A D_{i, t-1}+\beta_{8} \Delta I N A D_{i, t} \\
& +\beta_{9} \Delta I N A D_{i, t+1}+\beta_{10} \Delta P C L D_{i, t}+\beta_{11} P R J_{i, t}+\varepsilon_{i, t}
\end{aligned}
$$

onde:

$D P C L D_{i, t}$ : despesa com provisão para créditos de liquidação duvidosa registrada pelos bancos brasileiros escalonada pelos ativos totais do início do período;

$\Delta \% P I B_{t}$ : $\quad$ variação percentual do Produto Interno Bruto, a valores constantes (PIB real);

$C A P_{i, t}$ : índice de capitalização, que consiste na razão entre o patrimônio líquido e os ativos totais do período;

$\operatorname{LnAT}_{i, t-1}: \quad$ logaritmo natural dos ativos totais no início do período;

$\operatorname{LAIMP}_{i, t}$ : lucro antes da tributação e da despesa com provisão para créditos de liquidação duvidosa escalonado pelos ativos totais do início do período;

$\triangle E M P_{i, t}: \quad$ variação trimestral do saldo da carteira de empréstimos escalonada pelos ativos totais do início do período;

$\triangle I N A D_{i, t-2}: \quad$ variação trimestral dos créditos em situação de atraso de mais de 15 dias (defasagem de dois trimestres) escalonada pelos ativos totais do início do período;

$\triangle I N A D_{i, t-1}: \quad$ variação trimestral dos créditos em situação de atraso de mais de 15 dias (defasagem de um trimestre) escalonada pelos ativos totais do início do período;

$\triangle I N A D_{i, t}$ : variação dos créditos em situação de atraso de mais de 15 dias (trimestre corrente) escalonada pelos ativos totais do início do período;

$\triangle I N A D_{i, t+1}: \quad$ variação trimestral dos créditos em situação de atraso de mais de 15 dias (trimestre seguinte) escalonada pelos ativos totais do início do período;

$\triangle P C L D_{i, t}$ : variação do saldo da provisão para créditos de liquidação duvidosa escalonada pelos ativos totais do início do período;

$P R J_{i, t}$ : $\quad$ valores lançados a prejuízo escalonados pelos ativos totais do início do período;

$\beta_{0}: \quad$ intercepto;

$\beta_{1} a \beta_{11}$ : coeficientes angulares do modelo;

$\varepsilon_{i, t} \quad$ termo de erro $\left[N \sim\left(0, \sigma^{2}\right)\right]^{12}$.

${ }^{11} \mathrm{Na}$ especificação do modelo não foram considerados aspectos de endogeneidade. Como, ao proceder à regressão do modelo em dois estágios, foram verificadas significâncias estatísticas muito próximas às das estimações do modelo em um estágio, optou-se pela análise dos resultados fornecidos pela estimação em um estágio. 
Para controlar os fundamentos associados à DPCLD para proteção contra perdas futuras esperadas com empréstimos, foi inserida no modelo a variável explicativa que representa a variação do saldo de empréstimos em atraso do próximo período $\left(\triangle I N A D_{i, t+1}\right)$. Essa variável foi utilizada com a mesma finalidade em estudos anteriores, dentre os quais, os trabalhos desenvolvidos por Beaver e Engel (1996), Beatty e Liao (2011), Cheng, Warfield e Ye (2011), Bushman e Williams (2012) e El Sood (2012).

Com o propósito de controlar os fundamentos discricionários da DPCLD, relacionados ao gerenciamento de resultados e suavização de lucros, foi inserida no modelo a variável representativa do lucro antes dos impostos e da DPCLD $\left(\operatorname{LAIMP}_{i, t}\right)$. Essa variável tem sido utilizada em vários estudos como indicativa da presença de práticas discricionárias de gerenciamento de resultados por parte dos bancos na constituição da DPCLD, a exemplo das pesquisas de Ahmed, Takeda e Thomas (1999), Laeven e Majnoni (2003), Bikker e Metzemakers, (2005), Fonseca e Gonzales (2008), Bouvatier e Lepetit (2008, 2012b), Beatty e Liao (2011), Bushman e Williams (2012) e El Sood (2012).

Como variável de controle da perda incorrida da DPCLD, foram inseridas no modelo as variáveis representativas das operações lançadas a prejuízo no período $\left(P R J_{i, t}\right)$ e das variações das operações de operações de crédito em atraso $\left(\triangle I N A D_{i, t-2} ; \triangle I N A D_{i, t-1 ;} \Delta I N A D_{i, t}\right)$. A inserção dessas variáveis no modelo está em consonância com os trabalhos de Beaver e Engel (1996), Marcondes (2008), Cheng, Warfield e Ye (2011), Bushman e Williams (2012) e Dantas, Lustosa e Medeiros (2012).

Para controlar efeitos relacionados ao porte dos bancos (tamanho), foi inserido no modelo o logaritmo natural dos ativos totais no início do período $\left(\operatorname{LnA} T_{t-1}\right)$, seguindo os trabalhos de Kanagaretnam, Lobo e Mathieu (2003), Beatty e Liao (2011), Bushman e Williams (2012), El Sood (2012) e Berger e Bowman (2013).

A fim de controlar tendências macroeconômicas, foram inseridas no modelo variáveis que representam o índice de capitalização do banco $\left(C A P_{i, t}\right)$ do período, utilizada como proxy para o patrimônio de referência dos bancos da amostra, e a variação do saldo da carteira de empréstimos no período $\left(\triangle E M P_{i, t}\right)$. Essas medidas podem ser consideradas indicativas de tendências macroeconômicas, pois, em tempos de recessão, os bancos enfrentam problemas

\footnotetext{
${ }^{12}$ Pressuposto de normalidade dos resíduos: a distribuição dos erros é normal, com média zero e variância constante.
} 
de liquidez, com a consequente diminuição do índice de capitalização, o que provocar, por sua vez, uma diminuição no nível de empréstimos concedidos (BEATTY; LIAO, 2011). Variáveis representativas do patrimônio de referência e da carteira de empréstimos têm sido consideradas conjuntamente em modelos desenvolvidos por pesquisadores em trabalhos correlatos ao tema, dentre os quais podem-se citar Bikker e Metzemakers (2005) e El Sood (2012).

A variável independente representativa dos ciclos econômicos é a variação trimestral do PIB real em termos percentuais $\left(\Delta \% P I B_{t}\right)$, que tem sido a proxy mais utilizada para representar os ciclos econômicos na maioria dos trabalhos acadêmicos, inclusive nos que serviram de base para esta pesquisa, como os de Beatty e Liao (2011), Bouvatier e Lepetit (2012a), Bushman e Williams (2012), Dantas (2012) e Araújo (2014).

O sinal esperado para cada uma das variáveis independentes do modelo depende da hipótese a ser testada. O quatro 3 sintetiza os sinais esperados para os coeficientes angulares das variáveis independentes contidas no modelo em painel representado pela equação 13.

Quadro 3 - Sinais esperados das variáveis independentes do modelo

\begin{tabular}{|l|c|c|c|c|}
\hline \multirow{2}{*}{ Variável } & \multicolumn{4}{|c|}{ Sinal } \\
\cline { 2 - 5 } & Hipótese 2A & Hipótese 2B & Hipótese 3A & Hipótese 3B \\
\hline$\Delta \% \mathrm{PIB}_{\mathrm{t}}:$ & $(+)$ & $(+)$ & $(N R)$ & $(-)$ \\
\hline $\mathrm{CAP}_{\mathrm{i}, \mathrm{t}}:$ & $(-)$ & $(+)$ & $(+)$ & $(-)$ \\
\hline $\mathrm{LnAT}_{\mathrm{i}, \mathrm{t}-1}:$ & $(+)$ & $(+)$ & $(+)$ & $(+)$ \\
\hline $\mathrm{LAIMP}_{\mathrm{i}, \mathrm{t}}:$ & $(+)$ & $(+/-)$ & $(+/-)$ & $(+)$ \\
\hline$\Delta \mathrm{EMP}_{\mathrm{i}, \mathrm{t}}:$ & $(+)$ & $(+)$ & $(+)$ & $(+)$ \\
\hline$\Delta \mathrm{INAD}_{\mathrm{i}, \mathrm{t}-2}:$ & $(+)$ & $(+)$ & $(+)$ & $(+)$ \\
\hline$\Delta \mathrm{INAD}_{\mathrm{i}, \mathrm{t}-1}:$ & $(+)$ & $(+)$ & $(+)$ & $(+)$ \\
\hline$\Delta \mathrm{INAD}_{\mathrm{i}, \mathrm{t}}:$ & $(+)$ & $(+)$ & $(+)$ & $(+)$ \\
\hline$\Delta \mathrm{INAD}_{\mathrm{i}, \mathrm{t}+1}:$ & $(+)$ & $(+)$ & $(+)$ & $(+)$ \\
\hline$\Delta \mathrm{PCLD}_{\mathrm{i}, \mathrm{t}}:$ & $(+)$ & & & \\
\hline PRJ $_{\mathrm{i}, \mathrm{t}:}$ & $(+)$ & & & \\
\hline
\end{tabular}

Notas: Os sinais esperados são tratados na análise dos resultados, na discussão das variáveis independentes dos modelos e nas hipóteses da pesquisa. As variáveis $\triangle \mathrm{PCLDi,t}$ e PRJi,t não estão inseridas nos modelos que testam que testam as Hipóteses 2B, 3A e 3B.

Os resultados obtidos a partir do teste da Hipótese 2A da pesquisa permitem verificar se a DPCLD efetivamente registrada pelos bancos brasileiros tem, de fato, contribuído para a não 
exacerbação dos ciclos econômicos brasileiros, assumindo, dessa forma, uma característica predominantemente anticíclica, e possibilitando a continuidade da concessão de créditos em períodos de queda nos níveis de atividades da economia.

Já os resultados alcançados com o teste da Hipótese 2B da pesquisa possibilitam a análise do efeito dos ciclos econômicos brasileiros sobre a DPCLD calculada de acordo com a Resolução CMN $\mathrm{N}^{\mathrm{o}}$ 2.682/99, desconsiderando-se os elementos discricionários, e, adicionalmente, a comparação desses resultados com aqueles obtidos pelo teste da Hipótese $2 \mathrm{~A}$, de modo a se verificar qual das formas de cálculo seria menos suscetível às oscilações da economia.

Os achados proporcionados pelos testes das Hipóteses $3 \mathrm{~A}$ e $3 \mathrm{~B}$ da pesquisa proporcionam a análise dos comportamentos das DPCLD cujos valores tenham sido estimados a partir da aplicação dos modelos teóricos (perda esperada e perda incorrida, respectivamente), de Bouvatier e Lepetit (2012a).

Os resultados provenientes dos testes das Hipóteses 2A, 2B, 3A e 3B da pesquisa possibilitam uma reflexão sobre a metodologia de cálculo da DPCLD que seja eficiente no cumprimento do seu papel precípuo, que é o de proteção contra futuras perdas com créditos e, por consequência, seja menos suscetível às oscilações da economia. Os achados permitem, ainda, tecerem-se considerações acerca do custo-benefício do uso de práticas discricionárias, em relação aos ciclos da economia.

Essa verificação é importante porque o problema central da pesquisa consiste em verificar a relação entre os ciclos econômicos do Brasil e a DPCLD registrada pelos bancos brasileiros e, como consequência, se esta tem sido de fato capaz de conferir uma característica anticíclica aos empréstimos bancários, independentemente da sua característica predominante (perda esperada ou incorrida), ou mesmo da possível presença de elementos discricionários em sua determinação. 


\section{RESULTADOS}

Neste capítulo são apresentados, e discutidos, os resultados encontrados a partir das equações e modelos propostos no capítulo 3 , as respostas às hipóteses de pesquisa levantadas neste trabalho, bem como a resposta ao problema central desta investigação, a qual consiste em compreender a relação entre os ciclos econômicos e a despesa de provisão para créditos de liquidação duvidosa dos bancos brasileiros.

Conforme exposto ao longo desta pesquisa, existe um debate sobre qual seria a metodologia mais apropriada para o registro da DPCLD, por instituições financeiras. Há os que alegam que o modelo de provisão ex-post, por sua característica pró-cíclica, exacerba os ciclos econômicos e, em períodos de downturn, tende a agravar os efeitos da retração econômica, em decorrência da diminuição da capacidade de concessão de créditos bancários, dados os níveis insuficientes de provisão para perdas.

Por outro lado, há uma corrente contrária a mecanismos de provisão ex-ante, por se considerar que estes favoreceriam a criação de um ambiente propício a práticas discricionárias de gerenciamento de resultados, desviando o objetivo principal do registro de provisões para perdas com créditos, que é o de proteção dos bancos contra perdas e manutenção do nível de concessão de créditos.

Essa discussão motivou o trabalho de Bouvatier e Lepetit (2012a), que propuseram modelos teóricos de provisão para perdas com créditos, dentre os quais, um modelo de provisão puramente ex-ante e outro puramente ex-post, livres de práticas discricionárias, de acordo com os próprios pesquisadores.

O modelo brasileiro de provisão para créditos de liquidação duvidosa, adotado pelas instituições financeiras, advém do Conselho Monetário Nacional, através da sua Resolução No 2.682/99, e pode ser considerado misto. No entanto, como os bancos geralmente concedem empréstimos apenas para clientes classificados nos melhores ratings de crédito, infere-se que a provisão para créditos de liquidação duvidosa, no Brasil, possui mais características ex-post do que ex-ante.

O Conselho Monetário Nacional tem resistido à adoção das regras do IASB para a constituição de provisão para perdas com créditos de liquidação duvidosa. A posição do 
Órgão Regulador Brasileiro é a de que as regras de provisão emanadas da Resolução CMN N ${ }^{o}$ 2.682/99 são adequadas para proteção ao sistema bancário brasileiro e têm sido capazes de manter os níveis de crédito em tempos recessivos.

Esse debate sobre os mecanismos de constituição de provisões para perdas com créditos de liquidação duvidosa e suas respostas aos movimentos da economia (ciclos econômicos) motivaram o estudo das características do modelo de provisão adotados pelos bancos brasileiros e sobre sua resposta aos movimentos da economia, isto é, aos ciclos econômicos do País.

Para tanto, com base em estudos anteriores e nos propósitos desta pesquisa, foi proposto um modelo (ver equação 13) que capture a relação entre a variação do PIB brasileiro, adotado como proxy para os ciclos econômicos, e a DPCLD registrada pelos bancos brasileiros, denominada, neste trabalho, "DPCLD informada". De forma subjacente, foram inseridas no modelo variáveis de controle as quais permitem inferir sobre a característica dominante da DPCLD brasileira, se ex-ante ou ex-post.

Por outro lado, a Resolução CMN No 2.682/99 permite o uso de práticas discricionárias pelos bancos brasileiros ao permitir que sejam constituídas provisões adicionais que os bancos julguem necessárias. Ainda de acordo com a referida Resolução, cada banco deve possuir seu próprio sistema de modelagem de risco de crédito, fato que também pode estimular a adoção de práticas discricionárias. Tais fatos contribuíram para que, nesta pesquisa, fosse deduzida uma equação para calcular a DPCLD dos bancos brasileiros com base nas regras mínimas de provisão contidas na Resolução CMN N 2.682/99, ou seja, desconsiderando-se as provisões adicionais, denominada, neste trabalho, "DPCLD calculada".

A partir do modelo que captura a relação entre a variação do PIB e a DPCLD informada, é estimado o modelo que captura a relação entre a variação do PIB e a DPCLD calculada, com o propósito de verificar qual seria a resposta da DPCLD calculada às variações dos ciclos econômicos, e compará-la com a resposta da DPCLD informada às mesmas oscilações.

Adicionalmente, com o intuito de entender o comportamento de um modelo de provisão puramente ex-ante ou puramente ex-post, aplicam-se os modelos teóricos propostos por Bouvatier e Lepetit (2012a) aos bancos brasileiros. Os valores obtidos para a DPCLD, mediante a aplicação dos modelos teóricos backward-looking (perda incorrida) e forward- 
looking (perda esperada), de Bouvatier e Lepetit (2012a), também são objetos de análise sobre qual seria o seu comportamento em resposta às variações do PIB brasileiro.

\subsection{Análise da composição da provisão para créditos de liquidação duvidosa dos bancos brasileiros}

Com o objetivo de investigar se a provisão para créditos de liquidação duvidosa (PCLD) calculada de acordo com as regras mínimas de provisão contidas na Resolução $\mathrm{CMN} \mathrm{N}^{\circ}$ 2.682/99 possui mais características de um modelo de perda incorrida ou de perda esperada, procedeu-se ao cálculo da PCLD trimestral dos bancos brasileiros, segregada por nível de risco de crédito, no período de estudo considerado. Os cálculos foram efetuados a partir dos dados obtidos no documento IFT No 7022 - Créditos Concedidos por Nível de Risco, a qual evidencia o saldo da carteira de empréstimos de determinado banco, segregada por níveis de risco de crédito (do "AA" ao "H”).

O propósito inicial era calcular a PCLD trimestral dos bancos brasileiros, segregada por situação de adimplência (em curso normal e anormal) e por nível de risco de crédito (do "A" ao "H”). Entretanto, a dificuldade de obtenção dos dados nas notas explicativas dos bancos da amostra inviabilizou a realização dos cálculos na forma inicialmente pretendida. Dentre os obstáculos encontrados, destacam-se os seguintes:

a) nem todos os bancos divulgam suas carteiras de empréstimos segregadas por nível de risco e situação de adimplência ou, pelo menos, por faixa de vencimento, conforme determina a Resolução CMN No 2.682/99;

b) os bancos que divulgam suas carteiras de empréstimos segregadas por situação de adimplência não seguem um padrão; alguns fazem a segregação entre operações vincendas e vencidas (a partir do primeiro dia de atraso), enquanto outros separam suas operações em curso normal e anormal (até 15 dias e acima de 15 dias de atraso, respectivamente);

c) a Resolução CMN N $2.682 / 99$ determina que os bancos divulguem suas carteiras de crédito por faixas de risco e prazos de vencimento, mas, como não estabelece faixas- 
padrão, cada banco divulga à sua maneira, dificultando qualquer inferência sobre o nível de risco de crédito de uma operação em atraso.

Desse modo, seria impossível obter as informações necessárias à aplicação do modelo especificado na equação 1 sem que uma considerável manipulação de dados e aproximações fossem efetuadas, e isso comprometeria a confiabilidade dos resultados.

Assim, optou-se pelo cálculo da PCLD segregada apenas por nível de risco de crédito e pela utilização de proxies para a classificação das operações de crédito em situação normal e anormal, de maneira a possibilitar a análise da metodologia predominante no cálculo da PCLD dos bancos brasileiros, se ex-ante ou ex-post.

Apesar de os níveis de risco de "A" a "D" também abrangerem operações de crédito em curso anormal, considerava-se que estes fossem compostos, em sua maioria, por operações de crédito em curso normal. Essa condição é confirmada por meio de um teste de médias, que compara o somatório das operações de crédito classificadas nos níveis de risco de "A" a " $D$ "13 e o montante dos empréstimos em situação normal ${ }^{14}$, e demonstra não haver diferença estatisticamente significante entre as variáveis dos dois grupos (ttest $=0,2728, p=0,7850)$.

Já os níveis de risco de créditos de "E" a "H" abrangem, basicamente, operações de crédito em situação de atraso ou operações que, apesar de adimplentes, tenham sido contaminadas pela situação de atraso de outra operação de crédito vinculada a um mesmo tomador, conforme determina a Resolução CMN No 2.682/99, em seu art. $3^{\circ}$.

Dessa forma, para análise da característica predominante da PCLD dos bancos brasileiros, calculada de acordo com a Resolução $\mathrm{CMN} \mathrm{N}^{\circ} 2.682 / 99$, são adotadas as seguintes premissas:

a) como proxies para as operações de créditos em curso normal, as provisões calculadas de forma segregada por risco de crédito, classificadas entre os níveis "A" e "D"; e,

b) como proxies para as operações de crédito em curso anormal, as provisões calculadas de forma segregada por risco de crédito, classificadas entre os níveis "E" e "H".

\footnotetext{
${ }^{13}$ Os valores das carteiras de empréstimos dos bancos brasileiros, segregados por níveis de risco, do "A" ao " $\mathrm{H}$ " são obtidos nos documentos IFT No 7022 - Créditos Concedidos por Nível de Risco, no sítio do BACEN.

${ }^{14}$ Os montantes das carteiras de empréstimos dos bancos brasileiros, segregados em situação normal e anormal, são obtidos nos documentos IFT No 7019 - Operações de Crédito - Vencimento, no sítio do BACEN.
} 
O modelo utilizado para cálculo da PCLD trimestral não discricionária dos bancos brasileiros é composto pela soma do saldo da carteira de crédito segregada por nível de risco, ponderado pelo respectivo índice de provisão, conforme estabelecido na Resolução CMN No 2.682/99, e está representado na equação 14 :

$$
\begin{aligned}
P C L D_{i t}= & 0,005 A_{i t}+0,01 B_{i t}+0,03 C_{i t}+0,10 D_{i t}+0,30 E_{i t}+0,50 F_{i t} \\
& +0,70 G_{i t}+1,00 H_{i t}
\end{aligned}
$$

onde:

$P C L D_{i, t}$ : despesa com provisão para créditos de liquidação duvidosa;

$A_{i, t}, \ldots, H_{i, t}$ : saldo da carteira de crédito “operações de crédito", segregada por nível de risco, do $\mathrm{A}$ ao $\mathrm{H}$.

A tabela 2 evidencia as estatísticas descritivas do saldo da PCLD dos bancos brasileiros, calculado de forma segregada por nível de risco de crédito, de acordo com a metodologia descrita na Resolução CMN N 2.682/99. Observa-se que os valores médios da PCLD para os níveis "E" a "H” são maiores do que aqueles referentes aos níveis "A" a " $D$ ”, ou seja, os valores de PCLD são maiores para as operações em curso anormal do que para aquelas em curso normal. Com este achado, infere-se que a metodologia de cálculo da PCLD prescrita pela Resolução CMN No 2.682/99 possui mais características de um modelo de provisão expost do que de um modelo de provisão ex-ante.

Como a amostra é composta por bancos de diferentes tamanhos, dos quais cinco são muito maiores que os demais em termos de ativos totais, os valores médios e medianos da PCLD podem não ser consideradas medidas adequadas para análise, de forma que foram calculados os percentis da PCLD. Entretanto, ao se observarem os valores divididos em percentis na tabela 2, verifica-se a mesma tendência de valores de operações em curso normal menores do que aqueles em curso anormal. 
Tabela 2 - Estatísticas descritivas da PCLD trimestral segregada por nível de risco de crédito

\begin{tabular}{|c|c|c|c|c|c|c|c|c|c|c|c|}
\hline \multirow[b]{2}{*}{ Medida } & \multicolumn{8}{|c|}{ Nível } & \multicolumn{3}{|c|}{ Total } \\
\hline & A & B & $\mathrm{C}$ & $\mathrm{D}$ & $\mathrm{E}$ & $\mathrm{F}$ & G & $\mathrm{H}$ & A a D & $\mathrm{E}$ a H & $\mathrm{A}$ a $\mathrm{H}$ \\
\hline \multicolumn{12}{|l|}{ Posição } \\
\hline Média & 10.733 & 10.317 & 16.901 & 16.929 & 18.599 & 24.822 & 24.931 & 193.259 & 54.880 & 261.611 & 316.491 \\
\hline DP & 44.906 & 66.673 & 100.296 & 81.872 & 79.663 & 104.048 & 107.744 & 44.906 & 293.747 & 336.361 & 630.108 \\
\hline Mediana & 649 & 321 & 498 & 484 & 484 & 590 & 562 & 649 & 1.952 & 2.285 & 4.237 \\
\hline Mínimo & - & - & - & - & - & - & - & - & - & - & - \\
\hline Máximo & 898.608 & 1.608 .516 & 1.884 .930 & 1.209 .694 & 1.018 .922 & 1.997 .132 & 1.368 .191 & 12.800 .000 & 5.601 .748 & 17.184 .245 & 22.785 .993 \\
\hline \multicolumn{12}{|l|}{ Percentil } \\
\hline $10 \%$ & - & - & - & - & - & - & - & - & - & - & - \\
\hline $25 \%$ & 48 & 16 & 16 & 6 & - & - & - & 144 & 86 & 144 & 230 \\
\hline $50 \%$ & 649 & 321 & 498 & 484 & 484 & 590 & 562 & 4.735 & 1.952 & 6.371 & 8.323 \\
\hline $75 \%$ & 3.936 & 2.058 & 3.144 & 3.606 & 4.412 & 5.794 & 5.685 & 35.836 & 12.744 & 51.727 & 64.471 \\
\hline $90 \%$ & 16.121 & 13.926 & 15.602 & 18.206 & 27.289 & 31.552 & 33.396 & 219.225 & 63.855 & 311.462 & 375.317 \\
\hline
\end{tabular}

Notas: A, B $, \mathrm{C}, \mathrm{D}, \mathrm{E}, \mathrm{F}, \mathrm{G}, \mathrm{H}=$ níveis de risco de crédito; A a $\mathrm{D}=$ soma dos níveis de risco de A a $\mathrm{D}$; $\mathrm{E}$ a $\mathrm{H}=$ soma dos níveis de risco de $\mathrm{E}$ a $\mathrm{H}$; A a $\mathrm{H}=$ soma dos níveis de risco de $\mathrm{A}$ a $\mathrm{H} ; \mathrm{DP}=$ desvio padrão. Valores em milhares de reais. 
A característica predominantemente ex-post é confirmada ao se promover o teste de médias segregando-se a amostra em dois grupos conforme as proxies assumidas (curso normal: níveis de "A" a "D"; curso anormal: níveis de "E" a "H"). Percebe-se a diferença estatisticamente significante entre os dois grupos $($ ttest $=-13,7557, p=0,000)$ e que o valor dos créditos em curso anormal é maior do que o dos créditos em curso normal, denotando uma característica predominantemente ex-post na provisão para créditos de liquidação duvidosa constituída segundo a metodologia da Resolução CMN No 2.682/99.

Como os cinco maiores bancos em ativos totais também eram responsáveis por, aproximadamente, $68 \%$ da soma dos ativos totais, bem como do total da carteira de empréstimos dos bancos da amostra no $4^{\circ}$ trimestre de 2012, conforme exposto na tabela 3 , optou-se por efetuar os testes de média entre as operações de curso normal e anormal de forma separada, para os maiores bancos e os demais bancos da amostra ${ }^{15}$. Os resultados obtidos com os testes de médias da amostra segregada entre os cinco maiores bancos e os demais bancos estudados reforçam a tendência de característica predominantemente ex-post na provisão para créditos de liquidação duvidosa constituída segundo metodologia da Resolução CMN No 2.682/99 (ver tabela 3).

Os dados que serviram de base para os testes desta seção foram calculados de acordo com a as regras mínimas de provisão da Resolução $C M N N^{0}$ 2.682/99; desse modo, considera-se que a PCLD calculada esteja livre de elementos discricionários. Entretanto, a própria Resolução faculta aos bancos a constituição de provisões adicionais caso julguem necessário. Assim, os valores calculados não são necessariamente coincidentes com aqueles efetivamente registrados e divulgados nas demonstrações contábeis dos bancos brasileiros.

\footnotetext{
${ }^{15}$ A escolha da separação dos cinco maiores bancos deve-se ao fato de os ativos totais do sexto maior banco da amostra equivalerem, aproximadamente, a $65 \%$ dos ativos totais do quinto maior banco.
} 
Tabela 3 - Testes de médias PCLD - Níveis A-D versus Níveis E-H

\begin{tabular}{cccr}
\hline & \multicolumn{3}{c}{ Estatísticas } \\
\cline { 2 - 4 } Bancos & $\mathrm{N}^{\circ}$ Obs. & Média \\
\hline Amostra $(\mathrm{n}=148)$ & & & \\
A a D & 6.596 & 54.879 & 270.023 \\
E a H & 6.596 & 261.611 & 1.190 .331 \\
Diferença & & $-206.732^{* * *}$ & \\
Maiores ( $\mathrm{n}=5)$ & & & \\
A a D & 240 & 1.064 .088 & 947.865 \\
E a H & 240 & 4.877 .684 & 3.827 .199 \\
Diferença & & $-3.813 .576^{* * *}$ & \\
Demais (n=143) & & & \\
A a D & 6.356 & 16.772 & 44.274 \\
E a H & 6.356 & 87.310 & 290.579 \\
Diferença & & $-70.538^{* * *}$ \\
\hline
\end{tabular}

Notas: $\mathrm{A}$ a $\mathrm{D}=$ soma dos níveis de risco de $\mathrm{A}$ a $\mathrm{D} ; \mathrm{E}$ a $\mathrm{H}=$ soma dos níveis de risco de $\mathrm{E}$ a $\mathrm{H}$; $\mathrm{DP}=$ desvio padrão. Valores em milhares de reais.

*** p-valor $<0,01$ (ttest).

\subsection{A provisão para créditos de liquidação duvidosa calculada conforme a Resolução CMN No 2.682/99 e os valores efetivamente registrados pelos bancos}

Uma vez calculada a PCLD livre de elementos discricionários, pode ser efetuada a comparação entre os valores obtidos aplicando-se a regra contida na Resolução CMN N ${ }^{\circ}$ 2.682/99 e os saldos efetivamente constituídos pelos bancos brasileiros. Os testes de média apontam diferença estatisticamente significante entre a PCLD calculada e aquela efetivamente constituída pelos bancos brasileiros (ttest $=1,99, p=0,023)$, e que a PCLD constituída pelos bancos é, em média, maior do que a PCLD livre de elementos discricionários (ver tabela 4).

Portanto, os bancos, na média, costumam fazer uso de provisões adicionais bem acima do valor que seria constituído se fossem consideradas apenas as operações de créditos de acordo com seus respectivos níveis de riscos. De fato, esperava-se que os bancos fizessem uso provisões adicionais, mas não tão acima dos valores obtidos segundo as regras da Resolução CMN No 2.682/99, ao ponto de haver diferenças estatisticamente significantes entre esses valores. Outro fato a ser destacado é que as notas explicativas dos bancos informam a constituição de provisões adicionais, mas não costumam informar o que as motivou. 
Verificada a diferença estatisticamente significante entre os saldos da PCLD livres de elementos discricionários e os saldos efetivamente registrados pelos bancos, procedeu-se à análise comparativa entre a despesa com créditos de liquidação duvidosa calculada estritamente conforme a Resolução CMN No 2.682/99 (DPCLD calculada) e aquela efetivamente registrada pelos bancos brasileiros (DPCLD informada).

Os valores da DPCLD calculada para cada um dos bancos da amostra foram obtidos pela aplicação da fórmula deduzida a partir das orientações contidas na Resolução CMN No 2.682/99, representada na equação 4 (ver seção 3.5.1).

Os testes de médias não apontam diferenças estatisticamente significantes entre a DPCLD calculada e a DPCLD informada (ttest $=-0,58, p=0,28$ ). No entanto, verifica-se que possuem variâncias estatisticamente diferentes $[F(6.464,6.955)=0,096, p=0,000)]$ e baixo grau de correlação $(0,2846)$. Esses resultados são indícios de que, apesar de não apresentarem médias estatisticamente distintas, a DPCLD calculada e a DPCLD informada variam de forma diferente de um período para outro e, portanto, com base nesses testes, não se pode descartar a presença de fatores discricionários na DPCLD registrada pelos bancos brasileiros.

Verifica-se, de fato, a presença de fatores discricionários nos valores das DPCLD efetivamente registradas pelos bancos, de naturezas tanto microeconômicas quanto macroeconômicas, algumas das quais observam-se através dos resultados dos testes do modelo proposto para capturar a relação entre a DPCLD e os ciclos econômicos, que são apresentados na seção 4.4 .

Tabela 4 - Testes de médias PCLD e DPCLD

\begin{tabular}{cccccc}
\hline & $N^{\text {o }}$ Obs. & Média & DP & ttest & $p$-valor \\
\hline PCLD & & & & & \\
Informada & 6.596 & 370.677 & 1.669 .007 & & \\
Calculada & 6.596 & 316.490 & 1.450 .149 & 1,99 & 0,02 \\
DPCLD & & & & & \\
Informada & 6.596 & 65.466 & 306.210 & & \\
Calculada & 6.596 & 72.650 & 990.857 & $-0,58$ & 0,28 \\
\hline
\end{tabular}

Nota: DP = desvio padrão. Valores em milhares de reais e arredondados. DPCLD: Informada, registrada pelos bancos; Calculada, de acordo com as regras da Resolução CMN N ${ }^{\circ}$ 2.682/99. 


\subsection{A despesa com provisão para créditos de liquidação duvidosa de acordo com os modelos teóricos de Bouvatier e Lepetit (2012a)}

A despesa com créditos de liquidação duvidosa calculada estritamente conforme a Resolução CMN N 2.682/99 (DPCLD calculada) serviu de base para a determinação dos valores das DPCLD pelos métodos de perda incorrida e perda esperada, segundo os modelos teóricos propostos por Bouvatier e Lepetit (2012a).

A fórmula de cálculo dos valores de DPCLD pelo método da perda esperada para os bancos brasileiros, a partir da aplicação do modelo teórico de Bouvatier e Lepetit (2012a), aqui denominado "DPCLD - perda esperada", está evidenciada na equação 7 (ver seção 3.5.2) e consiste no produto entre:

a) a razão entre a média móvel (seis trimestres) da DPCLD calculada e a média móvel (seis trimestres) dos saldos dos empréstimos em atraso de mais de 15 dias;

b) o saldo total da carteira de empréstimos no trimestre corrente;

c) a razão entre média móvel (seis trimestres) dos saldos dos empréstimos em atraso de mais de 15 dias e a média móvel (seis trimestres) do total da carteira de empréstimos.

Já a determinação dos valores de DPCLD pelo método da perda incorrida para os bancos brasileiros, a partir da aplicação do modelo teórico de Bouvatier e Lepetit (2012a), aqui denominado "DPCLD - perda incorrida", está evidenciada na equação 6 (ver seção 3.5.2) e consiste no produto entre:

a) a razão entre a média móvel (seis trimestres) da DPCLD calculada e a média móvel (seis trimestres) dos saldos dos empréstimos em atraso de mais de 15 dias;

b) o saldo total da carteira de empréstimos no trimestre corrente; e

c) o produto entre:

- a razão entre a média móvel (seis trimestres) dos saldos dos empréstimos em atraso de mais de 15 dias e a média móvel (seis trimestres) do total da carteira de empréstimos; e 
- o hiato do produto elevado à elasticidade dos empréstimos multiplicada por $(-1) \cdot{ }^{16}$

Determinados os valores das DPCLD - perda incorrida e DPCLD - perda esperada, foram efetuados os testes de médias entre estes e o valor da DPCLD calculada segundo a Resolução $\mathrm{CMN} \mathrm{N}^{\mathrm{o}}$ 2.682/99. Os testes de médias apontam a existência de diferenças estatisticamente significantes (ttest $=-2,048, p=0,020)$ entre a DPCLD calculada e a DPCLD - perda esperada e, ainda, que os valores da DPCLD - perda esperada, calculados a partir da aplicação do modelo de Bouvatier e Lepetit (2012a), são, em média, maiores do que a DPCLD calculada conforme as regras contidas na Resolução CMN N 2.682/99 (ver tabela 5). Este achado pode ser mais um indicador da característica mista das regras para constituição da provisão para créditos de liquidação duvidosa emanadas da referida Resolução $\mathrm{CMN} \mathrm{N}^{\mathrm{o}}$ $2.682 / 99$.

Também foi efetuado o teste de médias entre os valores da DPCLD calculada segundo a Resolução CMN No 2.682/99 e da DPCLD - perda incorrida, apesar de os valores obtidos pela aplicação do modelo da DPCLD pelo método da perda incorrida de Bouvatier e Lepetit (2012a) serem, visivelmente, inferiores aos da DPCLD calculada. Os testes de médias confirmam a existência de diferenças estatisticamente significantes (ttest $=4,74, p=0,000$ ) entre as duas variáveis, e que a DPCLD calculada é, em média, maior do que DPCLD - perda incorrida (ver tabela 5).

Tabela 5 - Testes de médias DPCLD calculada versus Bouvatier e Lepetit (2012a)

\begin{tabular}{lrrrrr}
\hline & No Obs. & \multicolumn{1}{l}{ Média } & \multicolumn{1}{c}{ DP } & ttest & $p$-valor \\
\hline DPCLD & & & & & \\
Calculada & 6.595 & 63.694 & 1.111 .461 & & \\
$\quad$ Perda Esperada & 5.490 & 96.548 & 619.794 & $-2,05$ & 0,02 \\
DPCLD & & & & & \\
Calculada & 6.547 & 64.660 & 13.787 & & \\
$\quad$ Perda Incorrida & 6.072 & -1.215 & 251 & 7,74 & 0,00 \\
\hline
\end{tabular}

Notas: DP $=$ desvio padrão. Valores arredondados, em milhares de reais. DPCLD: Calculada, de acordo com as regras mínimas da Resolução CMN No 2.682/99; Perda Incorrida e Perda Esperada, conforme os modelos teóricos de Bouvatier e Lepetit (2012a).

\footnotetext{
${ }^{16}$ Para a determinação da elasticidade dos empréstimos, é necessária a estimação de uma regressão de dados em painel dinâmico, cujo modelo está evidenciado na equação 11. Os parâmetros $\rho_{1}$ e $\lambda_{1}$ determinados no painel dinâmico são utilizados para determinação do valor da elasticidade dos empréstimos $(w)$, conforme a equação $12: \mathrm{w}=\lambda_{1} /\left(1-\rho_{1}\right)=0,553 /(1-(-0,339)=0,761$. Os detalhamentos desses cálculos estão disponíveis para consulta no Apêndice B.
} 
Ao se observarem os dados evidenciados na tabela 5, chama a atenção o sinal negativo do valor médio da DPCLD dos bancos brasileiros, estimado pela aplicação do modelo de perda incorrida de Bouvatier e Lepetit (2012a). Este achado indica a predominância da reversão da DPCLD sobre o reconhecimento da referida despesa, ao longo do período estudado.

Os valores obtidos das DPCLD - perda esperada e DPCLD - perda incorrida, para os bancos brasileiros, a partir dos modelos teóricos de Bouvatier e Lepetit (2012a), também foram aplicados ao modelo teórico proposto na equação 13, a fim de verificar se os achados corroboram com as considerações dos referidos pesquisadores e, adicionalmente, como seria sua relação com os ciclos econômicos brasileiros.

\subsection{Análise da relação entre os ciclos econômicos do Brasil e a DPCLD dos bancos brasileiros}

A seguir são evidenciados os processos de estruturação de quatro modelos estimados para testar as relações entre os valores DPCLD, aferidos segundo as metodologias apresentadas nas seções 4.2 e 4.3 (DPCLD informada, calculada, perda esperada e perda incorrida), e os ciclos econômicos do Brasil, bem como a discussão dos resultados e as respostas às hipóteses de pesquisa (ver seção 2.7).

O modelo teórico proposto na equação 13 é o ponto de partida para estruturar cada um dos modelos testados. A estruturação dos modelos apropriados para análise da relação entre os valores estimados da DPCLD e os ciclos econômicos foi feita a partir da elaboração de testes do poder explicativo dos modelos, por meio da inserção de cada uma das variáveis explicativas.

Como nem todas as informações estão disponíveis para todos os bancos da amostra e nem para todas as variáveis dos modelos em todos os trimestres considerados para estudo, os painéis construídos são desbalanceados.

No processo de construção dos painéis, para fazer parte da amostra, os bancos devem apresentar informações em pelo menos oito trimestres dentro do intervalo de tempo considerado para estudo e apresentar informação diferente de "zero", a cada trimestre, para 
pelo menos uma entre as seguintes variáveis: despesas com créditos de liquidação duvidosa (DPCLD); variação trimestral do saldo da carteira de empréstimos ( $\triangle E M P)$; e variação trimestral da inadimplência $(\triangle I N A D)$. Essas três variáveis foram escolhidas por caracterizarem que o banco possui carteira de empréstimos.

As premissas adotadas para construção do banco de dados em painel referente às DPCLD informada e calculada de acordo com a Resolução CMN No 2.682/99, implicam o descarte das informações de quatro trimestres, do período total (48 trimestres) considerado para estudo:

a) os três primeiros trimestres, em decorrência da variável independente que representa a variação da inadimplência com defasagem de dois trimestres $\left(\triangle I N A D_{i, t-1}\right)$;

b) o último trimestre, por causa da variável independente que representa variação da inadimplência no trimestre seguinte $\left(\triangle I N A D_{i, t+1}\right)$.

Assim, dadas as premissas adotadas para estimação das variáveis do modelo proposto na equação 13, o banco de dados em painel para análise da relação entre os ciclos econômicos e as DPCLD dos bancos brasileiros, de acordo com a Resolução No 2.682/99, é constituído de um conjunto de 144 bancos observados durante 44 trimestres (do $4^{\circ}$ trimestre de 2001 ao $3^{\circ}$ trimestre de 2012).

Já as premissas adotadas para a construção do banco de dados em painel referente às DPCLD estimadas (perda esperada e perda incorrida) pela aplicação dos modelos de Bouvatier e Lepetit (2012a), implicam o descarte de informações de sete trimestres (os seis primeiros e o último), do período total considerado para estudo.

Desse modo, considerando-se as premissas adotadas para cálculo dos valores da DPCLD, pela aplicação dos modelos de Bouvatier e Lepetit (2012a), bem como as premissas adotadas para estimação das variáveis do modelo proposto na equação 13 , o banco de dados em painel para análise da relação entre os ciclos econômicos e as DPCLD dos bancos brasileiros, de acordo com Bouvatier e Lepetit (2012a), é constituído de um conjunto de 125 bancos observados durante 41 trimestres (do $3^{\circ}$ trimestre de 2001 ao $3^{\circ}$ trimestre de 2012).

A tabela 6 relaciona os bancos de dados em painel com os modelos derivados da equação 13 , para análise entre os ciclos econômicos e os diversos valores da DPCLD considerados no presente estudo. 
Tabela 6 - Painéis para análise modelos derivados da equação 13

\begin{tabular}{|c|c|c|c|}
\hline \multirow[t]{2}{*}{ Painel } & \multicolumn{2}{|c|}{ Composição } & \multirow[t]{2}{*}{ Modelo } \\
\hline & Bancos & Trimestres & \\
\hline \multirow[t]{2}{*}{ Painel 1} & 144 & 44 & DPCLD \\
\hline & & & DPCLDc \\
\hline \multirow[t]{2}{*}{ Painel 2} & 125 & 41 & DPCLDe \\
\hline & & & DPCLDi \\
\hline \multicolumn{4}{|c|}{$\begin{array}{l}\text { Notas: Modelos identificados pelas respectivas variáveis dependentes. } \\
\text { DPCLD: valores efetivamente registrados pelos bancos da amostra; } \\
\text { DPCLDc: valores calculados de acordo com as regras mínimas de provisão, } \\
\text { descritas na Resolução CMN N } 2.682 / 99 \text {; DPCLDe e DPCLDi: valores } \\
\text { obtidos pela aplicação dos modelos teóricos de Bouvatier e Lepetit (2012a), } \\
\text { para os métodos da perda esperada e da perda incorrida, respectivamente. }\end{array}$} \\
\hline
\end{tabular}

Os modelos teóricos propostos por Bouvatier e Lepetit (2012a) foram calibrados segundo a DPCLD calculada de acordo com as regras da Resolução CMN No 2.682/99. Como a DPCLD calculada consiste na soma da variação da PCLD e dos valores lançados a prejuízo (ver equação 4), as variáveis $\triangle P C L D$ e $P R J$ são desconsideradas no modelo de estimação do Painel 2.

Para mitigar efeitos de heterocedasticidade, todas as variáveis dos modelos são escalonadas pelos ativos totais do início de cada período. O ideal seria que as variáveis permanecessem em nível; no entanto, como em finanças, as variáveis utilizadas geralmente possuem tendências temporais, geralmente é necessário algum tipo de manipulação dos dados para resolver problemas de raiz unitária. (WOOLDRIDGE, 2014).

Os resultados dos testes de raízes unitárias, de riscos de multicolinearidade e de poder explicativo dos modelos são apresentados em seguida e foram determinantes para a escolha das variáveis explicativas de cada um dos modelos estruturados para análise.

\subsubsection{Estruturação dos modelos de análise: testes de estacionariedade, de risco de multicolinearidade e adequação das variáveis dos modelos}

Para testar a estacionariedade das variáveis dos modelos, efetuam-se os testes de raiz unitária: de Fisher, baseado no teste Dickey-Fuller aumentado (ADF-Fisher); e de Fisher, baseado no teste de Phillips-Perron (PP-Fisher), para painéis desbalanceados. 
De acordo com Gujarati (2006), o teste de Dickey-Fuller aumentado ajusta o teste DickeyFuller para levar em conta uma possível correlação serial nos termos de erro. Conforme o mesmo autor, o teste Phillips-Perron consiste no uso de métodos estatísticos não-paramétricos para levar em conta a correlação serial sem somar os termos de diferenças defasados. Os testes ADF-Fisher e PP-Fisher testam a hipótese nula de processo estocástico não estacionário, ou seja, da presença de raiz unitária, contra a hipótese alternativa de série estacionária.

Verificada a estacionariedade das variáveis dos modelos, procede-se à investigação da existência de multicolinearidade entre as variáveis de cada modelo proposto. Para tanto, é executada a estatística do Fator de Inflação de Variância (FIV). De acordo com Wooldridge (2014), o FIV do coeficiente de inclinação $j$ é dado pela expressão $F I V_{j}=1 /\left(1-R_{j}^{2}\right)$, que consiste no termo em $\operatorname{Var}\left(\boldsymbol{\beta}_{j}\right)$, que é determinado pela correlação entre $x_{j}$ e as outras variáveis explicativas do modelo. Considera-se que um FIV calculado com valor acima de 10 para uma variável seja indício de problemas de multicolinearidade, por implicar um $\mathrm{R}^{2}$ acima de 0,90 (GUJARATI, 2006; WOOLDRIDGE, 2010).

Os resultados do teste FIV, em conjunto com a análise de correlação entre as variáveis do modelo, através da tabela de correlação de Pearson e, quando necessário, a aplicação do procedimento stepwise, que identifica variáveis que podem ser excluídas do modelo, serviram de base para a determinação das variáveis explicativas componentes de cada um dos modelos derivados da equação 13 (ver tabela 6), para análise da relação entre os ciclos econômicos e a DPCLD dos bancos brasileiros.

\subsubsection{Modelo de análise da relação entre os ciclos econômicos do Brasil e a DPCLD registrada pelos bancos brasileiros}

Executados os testes de presença de raízes unitárias para as variáveis do modelo proposto na equação 13 (painel 1; tabela 6), verifica-se a rejeição da hipótese nula de existência de raízes unitárias para todas as variáveis, ao nível de 1\% de significância (ver tabela 7). Diante desses resultados, constata-se que o modelo é composto por variáveis estacionárias, afastando-se o risco de regressões espúrias. 
Tabela 7 - Testes ADF-Fisher e PP-Fisher - DPCLD informada e calculada

\begin{tabular}{lccccc}
\hline & \multicolumn{2}{c}{ ADF-Fisher } & & \multicolumn{2}{c}{ PP-Fisher } \\
\cline { 2 - 3 } \cline { 5 - 6 } Variável & Estatística & p-valor & & Estatística & $p$-valor \\
\hline DPCLD & 146,314 & 0,000 & & 135,106 & 0,000 \\
DPCLDc & 191,015 & 0,000 & & 187,919 & 0,000 \\
$\Delta \%$ PIB & 368,543 & 0,000 & & 401,639 & 0,000 \\
CAP & 41,880 & 0,000 & & 15,465 & 0,000 \\
LnAT & 39,669 & 0,000 & & 17,217 & 0,000 \\
LAIMP & 155,482 & 0,000 & & 148,719 & 0,000 \\
$\Delta$ EMP & 181,011 & 0,000 & & 173,735 & 0,000 \\
$\Delta$ INADii & 217,177 & 0,000 & & 222,699 & 0,000 \\
$\Delta$ INADi & 206,769 & 0,000 & & 215,550 & 0,000 \\
$\Delta$ INADa & 210,145 & 0,000 & & 223,036 & 0,000 \\
INADe & 205,546 & 0,000 & & 211,182 & 0,000 \\
PRJ & 112,376 & 0,000 & & 96,318 & 0,000 \\
$\Delta$ PCLD & 164,197 & 0,000 & 149,130 & 0,000 \\
\hline
\end{tabular}

Nota: DPCLD - despesa com créditos de liquidação duvidosa registrada pelos bancos; DPCLDc DPCLD calculada conforme a Resolução CMN No 2.682/99; $\Delta \%$ PIB - variação trimestral do PIB real; CAP - índice de capitalização; LnAT - Logaritmo natural dos ativos totais; LAIMP - lucro antes dos tributos e da provisão para créditos de liquidação duvidosa; $\triangle$ EMP - variação trimestral dos empréstimos; $\triangle \mathrm{INADii}$ - variação da inadimplência de dois trimestres anteriores; $\triangle \mathrm{INADi}$ - variação da inadimplência no trimestre anterior; $\triangle \mathrm{INADa}$ - variação da inadimplência no trimestre corrente; $\triangle \mathrm{INADe}$ - variação da inadimplência no trimestre seguinte; PRJ - total dos empréstimos baixados como prejuízo no trimestre; $\triangle \mathrm{PCLD}$ - variação do saldo da provisão para créditos de liquidação duvidosa. Todas as variáveis do modelo são escalonadas pelos ativos totais do início do trimestre corrente, exceto LnAT, CAP e $\Delta \%$ PIB.

Ao executar os testes FIV para as variáveis do modelo proposto, constata-se que todas as variáveis do modelo apresentam valores de FIV inferiores a 10, mitigando o risco de problemas de multicolinearidade entre as variáveis. No entanto, o FIV de 8,45 (ver tabela 8) observado para a variável representativa da variação trimestral do saldo da provisão para créditos de liquidação duvidosa $(\triangle P C L D)$, somado à análise da matriz de correlação entre as variáveis do modelo (ver tabela 9) motivaram a exclusão da referida variável, pois se verificam altos índices de correlação entre a $\triangle P C L D$ e quatro das dez variáveis do modelo, a saber:

a) lucro antes dos tributos e da DPCLD $[\operatorname{LAIMP}(0,792)]$;

b) variação trimestral do saldo da carteira de empréstimos $[\triangle E M P(0,872)]$;

c) variação trimestral do saldo das operações de crédito em situação de atraso [ $\triangle I N A D a$ $(0,962)] ;$ e 
d) variação do saldo das operações de crédito em situação de atraso no trimestre seguinte [ $\triangle I N A D e(0,751)]$.

Observam-se ainda índices de correlação acima de 70\% entre a variável $\triangle I N A D a$ e as variáveis $\triangle E M P(0,848)$ e $\operatorname{LAIMP}(0,777)$. Entretanto, decidiu-se pela manutenção da variável $\triangle I N A D a$ no modelo, dada a sua importância na análise da identificação da natureza predominante da DPCLD (ex-ante ou ex-post). Além disso, após a exclusão da variável $\triangle P C L D$, o valor da estatística FIV para a variável $\triangle I N A D a$ decresce de 7,13 para 2,39 [ver tabela 8; DPCLD(2)]. Além disso, é importante destacar que:

(...) não se pode fazer grande coisa a respeito, pois a multicolinearidade é específica de uma amostra sobre a qual o pesquisador pode não ter muito controle, especialmente se os dados forem de natureza não experimental - o que é a sina dos pesquisadores das ciências sociais (GUJARATI, 2006, p.292).

Mitigados os riscos de relação espúria entre as variáveis do modelo e de problemas de multicolinearidade, procede-se à verificação eventual da presença de variáveis independentes desnecessárias ao modelo, através do procedimento stepwise, ao nível de 5\% de significância. O stepwise, segundo Fávero (2015, p.118), "apresenta a propriedade de automaticamente excluir as variáveis explicativas que não se mostrarem estatisticamente diferentes de zero".

A execução do teste stepwise ${ }^{17}$ aponta a variável $\triangle I N A D i i$ como desnecessariamente incluída no modelo, ao nível de significância de 5\%. Decidiu-se, então, pela sua exclusão do modelo de análise.

\footnotetext{
${ }^{17}$ Os resultados dos testes stepwise estão disponíveis sob solicitação.
} 
Tabela 8 - Estatísticas FIV- DPCLD informada e calculada

\begin{tabular}{|c|c|c|c|c|c|c|}
\hline & \multicolumn{2}{|c|}{ DPCLD (1) } & \multicolumn{2}{|c|}{ DPCLD (2) } & \multicolumn{2}{|c|}{ DPCLDc } \\
\hline & FIV & $\mathrm{R}^{2}$ & FIV & $\mathrm{R}^{2}$ & FIV & $\mathrm{R}^{2}$ \\
\hline$\triangle \mathrm{PCLD}$ & 8,45 & 0,882 & & & & \\
\hline$\triangle \mathrm{INADa}$ & 7,13 & 0,860 & 2,39 & 0,582 & 2,37 & 0,577 \\
\hline LAIMP & 2,24 & 0,553 & 1,94 & 0,486 & 1,90 & 0,475 \\
\hline$\Delta \mathrm{EMP}$ & 1,64 & 0,389 & 1,63 & 0,386 & 1,63 & 0,385 \\
\hline CAP & 1,35 & 0,259 & 1,34 & 0,255 & 1,34 & 0,256 \\
\hline LnAT & 1,31 & 0,238 & 1,31 & 0,237 & 1,31 & 0,239 \\
\hline$\triangle \mathrm{INADe}$ & 1,18 & 0,152 & 1,07 & 0,062 & 1,06 & 0,061 \\
\hline PRJ & 1,02 & 0,019 & 1,02 & 0,017 & & \\
\hline$\triangle \mathrm{INADi}$ & 1,02 & 0,015 & 1,01 & 0,008 & 1,00 & 0,004 \\
\hline$\Delta \% \mathrm{PIB}$ & 1,00 & 0,005 & 1,00 & 0,002 & 1,00 & 0,002 \\
\hline$\Delta$ INADii & 1,00 & 0,004 & 1,00 & 0,003 & & \\
\hline
\end{tabular}

NOTAS: DPCLD (1): DPCLD informada, com a $\triangle$ PCLD no modelo; DPCLD (2): DPCLD informada, sem a $\triangle$ PCLD no modelo. DPCLDc - DPCLD calculada segundo a Resolução CMN N ${ }^{\circ} 2.682 / 99 ; \Delta \% \mathrm{PIB}$ - variação trimestral do PIB real; CAP - índice de capitalização; LnAT - logaritmo natural dos ativos totais; LAIMP lucro antes dos tributos e da provisão para créditos de liquidação duvidosa; $\triangle \mathrm{EMP}$ - variação trimestral dos empréstimos; $\triangle \mathrm{INADii}$ - variação da inadimplência de dois trimestres anteriores; $\triangle \mathrm{INADi}$ - variação da inadimplência no trimestre anterior; $\triangle \mathrm{INADa}$ - variação da inadimplência no trimestre corrente; $\triangle \mathrm{INADe}$ variação da inadimplência no trimestre seguinte; PRJ - total dos empréstimos baixados como prejuízo no trimestre; $\triangle \mathrm{PCLD}$ - variação do saldo da provisão para créditos de liquidação duvidosa. Todas as variáveis do modelo são escalonadas pelos ativos totais do início do trimestre corrente, exceto LnAT, CAP e $\Delta \% \mathrm{PIB}$. 
Tabela 9 - Matriz de correlação de Pearson - DPCLD informada e calculada

\begin{tabular}{|c|c|c|c|c|c|c|c|c|c|c|c|}
\hline & $\Delta \% \mathrm{PIB}$ & CAP & LnAT & LAIMP & $\Delta \mathrm{EMP}$ & $\triangle$ INADii & $\triangle \mathrm{INADi}$ & $\triangle \mathrm{INADa}$ & $\triangle \mathrm{INADe}$ & PRJ & $\triangle \mathrm{PCLD}$ \\
\hline$\Delta \%$ PIB & 1,0000 & & & & & & & & & & \\
\hline CAP & 0,0034 & 1,0000 & & & & & & & & & \\
\hline LAIMP & 0,0201 & 0,1225 & $-0,1066$ & 1,0000 & & & & & & & \\
\hline$\Delta \mathrm{EMP}$ & 0,0193 & $-0,0063$ & $-0,0522$ & 0,6642 & 1,0000 & & & & & & \\
\hline$\triangle \mathrm{INADii}$ & 0,0012 & 0,0062 & 0,0052 & 0,0574 & $-0,0055$ & 1,0000 & & & & & \\
\hline$\triangle \mathrm{INADi}$ & 0,0046 & 0,0070 & 0,0059 & 0,0311 & $-0,0047$ & $-0,0066$ & 1,0000 & & & & \\
\hline$\triangle \mathrm{INADa}$ & 0,0046 & $-0,0008$ & $-0,0357$ & 0,7766 & 0,8483 & 0,0125 & $-0,0071$ & 1,0000 & & & \\
\hline$\triangle \mathrm{INADe}$ & 0,0226 & 0,0019 & $-0,0314$ & 0,5301 & 0,6816 & 0,0021 & 0,0304 & 0,6708 & 1,0000 & & \\
\hline PRJ & 0,0028 & 0,0267 & $-0,0137$ & 0,0827 & 0,0240 & 0,0001 & 0,0024 & 0,0033 & 0,0080 & 1,0000 & \\
\hline$\triangle \mathrm{PCLD}$ & 0,0200 & $-0,0034$ & $-0,0350$ & 0,7922 & 0,8722 & 0,0312 & 0,0234 & 0,9620 & 0,7505 & 0,0065 & 1,0000 \\
\hline
\end{tabular}

Nota: $\Delta \%$ PIB - variação trimestral do PIB real; CAP - índice de capitalização; LnAT - logaritmo natural dos ativos totais; LAIMP - Lucro antes dos tributos e da despesa com provisão para créditos de liquidação duvidosa; $\triangle \mathrm{EMP}$ - variação trimestral dos empréstimos; $\triangle \mathrm{INAD}$ - variação da inadimplência de dois trimestres anteriores, trimestre anterior, atual e futuro; PRJ - total dos empréstimos baixados como prejuízo no trimestre; $\triangle \mathrm{PCLD}$ - variação do saldo da provisão para créditos de liquidação duvidosa. 
Dessa forma, após a realização dos testes de raízes unitárias, do risco de multicolinearidade e da exclusão de variáveis desnecessárias, o modelo estimado para análise da relação entre os ciclos econômicos do Brasil e a despesa com créditos de liquidação duvidosa efetivamente registrada pelos bancos brasileiros apresenta a seguinte estrutura:

$$
\begin{aligned}
\operatorname{DPCLD}_{i, t}= & \beta_{0}+\beta_{1} \Delta P I B_{t}+\beta_{2} C_{A P_{i, t}}+\beta_{3} L n A T_{i, t-1}+\beta_{4} L A I M P_{i, t}+\beta_{5} \Delta E M P_{i, t} \\
& +\beta_{6} \Delta I N A D_{i, t-1}+\beta_{7} \Delta I N A D_{i, t}+\beta_{8} \Delta I N A D_{i, t+1}+\beta_{9} P R J_{i, t}+\varepsilon_{i, t}
\end{aligned}
$$

onde:

$D P C L D_{i, t}$ : despesa com provisão para créditos de liquidação duvidosa registrada pelos bancos brasileiros escalonada pelos ativos totais do início do período;

$\triangle \% P I B_{t}$ : $\quad$ variação percentual do Produto Interno Bruto, a valores constantes (PIB real);

$C A P_{i, t}$ : índice de capitalização, que consiste na razão entre o patrimônio líquido e os ativos totais do período;

$\operatorname{LnAT}_{i, t-1}: \quad$ logaritmo natural dos ativos totais no início do período;

$L A I M P_{i, t}$ : lucro antes da tributação e da despesa com provisão para créditos de liquidação duvidosa, escalonado pelos ativos totais do início do período;

$\triangle E M P_{i, t}$ : variação trimestral do saldo da carteira de empréstimos escalonada pelos ativos totais do início do período;

$\triangle I N A D_{i, t-1}: \quad$ variação trimestral dos créditos em situação de atraso de mais de 15 dias (defasagem de um trimestre) escalonada pelos ativos totais do início do período;

$\triangle I N A D_{i, t}$ : variação dos créditos em situação de atraso de mais de 15 dias (trimestre corrente) escalonada pelos ativos totais do início do período;

$\triangle I N A D_{i, t+1}: \quad$ variação trimestral dos créditos em situação de atraso de mais de 15 dias (trimestre seguinte) escalonada pelos ativos totais do início do período;

$\beta_{0}$ : $\quad$ intercepto;

$\beta_{1}$ a $\beta_{9}$ : $\quad$ coeficientes angulares do modelo;

$\varepsilon_{i, t}: \quad$ termo de erro $\left[N \sim\left(0, \sigma^{2}\right)\right]$.

\subsubsection{Modelo de análise da relação entre os ciclos econômicos do Brasil da DPCLD calculada de acordo com as regras da Resolução CMN Nº 2.682/99}

Como o banco de dados em painel da DPCLD calculada de acordo com as regras da Resolução CMN No 2.682/99 é o mesmo da DPCLD efetivamente registrada pelos bancos brasileiros (painel 1; tabela 6), a construção do modelo de análise da relação entre os ciclos 
econômicos do Brasil e a DPCLD calculada teve como ponto de partida o modelo estimado na equação 15.

No entanto, como a DPCLD calculada consiste na soma da variação do saldo da PCLD com os valores lançados em prejuízo (ver equação 4), optou-se pela exclusão da variável $P R J$ do modelo evidenciado na equação 15 (a variável $\triangle P C L D$ já havia sido excluída anteriormente) $)^{18}$.

Ao executar o teste FIV para as variáveis do modelo que captura a relação entre os ciclos econômicos a DPCLD calculada conforme as regras da Resolução CMN No 2.682/99, verifica-se que todas as variáveis do modelo apresentam valores de FIV inferiores a 10, mitigando o risco de problemas de multicolinearidade entre as variáveis do modelo. No entanto, são observados altos índices de correlação entre a variável LAIMP e as variáveis $\triangle E M P(0,664)$ e $\triangle I N A D a(0,777)$, bem como entre esta última e a variável $\triangle E M P(0,848)$.

Além disso, ao se proceder aos testes de robustez da série, verifica-se a não significância do teste $F$ de Chow $(F(143,5439)=1,07 ; p=0,2645)$ para o modelo estimado, com a manutenção da variável LAIMP no modelo. Como o objetivo da pesquisa é averiguar a relação da $D P C L D$ com os ciclos econômicos e, de forma adjacente, avaliar se a DPCLD calculada conforme a Resolução CMN N $2.682 / 99$ possui mais características de um modelo de ex-ante ou ex-post, a retirada da variável LAIMP do modelo não é considerada um problema para a análise dos resultados.

Dessa forma, o modelo estimado para análise da relação entre os ciclos econômicos do Brasil e a despesa com créditos de liquidação duvidosa calculada de acordo com as regras da Resolução CMN No 2.682/99 apresenta a seguinte estrutura:

$$
\begin{gathered}
D P C L D c_{i, t}=\beta_{0}+\beta_{1} \Delta P I B_{t}+\beta_{2} C A P_{i, t}+\beta_{3} L n A T_{i, t-1}+\beta_{4} \Delta E M P_{i, t} \\
+\beta_{5} \Delta I N A D_{i, t-1}+\beta_{6} \Delta I N A D_{i, t}+\beta_{7} \Delta I N A D_{i, t+1}+\varepsilon_{i, t}
\end{gathered}
$$

\footnotetext{
${ }^{18}$ Como o banco de dados do modelo estimado para análise da DPCLD calculada estritamente nos moldes da Resolução CMN No 2.682/99 é o mesmo utilizado para estudo da DPCLD efetivamente registrada pelos bancos brasileiros e, ainda, considerando que os modelos são aninhados, está afastada a presença de raízes unitárias e o modelo para estudo da DPCLD calculada é, desse modo, estacionário.
} 
onde:

$D P C L D c_{i, t}$ : despesa com provisão para créditos de liquidação duvidosa, calculada de acordo com as regras mínimas de provisão da Resolução CMN No 2.682/99, escalonada pelos ativos totais do início do período;

$\triangle \% P I B_{t}: \quad$ variação do Produto Interno Bruto, a valores constantes (PIB real);

$C A P_{i, t}$ : índice de capitalização, que consiste na razão entre o patrimônio líquido e os ativos totais do período;

$\operatorname{LnAT}_{i, t-1}: \quad$ logaritmo natural dos ativos totais no início do período;

$\triangle E M P_{i, t}$ : variação trimestral do saldo da carteira de empréstimos escalonada pelos ativos totais do início do período;

$\triangle I N A D_{i, t-1}: \quad$ variação trimestral dos créditos em situação de atraso de mais de 15 dias (defasagem de um trimestre) escalonada pelos ativos totais do início do período;

$\triangle I N A D_{i, t}$ : variação dos créditos em situação de atraso de mais de 15 dias (trimestre corrente) escalonada pelos ativos totais do início do período;

$\triangle I N A D_{i, t+1}$ : variação trimestral dos créditos em situação de atraso de mais de 15 dias (trimestre seguinte) escalonada pelos ativos totais do início do período;

$\beta_{0}: \quad$ intercepto;

$\beta_{1}$ a $\beta_{7}$ : $\quad$ coeficientes angulares do modelo;

$\varepsilon_{i, t}: \quad$ termo de erro $\left[N \sim\left(0, \sigma^{2}\right)\right]$.

\subsubsection{Modelo de análise da relação entre os ciclos econômicos do Brasil e a DPCLD pela perda esperada, segundo Bouvatier e Lepetit (2012a)}

Os testes de raízes unitárias efetuados para as variáveis do modelo indicam a rejeição da hipótese nula de existência de raízes unitárias para todas as variáveis, ao nível de $1 \%$ de significância (ver tabela 10), fato que denota a estacionariedade da série e, assim, afasta o risco de regressões espúrias.

Os testes FIV para as variáveis do modelo de regressão, o qual tem como variável dependente a DPCLD estimada a partir do modelo teórico de perda esperada proposto por Bouvatier e Lepetit (2012a), apresentam valores abaixo de 10 para todas variáveis, mitigando o risco de problemas de multicolinearidade entre as variáveis (ver tabela 11). A análise da matriz de correlação (ver tabela 12) entre as variáveis explicativas do modelo também não motiva a exclusão de quaisquer variáveis, além das $\triangle P C L D$ e $P R J$, já desconsideradas. 
Tabela 10 - Testes ADF-Fisher e PP-Fisher - Perda esperada e incorrida

\begin{tabular}{lccccc}
\hline & \multicolumn{2}{c}{ ADF-Fisher } & & \multicolumn{2}{c}{ PP-Fisher } \\
\cline { 2 - 3 } \cline { 5 - 6 } Variável & Estatística & p-valor & & Estatística & $p$-valor \\
\hline DPCLDe & 67,120 & 0,000 & & 37,412 & 0,000 \\
DPCLDi & 51,358 & 0,000 & & 12,877 & 0,000 \\
$\Delta \%$ PIB & 152,791 & 0,000 & & 166,417 & 0,000 \\
CAP & 37,678 & 0,000 & & 16,068 & 0,000 \\
LnAT & 35,979 & 0,000 & & 17,458 & 0,000 \\
LAIMP & 143,607 & 0,000 & & 151,250 & 0,000 \\
$\Delta$ EMP & 41,835 & 0,000 & & 19,857 & 0,000 \\
$\Delta$ INADii & 179,440 & 0,000 & & 214,729 & 0,000 \\
$\Delta$ INADi & 219,799 & 0,000 & & 294,605 & 0,000 \\
$\Delta$ INADa & 191,596 & 0,000 & & 235,647 & 0,000 \\
$\Delta$ INADe & 177,725 & 0,000 & & 210,760 & 0,000 \\
\hline
\end{tabular}

Nota: DPCLDe - DPCLD pelo método da perda esperada de Bouvatier e Lepetit (2012a); DPCLDi DPCLD pelo método da perda incorrida de Bouvatier e Lepetit (2012a); $\Delta \% \mathrm{PIB}$ - variação trimestral do PIB real; CAP - índice de capitalização; LnAT - logaritmo natural dos ativos totais; LAIMP lucro antes dos tributos e da provisão para créditos de liquidação duvidosa; $\triangle \mathrm{EMP}$ - variação trimestral dos empréstimos; $\triangle \mathrm{INADii}$ - variação da inadimplência de dois trimestres anteriores; $\triangle \mathrm{INADi}$ - variação da inadimplência no trimestre anterior; $\triangle \mathrm{INADa}$ - variação da inadimplência no trimestre corrente; $\triangle \mathrm{INADe}$ - variação da inadimplência do trimestre seguinte; PRJ - total dos empréstimos baixados como prejuízo no trimestre; $\triangle \mathrm{PCLD}$ - variação do saldo da provisão para créditos de liquidação duvidosa. Todas as variáveis do modelo são escalonadas pelos ativos totais do início do trimestre corrente, exceto LnAT, CAP e $\Delta \% \mathrm{PIB}$.

Tabela 11 - Estatísticas FIV-DPCLD informada e calculada

\begin{tabular}{lccccc}
\hline & \multicolumn{2}{c}{ DPCLDe } & & \multicolumn{2}{c}{ DPCLDi } \\
\cline { 2 - 3 } \cline { 5 - 6 } & FIV & $\mathrm{R}^{2}$ & & FIV & $\mathrm{R}^{2}$ \\
\hline EEMP & 1,43 & 0,300 & & 1,43 & 0,300 \\
Giada & 1,42 & 0,298 & & 1,42 & 0,298 \\
CAP & 1,40 & 0,285 & & 1,40 & 0,285 \\
LnAT & 1,35 & 0,257 & & 1,35 & 0,257 \\
LAIMP & 1,32 & 0,241 & & 1,32 & 0,241 \\
$\Delta$ INADe & 1,04 & 0,039 & & 1,04 & 0,039 \\
$\Delta$ INADi & 1,01 & 0,009 & & 1,01 & 0,009 \\
$\Delta \%$ PIB & 1,01 & 0,005 & & 1,01 & 0,005 \\
$\Delta$ INADii & 1,00 & 0,005 & & 1,00 & 0,005 \\
\hline
\end{tabular}

NOTAS: DPCLDe - DPCLD pelo método da perda esperada de Bouvatier e Lepetit (2012a); DPCLDi - DPCLD pelo método da perda incorrida de Bouvatier e Lepetit (2012a). Variáveis do modelo escalonadas pelos ativos totais do início do trimestre corrente, exceto LnAT, CAP e $\Delta \% \mathrm{PIB}$. 
Tabela 12 - Matriz de correlação de Pearson - DPCLD - perda incorrida e perda esperada

\begin{tabular}{lrrrrrrrrr}
\hline & \multicolumn{1}{c}{$\Delta \%$ PIB } & \multicolumn{1}{c}{ CAP } & LnAT & LAIMP & $\Delta$ EMP & $\Delta$ INADii & $\Delta$ INADi & $\Delta$ INADa & $\Delta$ INADe \\
$\Delta \%$ PIB & 1,0000 & & & & & & & & \\
CAP & 0,0006 & 1,0000 & & & & & & & \\
LnAT & $-0,0142$ & $-0,5056$ & 1,0000 & & & & & & \\
LAIMP & 0,0124 & 0,1507 & $-0,1234$ & 1,0000 & & & & & \\
$\Delta$ EMP & 0,0174 & $-0,0056$ & $-0,0473$ & 0,7100 & 1,0000 & & & & \\
$\Delta$ INADii & 0,0022 & 0,0100 & 0,0036 & 0,0749 & $-0,0079$ & 1,0000 & & & \\
$\Delta$ INADi & 0,0051 & 0,0109 & 0,0051 & 0,0401 & $-0,0064$ & $-0,0064$ & 1,0000 & & \\
$\Delta$ INADa & $-0,0069$ & $-0,0129$ & $-0,0334$ & 0,7065 & 0,9191 & 0,0269 & $-0,0147$ & 1,0000 & \\
$\Delta$ INADe & 0,0232 & $-0,0113$ & $-0,0267$ & 0,5297 & 0,7062 & 0,0028 & 0,0339 & 0,7098 & 1,0000 \\
\hline
\end{tabular}

Nota: $\Delta \% \mathrm{PIB}$ - variação trimestral do PIB real; CAP - índice de capitalização; LnAT - Logaritmo natural dos ativos totais; LAIMP - Lucro antes dos tributos e da PCLD; $\triangle \mathrm{EMP}$ - variação trimestral dos empréstimos; $\triangle \mathrm{INAD}$ variação da inadimplência de dois trimestres atrás, trimestre anterior, atual e futuro; PRJ - total dos empréstimos baixados como prejuízo no trimestre; $\triangle \mathrm{PCLD}$ - variação trimestral do saldo da provisão para créditos de liquidação duvidosa.

Assim, após a realização dos testes de raízes unitárias, do risco de multicolinearidade e da exclusão de variáveis desnecessárias, o modelo estimado para análise da relação entre os ciclos econômicos do Brasil e a despesa com créditos de liquidação duvidosa pelo método da perda esperada, segundo Bouvatier e Lepetit (2012a), apresenta a seguinte estrutura:

$$
\begin{aligned}
\operatorname{DPCLDe}_{i, t}= & \beta_{0}+\beta_{1} \Delta P I B_{t}+\beta_{2} C A P_{i, t}+\beta_{3} L n A T_{i, t-1}+\beta_{4} L A I M P_{i, t}+\beta_{5} \Delta E M P_{i, t} \\
& +\beta_{6} \Delta I N A D_{i, t-2}+\beta_{7} \Delta I N A D_{i, t-1}+\beta_{8} \Delta I N A D_{i, t}+\beta_{9} \Delta I N A D_{i, t+1} \\
& +\varepsilon_{i, t}
\end{aligned}
$$

onde:

$D P C L D e_{i, t}$ : despesa com provisão para créditos de liquidação duvidosa pelo método da perda esperada, estimada a partir da aplicação do respectivo modelo teórico de Bouvatier e Lepetit (2012a), escalonada pelos ativos totais do início do período;

$\triangle \% P I B_{t}: \quad$ variação do Produto Interno Bruto, a valores constantes (PIB real);

$C A P_{i, t}$ : índice de capitalização, que consiste na razão entre o patrimônio líquido e os ativos totais do período;

$\operatorname{LnAT}_{i, t-1}: \quad$ logaritmo natural dos ativos totais no início do período;

$\operatorname{LAIMP}_{i, t}$ : lucro antes da tributação e da despesa com provisão para créditos de liquidação duvidosa escalonado pelos ativos totais do início do período;

$\triangle E M P_{i, t}$ : $\quad$ variação trimestral do saldo da carteira de empréstimos escalonada pelos ativos totais do início do período;

$\triangle I N A D_{i, t-2}$ : variação trimestral dos créditos em situação de atraso de mais de 15 dias (defasagem de dois trimestres) escalonada pelos ativos totais do início do período; 
$\triangle I N A D_{i, t-1}: \quad$ variação trimestral dos créditos em situação de atraso de mais de 15 dias (defasagem de um trimestre) escalonada pelos ativos totais do início do período;

$\triangle I N A D_{i, t}$ : variação dos créditos em situação de atraso de mais de 15 dias (trimestre corrente) escalonada pelos ativos totais do início do período;

$\triangle I N A D_{i, t+1}: \quad$ variação trimestral dos créditos em situação de atraso de mais de 15 dias (trimestre seguinte) escalonada pelos ativos totais do início do período;

$\beta_{0}: \quad$ intercepto;

$\beta_{1}$ a $\beta_{9}$ : $\quad$ coeficientes angulares do modelo;

$\varepsilon_{i, t}: \quad$ termo de erro $\left[N \sim\left(0, \sigma^{2}\right)\right]$.

\subsubsection{Modelo de análise da relação entre os ciclos econômicos do Brasil e a DPCLD pela perda incorrida, segundo Bouvatier e Lepetit (2012a)}

O banco de dados em painel da DPCLD pelo método da perda incorrida, obtida por meio da aplicação do respectivo modelo teórico proposto por Bouvatier e Lepetit (2012a) aos bancos brasileiros, é o mesmo da DPCLD pelo método da perda esperada, obtida por meio da aplicação do respectivo modelo teórico proposto pelos mesmos pesquisadores (painel 2; tabela 6). Dessa forma, a construção do modelo de análise da relação entre os ciclos econômicos do Brasil e a DPCLD pelo método da perda incorrida, de Bouvatier e Lepetit (2012a), tem como ponto de partida o modelo estimado na equação 17 , a qual, em relação ao modelo proposto neste estudo, desconsidera as variáveis $\triangle P C L D$ e $P R J^{19}$.

Ao executar o teste FIV para as variáveis do modelo que captura a relação entre a DPCLD pela perda incorrida, de Bouvatier e Lepetit (2012a), e os ciclos econômicos, percebe-se que todas as variáveis do modelo apresentam valores de FIV inferiores a 10, mitigando o risco de problemas de multicolinearidade entre as variáveis do modelo.

Dessa forma, o modelo estimado para análise da relação entre os ciclos econômicos do Brasil e a despesa com créditos de liquidação duvidosa pelo método da perda incorrida, segundo Bouvatier e Lepetit (2012a), apresenta a seguinte estrutura:

\footnotetext{
${ }^{19}$ Como o banco de dados do modelo estimado para análise da DPCLD pelo método da perda incorrida é o mesmo utilizado para estudo da DPCLD pelo método da perda esperada e, ainda, considerando que os modelos estão alinhados, está afastada a presença de raízes unitárias, e o modelo para estudo da DPCLD pelo método da perda incorrida, conforme o modelo teórico de Bouvatier e Lepetit (2012a) é, portanto, estacionário.
} 


$$
\begin{aligned}
\operatorname{DPCLDi}_{i, t}= & \beta_{0}+\beta_{1} \Delta P I B_{t}+\beta_{2} C A P_{i, t}+\beta_{3} L n A T_{i, t-1}+\beta_{4} L A I M P_{i, t}+\beta_{5} \Delta E M P_{i, t} \\
& +\beta_{6} \Delta I N A D_{i, t-2}+\beta_{7} \Delta I N A D_{i, t-1}+\beta_{8} \Delta I N A D_{i, t}+\beta_{9} \Delta I N A D_{i, t+1} \\
& +\varepsilon_{i, t}
\end{aligned}
$$

onde:

$D P C L D i_{i, t}$ : despesa com provisão para créditos de liquidação duvidosa pelo método da perda incorrida, estimada a partir da aplicação do respectivo modelo teórico de Bouvatier e Lepetit (2012a), escalonada pelos ativos totais do início do período;

$\triangle \% P I B_{t}: \quad$ variação do Produto Interno Bruto, a valores constantes (PIB real);

$C A P_{i, t}$ : índice de capitalização, que consiste na razão entre o patrimônio líquido e os ativos totais do período;

$\operatorname{LAIMP}_{i, t}$ : lucro antes da tributação e da despesa com provisão para créditos de liquidação duvidosa escalonado pelos ativos totais do início do período;

$\operatorname{LnAT}_{i, t-1}: \quad$ logaritmo natural dos ativos totais no início do período;

$\triangle E M P_{i, t}$ : variação trimestral do saldo da carteira de empréstimos escalonada pelos ativos totais do início do período;

$\triangle I N A D_{i, t-2}$ : variação trimestral dos créditos em situação de atraso de mais de 15 dias (defasagem de dois trimestres) escalonada pelos ativos totais do início do período;

$\triangle I N A D_{i, t-1}: \quad$ variação trimestral dos créditos em situação de atraso de mais de 15 dias (defasagem de um trimestre) escalonada pelos ativos totais do início do período;

$\triangle I N A D_{i, t}$ : variação dos créditos em situação de atraso de mais de 15 dias (trimestre corrente) escalonada pelos ativos totais do início do período;

$\triangle I N A D_{i, t+1}$ : variação trimestral dos créditos em situação de atraso de mais de 15 dias (trimestre seguinte) escalonada pelos ativos totais do início do período;

$\beta_{0}: \quad$ intercepto;

$\beta_{1}$ a $\beta_{9}$ : $\quad$ coeficientes angulares do modelo;

$\varepsilon_{i, t}: \quad$ termo de erro $\left[N \sim\left(0, \sigma^{2}\right)\right]$.

\subsubsection{Análise dos modelos estimados para investigar a relação entre os ciclos econômicos do Brasil e a DPCLD dos bancos brasileiros}

A seguir são apresentadas as análises das tabelas de composição de variâncias das variáveis, as análises das significâncias dos modelos e os testes de robustez. A análise de composição de variâncias das variáveis dos modelos estruturados na seção 4.4.1 proporcionam uma análise preliminar do comportamento dessas variáveis, tanto de forma longitudinal quanto 
transversal. A análise de significância dos modelos e os testes de robustez possibilitam a identificação do instrumento mais adequado para a análise de regressão de cada um dos modelos de dados em painel estruturados para a consecução desta pesquisa, bem como a investigação da presença de heterocedasticidade e multicolinearidade.

\subsubsection{Análise das tabelas de composição de variâncias das variáveis do painel}

Ao observar a tabela 13, de composição de variância das variáveis do painel construído para análise das DPCLD informada e calculada, verifica-se que, das nove variáveis independentes do modelo de estudo, sete (80\%) apresentam variações within (temporal) maiores do que variações between (cross-section). As duas variáveis com variação between maior do que within consistem no índice de capitalização $(C A P)$ e no logaritmo natural dos ativos totais $(\operatorname{Ln} A T)$, o que é esperado, por corresponderem a variáveis relacionadas ao tamanho do banco. A DPCLD calculada e a DPCLD informada também apresentam variação within maior do que variação between.

A análise da tabela de composição de variância das variáveis do painel construído para análise das DPCLD estimada segundo os modelos teóricos de Bouvatier e Lepetit (2012a) também evidenciou que sete das nove variáveis independentes mostram variações within maiores do que variações between. A exemplo do modelo de análise das DPCLD informada e calculada, as variáveis $C A P$ e $L n A T$ são as que apresentam variação between maior do que within (ver tabela 14$)^{20}$.

Como a variação ao longo tempo (within) é maior do que a variação entre os indivíduos da amostra (between) para a maioria das variáveis dos dois painéis, os interceptos possivelmente diferem entre os componentes da amostra, implicando que os parâmetros e os termos de erro são correlacionados.

De acordo com Gujarati (2006), a premissa adjacente ao modelo de componente de erros é a de que estes sejam extrações aleatórias de uma população muito maior, fato que denota a

\footnotetext{
${ }^{20}$ A variável explicativa $\Delta \%$ PIB, que é a principal fonte de investigação deste trabalho, trata-se de uma variável estritamente temporal e, desse modo, não deveria apresentar variação between. Entretanto, por serem os painéis desbalanceados, a falta de informações para alguns bancos em alguns períodos considerados para estudo faz com que a variável $\Delta \% \mathrm{PIB}$ apresente uma pequena variação between.
} 
ausência de correlação entre o termo de erros e as variáveis do modelo. Quando a premissa de aleatoriedade da amostra não se sustenta, espera-se que as variáveis e os termos de erro do modelo estejam correlacionados. No caso desta pesquisa, com uma amostra composta, na sua maioria, por bancos brasileiros que possuem carteira comercial, a premissa de aleatoriedade não se sustenta.

Conforme Gujarati (2006), existem várias possibilidades para a estimação de um modelo de dados em painel, a depender das premissas feitas sobre o intercepto, dos parâmetros e do termo de erros, dentre tais premissas:

a) o intercepto e os parâmetros são constantes ao longo do tempo e no espaço e o termo de erro capta essas diferenças no tempo e no espaço (modelo Pooled);

b) os coeficientes angulares são constantes, mas o intercepto varia entre os indivíduos (modelo de efeitos fixos); e

c) o intercepto e os coeficientes angulares variam entre indivíduos e ao longo do tempo (modelo de efeitos aleatórios).

O modelo de efeitos fixos decorre do fato de que, embora o intercepto varie entre os indivíduos, cada intercepto individual permanece constante ao longo do tempo; já o modelo de efeitos aleatórios assume que as unidades transversais se originam de um intercepto comum, o qual permanece o mesmo para todos os indivíduos ao longo do tempo (GUJARATI, 2006; BROOKS, 2008; FÁVERO, 2015). A análise preliminar das características da amostra e das variáveis do modelo de estudo sugere que o instrumento mais adequado para a análise seria o modelo de efeitos fixos, o que vem a se confirmar por meio dos testes de robustez efetuados, exceto para o modelo de estudo da DPCLD pelo método da perda incorrida de Bouvatier e Lepetit (2012a), para o qual a hipótese de modelo pooled não é rejeitada (ver seção 4.4.2.2).

Aa regressões de dados em painel é estimada considerando-se modelos de efeitos fixos e pooled com erros-padrão robustos clusterizados, para reforçar o afastamento de problemas de heterocedasticidade. Os resultados obtidos com as análises de regressão dos quatro modelos em painel, estimados para investigar as relações entre os ciclos econômicos do Brasil e a DPCLD dos bancos brasileiros, são apresentados e discutidos na seção 4.4.3. 
Tabela 13 - Composição de variância das variáveis do modelo

\begin{tabular}{|c|c|c|c|c|c|c|c|}
\hline \multirow{3}{*}{$\frac{\text { Variável }}{\text { DPCLD }}$} & \multicolumn{5}{|c|}{ Estatísticas } & & \\
\hline & & Média & \multirow{2}{*}{$\frac{\text { DP }}{0,067}$} & \multirow{2}{*}{$\frac{\text { Min. }}{-0,195}$} & \multirow{2}{*}{$\frac{\text { Máx. }}{3,730}$} & \multicolumn{2}{|c|}{ Observações } \\
\hline & Overall & 0,009 & & & & $\mathrm{~N}$ & 5.619 \\
\hline & Between & & 0,030 & $-0,000$ & 0,290 & $\mathrm{n}$ & 144 \\
\hline & Within & & 0,060 & $-0,475$ & 3,535 & T-bar & 39,021 \\
\hline \multirow[t]{3}{*}{ DPCLDc } & Overall & 0,014 & 0,222 & $-0,309$ & 12,885 & $\mathrm{~N}$ & 5.619 \\
\hline & Between & & 0,051 & $-0,000$ & 0,437 & $\mathrm{n}$ & 144 \\
\hline & Within & & 0,217 & $-0,481$ & 12,602 & T-bar & 39,021 \\
\hline \multirow[t]{3}{*}{$\Delta \% \mathrm{PIB}$} & Overall & 0,029 & 0,050 & $-0,079$ & 0,101 & $\mathrm{~N}$ & 5.619 \\
\hline & Between & & 0,003 & 0,011 & 0,038 & $\mathrm{n}$ & 144 \\
\hline & Within & & 0,050 & $-0,082$ & 0,103 & T-bar & 39,021 \\
\hline \multirow[t]{3}{*}{ CAP } & Overall & 0,247 & 0,221 & $-0,056$ & 0,999 & $\mathrm{~N}$ & 5.619 \\
\hline & Between & & 0,192 & 0,028 & 0,964 & $\mathrm{n}$ & 144 \\
\hline & Within & & 0,116 & $-0,389$ & 1,080 & T-bar & 39,021 \\
\hline \multirow[t]{3}{*}{ LnAT } & Overall & 14,206 & 2,127 & 8,758 & 20,685 & $\mathrm{~N}$ & 5.619 \\
\hline & Between & & 1,980 & 1,034 & 19,717 & $\mathrm{n}$ & 144 \\
\hline & Within & & 0,786 & 8,203 & 16,933 & T-bar & 39,021 \\
\hline \multirow[t]{3}{*}{ LAIMP } & Overall & 0,018 & 0,075 & $-0,581$ & 3,085 & $\mathrm{~N}$ & 5.619 \\
\hline & Between & & 0,031 & $-0,010$ & 0,302 & $\mathrm{n}$ & 144 \\
\hline & Within & & 0,068 & $-0,558$ & 2,904 & T-bar & 39,021 \\
\hline \multirow[t]{3}{*}{$\triangle \mathrm{EMPa}$} & Overall & 0,060 & 1,127 & $-5,861$ & 71,354 & $\mathrm{~N}$ & 5.619 \\
\hline & Between & & 0,286 & $-0,024$ & 3,256 & $\mathrm{n}$ & 144 \\
\hline & Within & & 1,105 & $-6,304$ & 68,158 & T-bar & 39,021 \\
\hline \multirow[t]{3}{*}{$\triangle \mathrm{INADi}$} & Overall & 0,004 & 0,139 & $-0,948$ & 7,803 & $\mathrm{~N}$ & 5.599 \\
\hline & Between & & 0,034 & $-0,004$ & 0,378 & $\mathrm{n}$ & 144 \\
\hline & Within & & 0,137 & $-0,950$ & 7,429 & T-bar & 38,882 \\
\hline \multirow[t]{3}{*}{$\triangle \mathrm{INADa}$} & Overall & 0,004 & 0,139 & $-0,948$ & 7,803 & $\mathrm{~N}$ & 5.619 \\
\hline & Between & & 0,033 & $-0,005$ & 0,360 & $\mathrm{n}$ & 144 \\
\hline & Within & & 0,137 & $-0,953$ & 7,446 & T-bar & 39,021 \\
\hline \multirow[t]{3}{*}{$\triangle \mathrm{INADe}$} & Overall & 0,002 & 0,062 & $-0,970$ & 3,586 & $\mathrm{~N}$ & 5.611 \\
\hline & Between & & 0,014 & $-0,004$ & 0,166 & $\mathrm{n}$ & 144 \\
\hline & Within & & 0,061 & $-0,982$ & 3,422 & T-bar & 38,965 \\
\hline \multirow[t]{3}{*}{ PRJ } & Overall & 0,010 & 0,176 & 0,000 & 12,884 & $\mathrm{~N}$ & 5.619 \\
\hline & Between & & 0,036 & 0,000 & 0,296 & $\mathrm{n}$ & 144 \\
\hline & Within & & 0,172 & $-0,285$ & 12,598 & T-bar & 39,021 \\
\hline
\end{tabular}

Nota: DP = desvio padrão. Variações: overall = geral; between = entre bancos; within = temporal. $\mathrm{N}=$ $\mathrm{n}^{\mathrm{o}}$ de observações; $\mathrm{n}=\mathrm{n}^{\mathrm{o}}$ de períodos; T-bar $=\mathrm{N} / \mathrm{n}$. DPCLD - despesa com créditos de liquidação duvidosa registrada pelos bancos; DPCLDc - DPCLD calculada conforme a Resolução CMN $\mathrm{N}^{\circ}$ 2.682/99; $\Delta \%$ PIB - variação trimestral do PIB real; CAP - índice de capitalização; LnAT - logaritmo natural dos ativos totais; LAIMP - lucro antes dos tributos e da DPCLD; $\triangle E M P$ - variação trimestral dos empréstimos; PRJ - total dos empréstimos baixados como prejuízo no trimestre. Variáveis escalonadas pelos ativos totais. 
Tabela 14 - Composição das variáveis do modelo - Bouvatier e Lepetit (2012a)

\begin{tabular}{|c|c|c|c|c|c|c|c|}
\hline \multirow{3}{*}{$\frac{\text { Variável }}{\text { DPCLDe }}$} & \multicolumn{5}{|c|}{ Estatísticas } & & \\
\hline & & Média & \multirow{2}{*}{$\frac{\mathrm{DP}}{0,095}$} & \multirow{2}{*}{$\frac{\text { Min. }}{-0,010}$} & \multirow{2}{*}{$\begin{array}{l}\text { Máx. } \\
2,954\end{array}$} & \multicolumn{2}{|c|}{ Observações } \\
\hline & Overall & 0,013 & & & & $\mathrm{~N}$ & 4.543 \\
\hline & Between & & 0,041 & $-0,000$ & 0,302 & $\mathrm{n}$ & 126 \\
\hline & Within & & 0,085 & $-0,287$ & 2,797 & T-bar & 36,056 \\
\hline \multirow[t]{3}{*}{ DPCLDi } & Overall & $-0,000$ & 0,003 & $-0,127$ & 0,043 & $\mathrm{~N}$ & 4.543 \\
\hline & Between & & 0,001 & $-0,009$ & 0,001 & $\mathrm{n}$ & 126 \\
\hline & Within & & 0,003 & $-0,126$ & 0,043 & T-bar & 36,056 \\
\hline \multirow[t]{3}{*}{$\Delta \% \mathrm{PIB}$} & Overall & 0,028 & 0,050 & $-0,079$ & 0,101 & $\mathrm{~N}$ & 4.543 \\
\hline & Between & & 0,002 & 0,024 & 0,035 & $\mathrm{n}$ & 126 \\
\hline & Within & & 0,050 & $-0,080$ & 0,102 & T-bar & 36,056 \\
\hline \multirow[t]{3}{*}{ CAP } & Overall & 0,229 & 0,205 & $-0,056$ & 0,990 & $\mathrm{~N}$ & 4.543 \\
\hline & Between & & 0,182 & 0,027 & 0,968 & $\mathrm{n}$ & 126 \\
\hline & Within & & 0,096 & $-0,399$ & 0,937 & T-bar & 36,056 \\
\hline \multirow[t]{3}{*}{ LnAT } & Overall & 14,350 & 2,184 & 8,758 & 20,685 & $\mathrm{~N}$ & 4.543 \\
\hline & Between & & 2,050 & 10,364 & 19,775 & $\mathrm{n}$ & 126 \\
\hline & Within & & 0,729 & 10,020 & 16,946 & T-bar & 36,056 \\
\hline \multirow[t]{3}{*}{ LAIMP } & Overall & 0,018 & 0,070 & $-0,367$ & 3,085 & $\mathrm{~N}$ & 4.543 \\
\hline & Between & & 0,034 & $-0,023$ & 0,322 & $\mathrm{n}$ & 126 \\
\hline & Within & & 0,061 & $-0,478$ & 2,905 & T-bar & 36,056 \\
\hline \multirow[t]{3}{*}{$\Delta \mathrm{EMP}$} & Overall & 0,061 & 1,164 & $-5,861$ & 71,354 & $\mathrm{~N}$ & 4.543 \\
\hline & Between & & 0,297 & $-0,024$ & 3,256 & $\mathrm{n}$ & 126 \\
\hline & Within & & 1,139 & $-6,322$ & 68,159 & T-bar & 36,056 \\
\hline \multirow[t]{3}{*}{$\triangle \mathrm{INADii}$} & Overall & 0,005 & 0,155 & $-0,948$ & 7,803 & $\mathrm{~N}$ & 4.521 \\
\hline & Between & & 0,038 & $-0,006$ & 0,397 & $\mathrm{n}$ & 126 \\
\hline & Within & & 0,152 & $-0,959$ & 7,411 & T-bar & 35,881 \\
\hline \multirow[t]{3}{*}{$\Delta \mathrm{INADi}$} & Overall & 0,005 & 0,155 & $-0,948$ & 7,803 & $\mathrm{~N}$ & 4.530 \\
\hline & Between & & 0,036 & $-0,007$ & 0,378 & $\mathrm{n}$ & 126 \\
\hline & Within & & 0,152 & $-0,949$ & 7,430 & T-bar & 35,952 \\
\hline \multirow[t]{3}{*}{$\triangle \mathrm{INADa}$} & Overall & 0,003 & 0,125 & $-0,948$ & 7,803 & $\mathrm{~N}$ & 4.543 \\
\hline & Between & & 0,032 & $-0,007$ & 0,360 & $\mathrm{n}$ & 126 \\
\hline & Within & & 0,122 & $-0,951$ & 7,446 & T-bar & 36,056 \\
\hline \multirow[t]{3}{*}{$\triangle \mathrm{INADe}$} & Overall & 0,002 & 0,066 & $-0,970$ & 3,586 & $\mathrm{~N}$ & 4.536 \\
\hline & Between & & 0,015 & $-0,006$ & 0,166 & $\mathrm{n}$ & 126 \\
\hline & Within & & 0,065 & $-0,982$ & 3,422 & T-bar & 36,000 \\
\hline
\end{tabular}

Nota: DP = desvio padrão. Variações: overall = geral; between = entre bancos; within = temporal. $\mathrm{N}=$ $\mathrm{n}^{\mathrm{o}}$ de observações; $\mathrm{n}=\mathrm{n}^{\mathrm{o}}$ de períodos; T-bar $=\mathrm{N} / \mathrm{n}$. DPCLD: perda esperada (DPCLDe) e perda incorrida (DPCLDi) de Bouvatier e Lepetit (2012a); $\triangle \%$ PIB - variação trimestral do PIB real; CAP índice de capitalização; LnAT - logaritmo natural dos ativos totais; LAIMP - lucro antes dos tributos e da DPCLD; $\triangle$ EMP - variação trimestral dos empréstimos; PRJ - total dos empréstimos baixados como prejuízo no trimestre. Variáveis escalonadas pelos ativos totais. 


\subsubsection{Análise das significâncias dos modelos e testes de robustez}

A tabela 15 evidencia os coeficientes de determinação $\mathrm{R}^{2}\left(\mathrm{R}^{2}\right.$ e $\mathrm{R}^{2}$ ajustado) e a estatística $F$ dos modelos.

Tabela 15 - Regressões com erros-padrão robustos clusterizados

\begin{tabular}{lcccc}
\hline & DPCLD & DPCLDc & DPCLDe & DPCLDi \\
\hline $\mathrm{R}^{2}$ & 0,7459 & 0,1069 & 0,1064 & 0,0812 \\
$\mathrm{R}^{2}$ ajustado & 0,7455 & 0,1057 & 0,1046 & 0,0794 \\
$F$ & $16,87^{* * *}$ & $25,20^{* * *}$ & $30,51^{* * *}$ & $44,19^{* * *}$ \\
\hline
\end{tabular}

Nota: Nível de significância dos parâmetros: 1\% (***). DPCLD - despesa com créditos de liquidação duvidosa registrada pelos bancos; DPCLDc - DPCLD calculada conforme a Resolução CMN No 2.682/99; DPCLD: perda esperada (DPCLDe) e perda incorrida (DPCLDi) de Bouvatier e Lepetit (2012a).

Os valores dos coeficientes $\mathrm{R}^{2}$, indicam que o modelo cuja variável dependente é a DPCLD registrada pelos bancos brasileiros explica 74,59\% do comportamento da DPCLD informada. Por sua vez, os demais modelos estimados, cujas variáveis dependentes são a DPCLD calculada conforme as regras mínimas de provisão da Resolução CMN No 2.682/99 e as DPCLD (perda esperada e perda incorrida) obtidas a partir da aplicação dos modelos teóricos de Bouvatier e Lepetit (2012a), apresentam baixos valores dos coeficientes $R^{2}$, o que indica que tais modelos são inadequados para propósitos de previsão.

Como esta pesquisa não visa a prever o comportamento futuro, mas apenas analisar o comportamento da DPCLD ao longo do tempo em relação às variáveis explicativas (independentes), particularmente em relação às variações do PIB, as quais são a proxy para os ciclos econômicos, o baixo valor do $\mathrm{R}^{2}$ para os modelos estudados não compromete os objetivos da análise.

Analisadas as significâncias dos modelos, em seguida, são realizados os testes de robustez, cujos resultados estão evidenciados na tabela 16 . O primeiro passo é verificar a adequação da modelagem de dados em painel para os modelos do presente estudo, através do teste $\mathrm{F}$ de Chow, que testa a hipótese nula de que todos os efeitos individuais dos bancos da amostra são iguais a zero (FÁVERO, 2015). De acordo com Batalgi (2012, p. 60), "Using the Chow test, the question of whether 'to pool or not to pool' reduces to a test of the validity of the null 
hipothesys $H_{0} ; \delta_{i}=\delta$, for all $i{ }^{\prime 2}{ }^{21}$

Os resultados dos testes de Chow para os quatro modelos estimados rejeitam a hipótese nula, ao nível de significância de $1 \%$, de que todos os efeitos individuais dos bancos da amostra sejam iguais a zero, o que atesta a adequação da modelagem em painel para os dados deste estudo.

O teste LM de Breusch-Pagan compara os estimadores do modelo pooled àqueles obtidos pelo modelo de efeitos aleatórios e testa a hipótese nula de que a variância entre os indivíduos da amostra é igual a zero (caso em que o modelo pooled seria adequado), contra a hipótese alternativa da existência de diferenças estatisticamente significantes entre os indivíduos (BATALGI, 2008; FÁVERO, 2015).

Os resultados dos testes LM de Breusch-Pagan para os modelos estudados indicam a não rejeição da hipótese nula para utilização do modelo pooled apenas para o modelo que estuda a DPCLD pelo modelo da perda incorrida de Bouvatier e Lepetit (2012a). Para os demais modelos de estudo, rejeita-se a hipótese nula, indicando a existência de diferenças estatisticamente significantes entre os indivíduos da amostra e que, portanto, a utilização do modelo de dados em painel com efeitos fixos ou aleatórios é mais adequada para testar os modelos.

No intuito de determinar se os painéis estimados são de efeitos fixos ou aleatórios, precede-se ao teste de Hausman para os três modelos que rejeitaram a hipótese nula do teste de LM de Breusch-Pagan: DPCLD registrada pelos bancos brasileiros; DPCLD calculada de acordo com as regras mínimas de provisão da Resolução CMN No 2.682/99 e DPCLD pelo método da perda esperada de Bouvatier e Lepetit (2012a).

De acordo com Gujarati (2006), a hipótese nula subjacente ao teste de Hausman é que os estimadores do modelo de efeitos fixos e os do modelo de efeitos aleatórios não diferem substancialmente; assim, se hipótese nula for rejeitada, é preferível empregar o modelo de efeitos fixos.

\footnotetext{
${ }^{21}$ Tradução livre: "Ao se aplicar o teste de Chow, a questão de usar ou não o modelo pooled se reduz a testar a validade da hipótese nula $H_{0}$; $\delta_{i}=\delta$, para todo $i$ ", ou seja, a hipótese nula de que os efeitos dos indivíduos são iguais.
} 
Tabela 16 - Testes de robustez

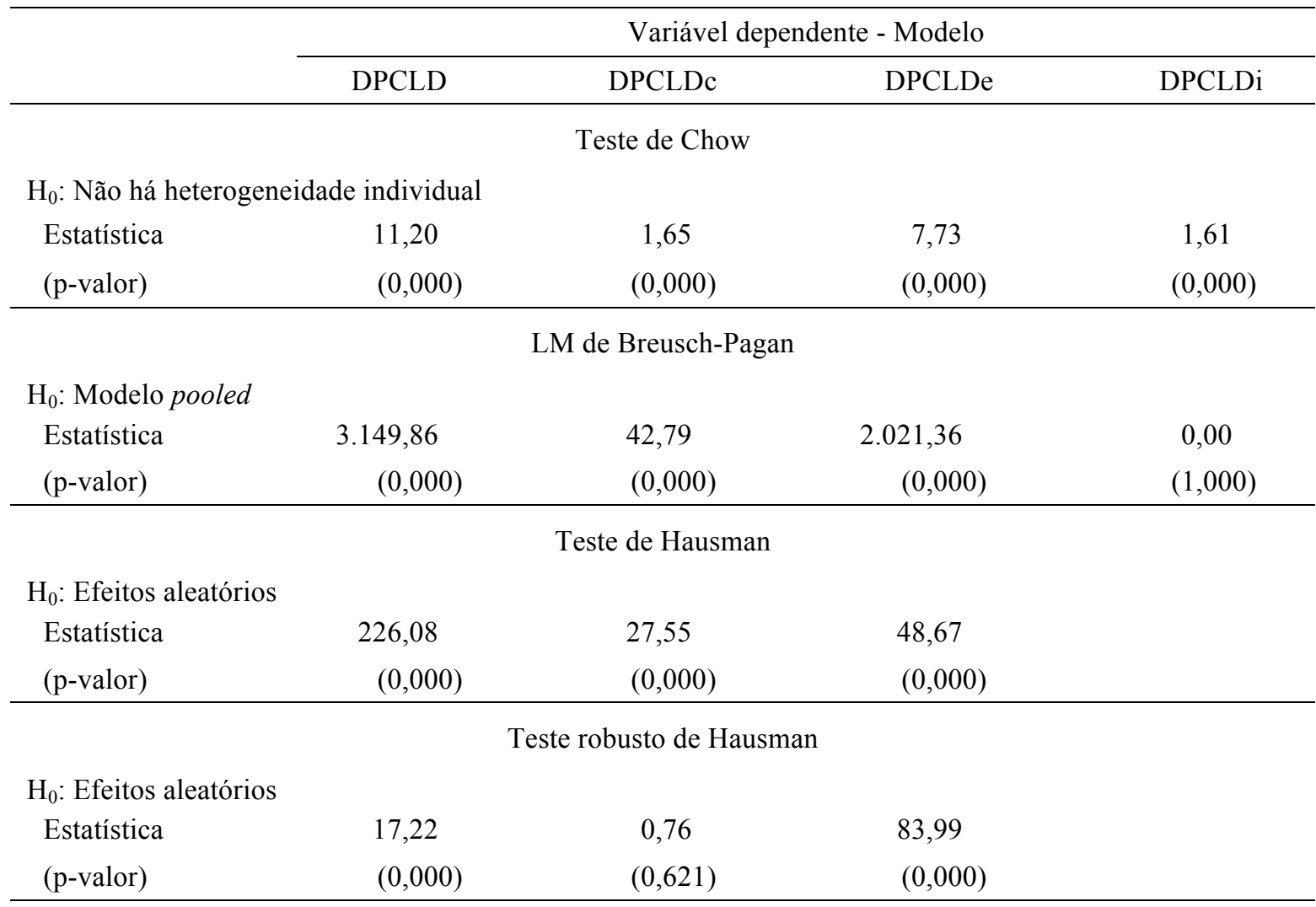

Teste de Schaffer e Stillman

$\mathrm{H}_{0}$ : Efeitos aleatórios

\begin{tabular}{lccc} 
Estatística & 235,240 & 63,37 & 49,108 \\
(p-valor) & $(0,000)$ & $(0,000)$ & $(0,000)$ \\
\hline
\end{tabular}

Teste de Breush-Pagan-Godfrey

$\mathrm{H}_{0}$ : Variância constante

\begin{tabular}{lrrrr} 
Estatística & $83.845,78$ & 0,12 & 352,59 & $6.871,57$ \\
(p-valor) & $(0,000)$ & $(0,7326)$ & $(0,000)$ & $(0,000)$ \\
\hline
\end{tabular}

Teste de Wooldridge

$\mathrm{H}_{0}$ : Não há autocorrelação de primeira ordem

$\begin{array}{lcccc}\text { Estatística } & 0,000 & 0,940 & 29.161,046 & 9,08 \\ (\mathrm{p} \text {-valor }) & (0,994) & (0,334) & (0,000) & (0,003)\end{array}$

Nota: DPCLD - despesa com créditos de liquidação duvidosa registrada pelos bancos; DPCLDc - DPCLD não discricionária, calculada conforme a Resolução CMN N 2.682/99; DPCLD: perda esperada (DPCLDe) e perda incorrida (DPCLDi) de Bouvatier e Lepetit (2012a). Como o modelo da DPCDi não rejeita a hipótese de modelo pooled, os resultados dos testes para efeitos fixos e aleatórios não estão evidenciados. 
Executado o teste de Hausman, os resultados indicam a rejeição da hipótese nula de efeitos aleatórios para os três modelos em questão, indicando a existência de efeitos fixos. Conforme mencionado anteriormente, para garantir o afastamento de problemas de heterocedasticidade, consideraram-se modelos de regressão com erros-padrão robustos clusterizados, tanto para a regressão pooled como para as regressões com efeitos fixos.

No entanto, embora o teste de Hausman investigue a consistência entre os parâmetros estimados por efeitos fixos e por efeitos aleatórios, parte-se da premissa de que os termos de erro obtidos na estimação por efeitos aleatórios sejam identicamente distribuídos, fato que não ocorre com a estimação com erros-padrão robustos; neste caso, deve ser aplicado o teste robusto de Hausman (CAMERON, TRIVEDI, 2009; FÁVERO, 2015).

Ao executar o teste robusto de Hausman, a hipótese nula de efeitos aleatórios é rejeitada para os modelos que estudam a DPCLD registrada pelos bancos brasileiros e para a DPCLD pela perda esperada, de Bouvatier e Lepetit (2012a). Já para o modelo de estudo da DPCLD calculada de acordo com a Resolução CMN No 2.682/99, a hipótese nula do teste robusto de Hausman não é rejeitada, indicando ser mais adequada a estimativa por efeitos aleatórios.

A fim de se confirmarem os resultados encontrados com o teste robusto de Hausman, foi realizado o teste de Schaffer e Stillman, que é alternativo ao teste robusto de Hausman e é efetuado após a regressão por efeitos aleatórios com erros padrão robustos clusterizados. Os resultados obtidos com o teste de Schaffer e Stillman rejeitam a hipótese nula de efeitos aleatórios para os três modelos testados, indicando ser mais adequada a estimativa por efeitos fixos.

Como dois dos três testes para efeitos fixos e aleatórios rejeitaram a hipótese nula de estimação de efeitos aleatórios para o modelo que estuda a DPCLD calculada de acordo com as regras da Resolução CMN N² 2.682/99, decidiu-se pela sua estimação por efeitos fixos.

Assim, as regressões dos quatro modelos de análise, cujos resultados estão evidenciados na tabela 17 (ver seção 4.4.3), foram efetuadas considerando-se:

a) modelo de efeitos fixos com erros-padrão robustos: DPCLD registrada pelos bancos brasileiros, DPCLD calculada de acordo com as regras mínimas de provisão da Resolução CMN No 2.682/99 e DPCLD pela perda esperada, estimada através da aplicação do respectivo modelo teórico de Bouvatier e Lepetit (2012a); 
b) modelo pooled: DPCLD pela perda incorrida, estimada por meio da aplicação do respectivo modelo teórico de Bouvatier e Lepetit (2012a).

No intuito de se verificar a presença de heterocedasticidade e multicolinearidade, são efetuados os testes de Breush-Pagan-Godfrey e o teste de Wooldridge, respectivamente. Os resultados dos testes de Breush-Pagan-Godfrey não rejeitam a hipótese nula de homocedasticidade apenas para o modelo da DPCLD calculada segundo as regras mínimas de provisão da Resolução CMN N 2.682/99. Quanto ao risco de multicolinearidade, os resultados dos testes de Wooldridge não rejeitam a hipótese nula de inexistência de autocorrelação contemporânea apenas para os modelos da DPCLD informada pelos bancos brasileiros e da DPCLD calculada segundo as regras mínimas de provisão da Resolução CMN $N^{0} 2.682 / 99$.

Portanto, dos quatro modelos estimados, apenas o que tem como variável dependente a DPCLD calculada segundo as regras mínimas de provisão da Resolução CMN No 2.682/99 não apresenta, simultaneamente, problemas de heterocedasticidade e multicolinearidade. Entretanto, apesar dos testes de Breush-Pagan-Godfrey e de Wooldridge indicarem presença de heterocedasticidade para os demais modelos, considera-se que tais problemas tenham sido corrigidos ao se utilizarem regressões com erros-padrão robustos (WOOLDRIDGE, 2010; CAMERON, TRIVEDI, 2009; FÁVERO, 2015).

\subsubsection{Análises das regressões dos modelos de dados em painel que investigam as relações entre os ciclos econômicos do Brasil e a DPCLD dos bancos brasileiros}

As discussões dos resultados das regressões dos modelos estruturados na seção 4.4.1 e as respostas às hipóteses da pesquisa são apresentadas a seguir e, sempre que possível, os achados são comparados com a literatura pesquisada.

Especificamente o modelo de análise da DPCLD registrada pelos bancos brasileiros tem seus resultados comparados, sempre que possível, com os achados das pesquisas de Dantas (2012) e Araújo (2014), cujos trabalhos também envolveram estudos da despesa com provisão para créditos de liquidação duvidosa em bancos brasileiros. A tabela 17 sintetiza os resultados encontrados com a estimação das regressões. 
Tabela 17 - Regressões com erros-padrão robustos clusterizados

\begin{tabular}{|c|c|c|c|c|}
\hline \multirow[b]{2}{*}{ Regressores } & \multicolumn{4}{|c|}{ Variável Dependente - Modelo } \\
\hline & DPCLD & DPCLDc & DPCLDe & DPCLDi \\
\hline$\Delta \% \mathrm{PIB}$ & $\begin{array}{l}-0,012 * * \\
(0,012)\end{array}$ & $\begin{array}{c}0,036 \\
(0,101)\end{array}$ & $\begin{array}{c}0,015 \\
(0,499)\end{array}$ & $\begin{array}{l}0,002 * * * \\
(0,004)\end{array}$ \\
\hline CAP & $\begin{array}{l}-0,011 * * \\
(0,047)\end{array}$ & $\begin{array}{c}0,031 \\
(0,157)\end{array}$ & $\begin{array}{c}0,011 \\
(0,414)\end{array}$ & $\begin{array}{l}-0,000 \\
(0,665)\end{array}$ \\
\hline LnAT & $\begin{array}{l}0,001 * * \\
(0,034)\end{array}$ & $\begin{array}{c}0,004 \\
(0,292)\end{array}$ & $\begin{array}{c}0,006 \\
(0,247)\end{array}$ & $\begin{array}{c}0,000 * \\
(0,078)\end{array}$ \\
\hline LAIMP & $\begin{array}{l}0,551^{* * *} \\
(0,008)\end{array}$ & & $\begin{array}{l}0,242 * * * \\
(0,001)\end{array}$ & $\begin{array}{l}-0,014 * * * \\
(0,000)\end{array}$ \\
\hline$\triangle \mathrm{EMP}$ & $\begin{array}{c}0,009 \\
(0,131)\end{array}$ & $\begin{array}{l}0,013 * * \\
(0,035)\end{array}$ & $\begin{array}{l}0,019^{* * *} \\
(0,000)\end{array}$ & $\begin{array}{l}0,001 * * * \\
(0,008)\end{array}$ \\
\hline$\triangle \mathrm{INADii}$ & & & $\begin{array}{l}0,003 * * * \\
(0,005)\end{array}$ & $\begin{array}{c}0,000 \\
(0,398)\end{array}$ \\
\hline$\triangle \mathrm{INADi}$ & $\begin{array}{c}0,008 * \\
(0,073)\end{array}$ & $\begin{array}{c}0,016 \\
(0,312)\end{array}$ & $\begin{array}{l}0,013 * * \\
(0,021)\end{array}$ & $\begin{array}{l}-0,001 \\
(0,202)\end{array}$ \\
\hline$\triangle \mathrm{INADa}$ & $\begin{array}{l}-0,040 \\
(0,591)\end{array}$ & $\begin{array}{l}0,591^{* * * *} \\
(0,000)\end{array}$ & $\begin{array}{c}0,034 \\
(0,322)\end{array}$ & $\begin{array}{c}0,001 \\
(0,754)\end{array}$ \\
\hline$\triangle \mathrm{INADe}$ & $\begin{array}{l}-0,028 \\
(0,106)\end{array}$ & $\begin{array}{l}0,128 * * \\
(0,015)\end{array}$ & $\begin{array}{l}-0,013 \\
(0,280)\end{array}$ & $\begin{array}{l}0,013 * * \\
(0,040)\end{array}$ \\
\hline PRJ & $\begin{array}{c}0,004 \\
(0,259)\end{array}$ & & & \\
\hline const. & $\begin{array}{l}-0,013 \\
(0,126)\end{array}$ & $\begin{array}{l}-0,055 \\
(0,342)\end{array}$ & $\begin{array}{l}-0,076 \\
(0,293)\end{array}$ & $\begin{array}{l}-0,001 * * * \\
(0,005)\end{array}$ \\
\hline $\mathrm{N}$ & 5.591 & 5.591 & 4.510 & 4.510 \\
\hline $\mathrm{n}$ & 144 & 144 & 126 & 126 \\
\hline
\end{tabular}

Nota: Níveis de significância ( $p$-valores) entre parênteses. Nível de significância dos parâmetros: 1\% (***); $5 \%(* *) ; 10 \%(*) . \mathrm{N}=\mathrm{n}^{\circ}$ de observações; $\mathrm{n}=\mathrm{n}^{\circ}$ de períodos. DPCLD - despesa com créditos de liquidação duvidosa registrada pelos bancos; DPCLDc - DPCLD não discricionária, calculada segundo a Resolução CMN N ${ }^{\circ}$ 2.682/99; DPCLD: perda esperada (DPCLDe) e perda incorrida (DPCLDi) de Bouvatier e Lepetit (2012a); $\Delta \%$ PIB - variação trimestral do PIB real; CAP - índice de capitalização; LnAT - logaritmo natural dos ativos totais; LAIMP - lucro antes dos tributos e da provisão para créditos de liquidação duvidosa; $\triangle \mathrm{EMP}$ - variação trimestral dos empréstimos; $\triangle \mathrm{INADii}$ - variação da inadimplência de dois trimestres anteriores; $\triangle \mathrm{INADi}$ - variação escalonada da inadimplência no trimestre anterior; $\triangle \mathrm{INADa}$ - variação da inadimplência no trimestre corrente; $\triangle \mathrm{INADe}$ - variação da inadimplência do trimestre seguinte; PRJ - total dos empréstimos baixados como prejuízo no trimestre. Todas as variáveis do modelo são escalonadas pelos ativos totais do início do trimestre corrente, exceto LnAT, CAP e $\Delta \% \mathrm{PIB}$. 


\subsubsection{Análise da relação entre os ciclos econômicos do Brasil e a DPCLD efetivamente registrada pelos bancos brasileiros}

Os resultados da regressão do modelo que investiga a relação entre os ciclos econômicos do Brasil e a DPCLD efetivamente registrada pelos bancos brasileiros (tabela 17; coluna “DPCLD”) indicam relações estatísticas, ao nível mínimo de significância de 10\%, para cinco das nove variáveis explicativas.

Os resultados revelam a existência de relação negativa $($ sig. $<5 \%)$ entre a variação do PIB e a DPCLD efetivamente registrada pelos bancos brasileiros. Esse achado evidencia que a DPCLD registrada pelos bancos brasileiros estimula a característica pró-cíclica dos empréstimos bancários, pois os bancos tendem a constituir menos PCLD em épocas de expansão econômica (variação positiva do PIB) e provisionam mais em períodos recessivos (variação negativa do PIB).

Resultados semelhantes foram encontrados na pesquisa de Araújo (2014) sobre a ciclicidade da DPCLD em bancos comerciais e no estudo de Dantas (2012), o qual investigou os determinantes da qualidade da auditoria em instituições financeiras. Esses achados corroboram com a visão de que, em épocas de expansão econômica, os bancos tendem a ser menos exigentes na avaliação de risco de crédito de seus clientes para concessão de empréstimos e, durante períodos recessivos, justamente quando a demanda por créditos aumenta, os bancos restringem os níveis de concessões de empréstimos e, dessa forma, contribuem para agravar ainda mais os períodos recessivos (BOUVATIER; LEPETIT, 2008; BEATTY; LIAO, 2011; BUSHMAN; WILLIAMS, 2012).

Também se observa relação negativa (sig. $<5 \%$ ) entre a variável representativa do nível de capitalização dos bancos $(C A P)$ e a DPCLD registrada pelos bancos brasileiros, o que pode indicar gerenciamento de capital por parte dos bancos brasileiros, por meio de um trade-off entre DPCLD e patrimônio de referência. Esse achado é diferente daquele encontrado por Araújo (2014) em sua pesquisa, mas, por outro lado, condiz com os resultados das pesquisas de Kim e Kross (1998) e Alali e Jaggi (2011).

A relação positiva $($ sig. $<1 \%$ ) entre a variável representativa do lucro antes dos tributos e da DPCLD $(L A I M P)$ e a DPCLD registrada pelos bancos brasileiros é um indicativo da 
utilização da DPCLD para práticas discricionárias de gerenciamento de resultados pelos bancos brasileiros. Em seus trabalhos, Dantas (2012) e Araújo (2014) encontraram resultados semelhantes, que sugerem a utilização da DPCLD dos bancos brasileiros para práticas de gerenciamento de resultados. Araújo (2014) pondera que o gerenciamento de resultados pode contribuir para a redução da pró-ciclicidade da DPCLD, entretanto, há estudos indicativos de que a parcela da DPCLD constituída com o objetivo de gerenciamento de resultados não influencia a flutuação do nível de empréstimos bancários (BOUVATIER; LEPETIT, 2008; BUSHMAN; WILLIAMS, 2012).

Observa-se, ainda, relação positiva (sig. $<1 \%$ ) entre a variável representativa do tamanho (porte) da instituição financeira ( $\operatorname{nAT}$ ) e a DPCLD registrada pelos bancos brasileiros, que é um indicativo de que instituições financeiras maiores tendem a constituir mais provisões para créditos de liquidação duvidosa. Infere-se que tal fato possa decorrer de duas situações:

a) bancos maiores possuem carteiras de créditos mais diversificadas e mais recursos para emprestar;

b) bancos de maior porte possuem sistemas de gerenciamento de riscos de crédito mais robustos e, por isso, tendem a ser mais exigentes nas suas avaliações de riscos de crédito.

Os resultados também indicam uma relação positiva (sig. < 10\%) entre a variável representativa da variação da inadimplência do trimestre anterior $\left(\triangle I N A D_{i}\right)$ e a DPCLD do trimestre corrente, registrada pelos bancos brasileiros. Embora o nível de significância estatística seja superior a 5\%, considera-se esse achado como um indício da característica predominantemente ex-post da DPCLD constituída pelos bancos brasileiros. Em sua pesquisa, Dantas (2012) não examinou a variação das operações de crédito inadimplentes com um trimestre de defasagem, mas testou e encontrou uma relação positiva (sig. $<1 \%$ ) entre o saldo das operações de crédito vencidas e a DPCLD registradas pelos bancos brasileiros, o que reforça a tendência de característica de perda incorrida da DPCLD registrada pelos bancos brasileiros.

Não foram encontradas relações com significância estatística entre as demais variáveis independentes e a DPCLD registrada pelos bancos brasileiros, que são as seguintes: $\triangle E M P$, representativa da variação trimestral do saldo da carteira de empréstimos; $\triangle I N A D a$, que representa a variação do saldo das operações de crédito inadimplentes no trimestre corrente; $\triangle I N A D e$, a qual representa as variações do saldo das operações de crédito inadimplentes no 
trimestre seguinte; e $P R J$, representativa do total das operações de créditos lançadas a prejuízo no trimestre.

Esperava-se encontrar relação positiva, com significância estatística, entre a a variação nos níveis de inadimplência e a DPCLD, já que o propósito precípuo da DPCLD registrada pelos bancos brasileiros deveria ser a proteção da instituição financeira contra perdas com créditos. Também se esperava uma relação positiva, com significância estatística, entre a variável representativa das operações lançadas a prejuízo $(P R J)$ e a DPCLD registrada pelos bancos brasileiros, pois, numericamente, $D P C L D=\triangle I N A D+P R J$ (ver equação 4); entretanto, não tal relação não é verificada. De forma diversa do presente trabalho, Dantas (2012) encontrou relação positiva entre a variação da inadimplência do trimestre corrente, bem como entre as operações lançadas a prejuízo, e a DPCLD dos bancos brasileiros; entretanto, o fato de o pesquisador ter considerado as diferenças regionais do País pode ter influenciado os seus achados.

Quanto à variação do saldo da carteira de empréstimos $(\triangle E M P)$, esperava-se encontrar relação positiva, com significância estatística, entre esta variável e a DPCLD registrada pelos bancos brasileiros, fato que caracterizaria a parcela da sua natureza ex-ante. Entretanto, a relação positiva, mas sem significância estatística, pode ser explicada justamente pelo fato da baixa provisão constituída no momento da concessão do credito, ou mesmo a ausência da constituição de qualquer valor a título de PCLD, para operações cujo rating de concessão é "AA". Diferentemente dos achados deste trabalho, Araújo (2014) encontrou uma relação negativa, significante ao nível de $10 \%$, entre a variação do saldo da carteira de empréstimos e a DPCLD constituída pelos bancos brasileiros, sugerindo que a DPCLD diminuiria com o aumento do volume das operações de crédito; entretanto, como o próprio pesquisador pondera, dado o nível de significância de $10 \%$, não seria seguro afirmar a ocorrência de tal comportamento. Por outro lado, Dantas (2014) constatou relação positiva, com significância estatística ao nível de $1 \%$, entre a variação do saldo da carteira de empréstimos e a DPCLD registrada pelos bancos brasileiros; porém, o fato de o pesquisador ter considerado as diferenças regionais do País em suas análises pode ter influenciado os seus achados.

Os resultados encontrados na presente pesquisa, considerando-se os parâmetros das variáveis explicativas e suas significâncias, sugerem que a motivação predominante dos bancos brasileiros ao constituírem a DPCLD está mais relacionada a práticas de gerenciamento de resultados e aos movimentos macroeconômicos, seguidos de mecanismos de gerenciamento 
de capital e, paradoxalmente, em último lugar, à variação da inadimplência e, ainda assim, com relativa defasagem entre a ocorrência dos atrasos e o aumento das respectivas provisões. $^{22}$

Rejeita-se, assim, a hipótese 2A desta pesquisa, de que a despesa com provisão para créditos de liquidação duvidosa registrada pelos bancos brasileiros seja anticíclica.

\subsubsection{Análise da relação entre os ciclos econômicos do Brasil e a DPCLD calculada de acordo com as regras mínimas de provisão da Resolução CMN N².682/99}

Os resultados da regressão do modelo que investiga a relação entre os ciclos econômicos do Brasil e a DPCLD calculada de acordo com as regras mínimas provisão na Resolução CMN $\mathrm{N}^{\mathrm{o}} 2.682 / 99$ (tabela 17; coluna "DPCLDc") indicam relações estatísticas, ao nível mínimo de significância de $10 \%$, para três das sete variáveis explicativas.

Os resultados não evidenciam a existência de relação com significância estatística entre a variação do PIB e a DPCLD calculada de acordo com as regras mínimas de provisão da Resolução CMN No 2.682/99, entretanto, a relação positiva ao nível de significância de 10,1\% sugere uma tendência anticíclica da DPCLD calculada. Este achado sugere que as regras mínimas de provisão da Resolução CMN No 2.682/99 permitem a constituição de reservas de PCLD em períodos de expansão para que, em períodos recessivos, seja possível a manutenção do nível de concessão de empréstimos bancários e, dessa forma, não se exacerbem os ciclos econômicos.

São observadas relações positivas, estatisticamente significantes, entre as seguintes variáveis explicativas e a DPCLD calculada de acordo com as regras mínimas de provisão dessa Resolução $\mathrm{CMN} \mathrm{N}^{\mathrm{o}}$ 2.682/99: $\triangle E M P$, representativa da variação trimestral do saldo da

\footnotetext{
${ }^{22}$ Dados os resultados encontrados para os fatores que influenciam o valor da DPCLD efetivamente registrada pelos bancos brasileiros, decidiu-se separar os bancos da amostra entre públicos e privados para verificar se os achados desta pesquisa permaneciam os mesmos. Após a retirada dos bancos públicos da amostra (10 bancos), os resultados da regressão, considerando-se apenas os bancos privados, foram praticamente os mesmos aqui apresentados. No caso dos bancos públicos, não se observaram relações com significância estatística entre nenhuma das variáveis do modelo e a DPCLD registrada pelos bancos públicos. Infere-se que tal fato seja decorrente da existência de variáveis relevantes, próprias das características diferenciadas dos bancos públicos, não consideradas no modelo, ou mesmo do reduzido tamanho da amostra de bancos públicos ( 9 bancos e 44 trimestres). Os resultados desses testes efetuados estão disponíveis sob solicitação.
} 
carteira de empréstimos (sig. < 5\%); $\triangle I N A D a$, que representa a variação do nível de inadimplência no trimestre corrente (sig. < 1\%); e $\triangle I N A D e$, representativa da variação da inadimplência no trimestre seguinte $($ sig. $<5 \%)$. A relação positiva entre a DPCLD calculada e variação do saldo da carteira de empréstimos $(\triangle E M P)$, assim como a relação positiva entre a DPCLD calculada e a variação do saldo da inadimplência do trimestre seguinte ( $\triangle I N A D e$ ), evidenciam o caráter ex-ante da DPCLD calculada de acordo com as regras mínimas de provisão da Resolução CMN No 2.682/99. Por outro lado, a relação positiva entre a DPCLD calculada e variação do saldo da inadimplência do trimestre corrente ( $\triangle I N A D a$ ) confirma o caráter ex-post da DPCLD calculada de acordo com as regras mínimas de provisão da Resolução CMN No 2.682/99.

Ao se observarem os parâmetros das variáveis $\triangle E M P, \triangle I N A D a$ e $\triangle I N A D e$, verifica-se que o coeficiente da variável $\triangle I N A D a$ é bem maior do que os coeficientes das variáveis $\triangle I N A D e$ e $\triangle E M P$. Isto significa que a DPLD calculada é mais sensível a variações no nível da inadimplência no trimestre corrente $(\triangle I N A D a)$ do que a variações no nível da inadimplência do trimestre seguinte $(\triangle I N A D e)$ e no saldo trimestral da carteira de empréstimos. Esses achados comprovam a característica mista da DPCLD calculada, com a predominância da característica ex-post, ou seja, a DPCLD calculada conforme as regras mínimas de provisão da Resolução CMN No 2.682/99 é de fato mista, mas a sua característica predominante é de perda incorrida.

Por outro lado, os resultados permitem verificar que, mesmo com a característica predominantemente ex-post, a DPCLD calculada de acordo com as regras mínimas de provisão da Resolução $\mathrm{CMN}$ N$^{0}$ 2.682/99 seria capaz de cumprir seu papel precípuo de proteger os bancos brasileiros contra perdas com empréstimos e, com isso, tenderia a atenuar a característica pró-cíclica dos empréstimos, contribuindo para a não exacerbação dos ciclos econômicos. Esses achados vão ao encontram do que Bushman e Williams (2012) ponderam sobre a pró-ciclicidade dos empréstimos: o problema não está na escolha método de provisão para perdas com créditos, mas nos elementos que motivam a constituição da dessa provisão.

Não foram encontradas relações com significância estatística entre as seguintes variáveis explicativas e a DPCLD calculada de acordo com as regras mínimas de provisão da Resolução CMN No 2.682/99: CAP, representativa do índice de capitalização do banco; $\operatorname{LnAT}$, a qual representa o porte da instituição financeira; e $\triangle I N A D i$, que representa a variação da inadimplência do trimestre anterior. Conforme esses achados, o valor da DPCLD calculada 
não seria influenciado pelo valor do capital regulatório (CAP); além disso, a DCLD calculada segundo as regras mínimas de provisão da Resolução CMN No 2.682/99 independeria do tamanho do banco (LnAT) e não retardaria o reconhecimento da provisão para perdas com créditos $(\triangle I N A D i)$.

De acordo com Beatty e Liao (2011), bancos que retardam o reconhecimento de provisões para perdas com créditos costumam ter problemas de capital em períodos recessivos e, por isso, ficam menos propensos a emprestar em períodos de crise, o que termina por agravar as crises financeiras. As regras mínimas de provisão para créditos de liquidação duvidosa da Resolução CMN No 2.682/99 parecem não proporcionar esse tipo de problema.

Rejeita-se, dessa forma, a hipótese $2 \mathrm{~B}$ desta pesquisa (sig. $=10,1 \%$ ), de que a despesa com provisão para créditos de liquidação duvidosa calculada com base nas regras mínimas de provisão Resolução CMN No 2.682/99, seja anticíclica.

\subsubsection{Análise da relação entre os ciclos econômicos do Brasil e a DPCLD pela perda esperada, de Bouvatier e Lepetit (2012a)}

Os resultados da regressão do modelo que investiga a relação entre os ciclos econômicos do Brasil e a DPCLD pela perda esperada (tabela 17; coluna "DPCLDe"), estimada a partir da aplicação do respectivo modelo teórico de Bouvatier e Lepetit (2012a), indicam relações estatísticas, ao nível mínimo de significância de 10\%, para quatro das nove variáveis explicativas.

Os resultados encontrados não evidenciam a existência de relação com significância estatística entre a variação do PIB e a DPCLD pelo método da perda esperada, estimada pela aplicação do respectivo modelo teórico proposto por Bouvatier e Lepetit (2012a). Os achados do presente trabalho vão ao encontro do que afirmam Bouvatier e Lepetit (2012a), de que, em um sistema de provisão para perdas com créditos pelo método da perda esperada, a anticiclicidade dos empréstimos em atraso em relação aos ciclos econômicos deixa de ser relevante na determinação das provisões para perdas com empréstimos, pois o objetivo precípuo da DPCLD pela perda esperada é o de se antecipar a perdas com empréstimos. 
São observadas relações positivas, estatisticamente significantes, entre as seguintes variáveis explicativas e DPCLD pelo método da perda esperada, estimada pela aplicação do respectivo modelo teórico proposto por Bouvatier e Lepetit (2012a): LAIMP, que representa o lucro antes da tributação e da constituição da DPCLD (sig. < 1\%); $\triangle E M P$, representativa da variação trimestral do saldo da carteira de empréstimos (sig. < 1\%); $\triangle I N A D i i$, a qual da variação da inadimplência com defasagem de dois trimestres (sig. < 1\%); e $\triangle I N A D i$, representativa da variação da inadimplência do trimestre anterior (sig. < 5\%).

A relação positiva entre a variação trimestral do saldo da carteira de empréstimos $(\triangle E M P)$ e a DPCLD pela perda esperada evidencia o caráter ex-ante da DPCLD pela perda esperada, de Bouvatier e Lepetit (2012a), no que se refere à contratação de novos empréstimos; entretanto, era esperada também uma relação positiva estatisticamente significante entre variação da inadimplência futura $(\triangle I N A D e)$ e a DPCLD pela perda esperada de Bouvatier e Lepetit (2012a), fato não que não se confirmou no modelo testado. Por outro lado, as relações positivas entre as variáveis $\triangle I N A D i i$ e $\triangle I N A D i$ denotam a existência de elementos ex-post de reconhecimento de perdas com empréstimos, achados que não coadunam com um modelo de registro de DPCLD pelo método da perda esperada.

Não foram encontradas relações com significância estatística entre as seguintes variáveis explicativas e a DPCLD pela perda esperada, de Bouvatier e Lepetit (2012a): CAP, que representa do índice de capitalização do banco; $L n A T$, representativa do porte da instituição financeira; e $\triangle I N A D a$, a qual representa a variação da inadimplência do trimestre corrente. A inexistência de relação com significância estatística entre a variável CAP e a DPCLD pela perda esperada confirma o achado de Bouvatier e Lepetit (2012a), de que as regras de provisão para créditos de liquidação duvidosa pela perda esperada reduzem o efeito do requerimento de capital sobre a propensão dos bancos a emprestar.

Dessa forma, apesar de a estimação da DPCLD pelo método da perda esperada, estimada pela aplicação do modelo teórico proposto por Bouvatier e Lepetit (2012a), ter confirmado algumas características, descritas pelos pesquisadores, que se esperam em um modelo de provisão pela perda esperada, tais como a não relação com os ciclos econômicos e a constituição de provisão para perdas com empréstimos no momento em que a operação é contratada, não se pode afirmar, a partir das premissas adotadas para sua aplicação aos bancos brasileiro, que o modelo teórico de DPCLD pela perda esperada, proposto por Bouvatier e Lepetit (2012a), consiga de fato atingir a sua finalidade. 
Também se deve considerar que, para calibragem de seus modelos teóricos, Bouvatier e Lepetit (2012a) utilizaram dados de bancos europeus, cujas regras de provisão para créditos de liquidação duvidosa são diferentes do modelo brasileiro, particularmente em relação às regras mínimas de provisão para créditos de liquidação duvidosa emanadas da Resolução $\mathrm{CMN} \mathrm{N}^{\mathrm{o}} 2.682 / 99$. Além disso, por mais que se busque estimar uma DPCLD puramente pelo método da perda esperada, livre de elementos discricionários, tal propósito parece impossível de ser alcançado, considerando que os próprios modelos internos de análise de risco de créditos dos bancos possuem elementos discricionários, que influenciam na DPCLD constituída, fato certamente ocorrido ao se aplicar o referido modelo teórico ao caso brasileiro.

Não se rejeita, dessa forma, a hipótese 3A desta pesquisa, de que a despesa com provisão para créditos de liquidação duvidosa, estimada a partir do modelo teórico de Bouvatier e Lepetit (2012a), pelo método da perda esperada, não tem relação com os ciclos econômicos.

\subsubsection{Análise da relação entre os ciclos econômicos do Brasil e a DPCLD pela perda incorrida, de Bouvatier e Lepetit (2012a)}

Os resultados da regressão do modelo que investiga a relação entre os ciclos econômicos do Brasil e a DPCLD pela perda incorrida (tabela 17; coluna "DPCLDi”), estimada a partir da aplicação do respectivo modelo teórico de Bouvatier e Lepetit (2012a), indicam relações estatísticas, ao nível mínimo de significância de 10\%, para cinco das nove variáveis explicativas.

Antes da análise dos resultados obtidos, chama-se a atenção para o valor médio negativo da DPCLD estimada pelo o método da perda incorrida (ver tabela 5), de Bouvatier e Lepetit (2012a), que indica que, ao longo do período estudado, houve mais reversão do que constituição de PCLD.

Dado o sinal negativo da DPCLD pela perda incorrida, estimada a partir do respectivo modelo teórico de Bouvatier e Lepetit (2012a), os resultados encontrados apontam a existência de relação negativa com significância estatística (sig. < 1\%) entre a variação do PIB e a DPCLD pelo método da perda incorrida, sinalizando que, em períodos de expansão, os bancos 
provisionam menos e, em períodos recessivos, os níveis de constituição de provisões para créditos de liquidação duvidosa aumentam. Este achado, da relação negativa entre a variação do PIB e a DPCLD pela perda incorrida, de Bouvatier e Lepetit (2012a), confirma os resultados encontrados pelos pesquisadores que, ao calibrarem seus modelos teóricos com os dados dos bancos europeus, observaram que a DPCLD pelo método da perda incorrida exacerba a pró-ciclicidade dos empréstimos bancários.

Em relação ao achado desta pesquisa, como as premissas adotadas para aplicação do modelo teórico da perda incorrida de Bouvatier e Lepetit (2012a) basearam-se nas regras mínimas de provisão da Resolução CMN No 2.682/99, acredita-se que o modelo testado tenha sido influenciado pelas próprias regras da referida Resolução, bem como pelos elementos discricionários considerados nos modelos internos de análise de risco de crédito dos bancos brasileiros.

São observadas relações negativas, estatisticamente significantes, entre as seguintes variáveis explicativas e a DPCLD pelo método da perda incorrida, estimada pela aplicação do respectivo modelo teórico proposto por Bouvatier e Lepetit (2012a): $\triangle E M P$, que representa a variação trimestral do saldo da carteira de empréstimos (sig. $<1 \%$ ); e $\triangle I N A D e$, representativa da variação da inadimplência do trimestre seguinte (sig. $<5 \%$ ).

Por outro lado, não foram encontradas relações estatisticamente significantes entre as seguintes variáveis explicativas e a DPCLD pela perda incorrida, de Bouvatier e Lepetit (2012a): $\triangle I N A D i i$, representativa da variação da inadimplência com dois trimestres de defasagem; $\triangle I N A D i$, que representa a variação da inadimplência do trimestre anterior; e $\triangle I N A D a$, a qual representa a variação da inadimplência do trimestre corrente.

Esses achados são inconsistentes com o conceito de DPCLD pelo método da perda incorrida, pois denotam que as perdas incorridas com empréstimos (IINADii, $\triangle I N A D i$ e $\triangle I N A D a$ ) não seriam consideradas para a constituição da DPCLD. Além disso, a relação negativa estatisticamente significante entre as variáveis explicativas $\triangle E M P$ e $\triangle I N A D e$, e a DPCLD pelo método da perda incorrida de Bouvatier e Lepetit (2012a), aponta que, quanto maior a variação positiva no saldo da carteira de empréstimos e do nível esperado de inadimplência, menor a DPCLD constituída.

Como as premissas adotadas para aplicação do modelo teórico da perda incorrida de Bouvatier e Lepetit (2012a) tiveram como base as regras mínimas de provisão da Resolução 
CMN N ${ }^{0} 2.682 / 99$, é possível que o modelo testado tenha sido influenciado pelas próprias regras da referida Resolução, bem como pelos elementos discricionários considerados nos modelos internos de análise de risco de crédito dos bancos brasileiros.

Não se verificou relação estatisticamente significante entre a variável independente $C A P$ e a DPCLD pela perda incorrida de Bouvatier e Lepetit (2012a), contrariando os achados desses pesquisadores, de que as regras de provisão para créditos de liquidação duvidosa, pelo método da perda incorrida, contribuem para que os bancos, em períodos recessivos, enfrentem problemas de requerimento de capital e, em decorrência, emprestem menos e acabem por contribuir para o agravamento das crises.

Dessa forma, os resultados deste estudo confirmam que a estimação da DPCLD pelo método da perda incorrida, a partir da aplicação do modelo teórico de Bouvatier e Lepetit (2012a), para os bancos brasileiros, é pró-cíclica. Entretanto, a aplicação do modelo teórico não se confirma para o caso brasileiro, consideradas as premissas adotadas para a sua aplicação neste trabalho, devido a alguns fatores, tais como:

a) como as premissas para aplicação do modelo teórico da perda incorrida de Bouvatier e Lepetit (2012a) se basearam nas regras mínimas de provisão da Resolução CMN N ${ }^{\circ}$ 2.682/99, o modelo testado pode ter sido influenciado pelo caráter misto da DPCLD calculada de acordo com a referida Resolução;

b) apesar de a DPCLD calculada de acordo com as regras mínimas de provisão Resolução CMN N 2.682/99 ser considerada livre de elementos discricionários, outros elementos discricionários, próprios dos modelos internos de análise de risco de crédito dos bancos brasileiros, podem ter influenciado na calibração do modelo teórico de Bouvatier e Lepetit (2012a) para estimação da DPCLD pela perda incorrida;

c) os valores estimados da DPCLD pela perda incorrida de Bouvatier e Lepetit (2012a) são muito inferiores aos da DPCLD calculada de acordo com as regras mínimas de provisão da Resolução CMN No 2.682/99 (ver tabela 5) os quais, por sua vez, já são menores do que os valores da DPCLD pela perda esperada, estimados pela aplicação do respectivo modelo teórico de Bouvatier e Lepetit (2012a); esse fato pode pode ter gerado problemas nos resultados da regressão. 
Dessa forma, não se rejeita a hipótese 3B desta pesquisa, de que a despesa com provisão para créditos de liquidação duvidosa para os bancos brasileiros, estimada a partir do modelo teórico de Bouvatier e Lepetit (2012a), pelo método da perda incorrida, seja pró-cíclica.

\subsection{Síntese dos resultados}

Nesta seção é apresentada uma síntese dos achados desta pesquisa e a resposta ao problema investigado. No quadro 4, resumem-se os resultados dos testes das hipóteses da pesquisa, construídas para responder ao problema da pesquisa, que consiste em investigar a relação entre os ciclos econômicos do Brasil e a despesa com créditos de liquidação duvidosa dos bancos brasileiros.

Quadro 4 - Resultados dos testes de hipóteses

\begin{tabular}{|c|c|c|c|}
\hline \multirow[t]{2}{*}{ Hipótese } & \multirow[t]{2}{*}{ Enunciado } & \multicolumn{2}{|c|}{ Rejeita? } \\
\hline & & Sim & Não \\
\hline $\mathrm{H}_{1}$ & $\begin{array}{l}\text { O componente de perda esperada da despesa com provisão para } \\
\text { créditos de liquidação duvidosa dos bancos brasileiros é } \\
\text { preponderante na composição dessa provisão. }\end{array}$ & $X$ & \\
\hline $\mathrm{H}_{2 \mathrm{~A}}$ & $\begin{array}{l}\text { A despesa com provisão para créditos de liquidação duvidosa } \\
\text { registrada pelos bancos brasileiros é anticíclica. }\end{array}$ & $\mathrm{X}$ & \\
\hline $\mathrm{H}_{2 \mathrm{~B}}$ & $\begin{array}{l}\text { A despesa com provisão para créditos de liquidação duvidosa dos } \\
\text { bancos brasileiros, calculada com base nas regras mínimas de } \\
\text { provisão da Resolução CMN N } 2.682 / 99 \text {, é anticíclica. }\end{array}$ & $\mathrm{X}$ & \\
\hline $\mathrm{H}_{3 \mathrm{~A}}$ & $\begin{array}{l}\text { A despesa com provisão para créditos de liquidação duvidosa dos } \\
\text { bancos brasileiros, estimada a partir do modelo teórico de } \\
\text { Bouvatier e Lepetit (2012a), pelo método da perda esperada, não } \\
\text { tem relação com os ciclos econômicos. }\end{array}$ & & $X$ \\
\hline $\mathrm{H}_{3 \mathrm{~B}}$ & $\begin{array}{l}\text { A despesa com provisão para créditos de liquidação duvidosa dos } \\
\text { bancos brasileiros, estimada a partir do modelo teórico de } \\
\text { Bouvatier e Lepetit (2012a), pelo método da perda incorrida, é } \\
\text { pró-cíclica. }\end{array}$ & & $\mathrm{X}$ \\
\hline
\end{tabular}

Os achados desta pesquisa confirmam a característica predominantemente ex-post da composição dos saldos da PCLD dos bancos brasileiros, ao segregar os bancos da amostra em dois grupos, conforme as proxies assumidas (curso normal: níveis de "A a "D"; curso 
anormal: níveis de "E" a "H") e efetuar teste de médias entre os dois grupos de variáveis (ttest $=-13,7557, p=0,000)$.

Os resultados encontrados com a estimação dos modelos de dados em painel, especificamente os de teste da segunda hipótese da pesquisa, indicam que as práticas discricionárias adotadas pelos bancos brasileiros na constituição de provisões adicionais são consideráveis ao ponto de quase anularem o principal objetivo das regras de constituição de PCLD, da proteção contra perdas com empréstimos (hipótese 2A).

Por outro lado, os achados também demonstram que, mesmo um modelo de provisão com característica predominantemente ex-post, como é o caso do modelo advindo da Resolução CMN N $2.682 / 99$, pode ser eficiente na proteção contra perdas com empréstimos e guardar uma relação positiva com os ciclos econômicos, promovendo a anticiclicidade dos empréstimos (hipótese 2B). Entretanto, a efetividade do modelo depende dos aspectos que motivam os bancos na constituição das provisões para créditos de liquidação duvidosa.

Já com referência à aplicação dos modelos teóricos de Bouvatier e Lepetit (2012a), confirmam-se os achados dos pesquisadores: o modelo de DPCLD pela perda esperada não possui relação com os ciclos econômicos; e que o modelo de DPCLD pela perda incorrida possui relação negativa com os ciclos econômicos.

Entretanto, considerando-se os achados referentes aos relacionamentos entre as demais variáveis dos modelos de Bouvatier e Lepetit (2012a) e os valores estimados da DPCLD (perda esperada e perda incorrida), decidiu-se pela não validação dos modelos, aplicados aos bancos brasileiros, dadas as premissas adotadas neste trabalho. 


\section{CONSIDERAÇÕES FINAIS}

Este trabalho teve por objetivo investigar a relação entre os ciclos econômicos e a constituição da despesa com créditos de liquidação duvidosa dos bancos brasileiros. O propósito foi verificar como a DPCLD reconhecida pelos bancos brasileiros tem respondido às oscilações do ambiente macroeconômico brasileiro. Esta pesquisa foi motivada pelo debate sobre qual seria o método mais adequado de provisão para perdas, capaz de diminuir a pró-ciclicidade dos empréstimos bancários que, de forma geral, tendem a exacerbar os ciclos econômicos, tanto em períodos de expansão como, principalmente, em períodos recessivos, quando o crédito é restrito justamente no momento de maior demanda.

A crise financeira mundial, que teve início no ano de 2008 e sete anos depois ainda causa reflexos na economia mundial teve, como uma de suas consequências, a constatação de que os modelos de provisão para perdas com créditos bancários pelo método da perda incorrida não seriam capazes de evitar a pró-ciclicidade das operações de crédito e, dessa forma, teriam sido um dos instrumentos determinantes para o agravamento da crise financeira. Com isso, o FSB (2009) recomendou a aceleração do processo de substituição da norma internacional IAS 39, que recomenda a constituição de perdas com créditos pelo método da perda incorrida, pela norma internacional IFRS 9, que possui, em seu escopo, a metodologia da perda esperada para a constituição de provisão para perdas com com créditos.

No Brasil, a metodologia de provisão para créditos de liquidação duvidosa adotada pelos bancos brasileiros emana da Resolução CMN No 2.682/99 e pode ser considerada um modelo misto de provisão, pois suas regras preveem a constituição de provisões para perdas já no momento da contratação, a depender do rating de crédito da operação e do tomador, com revisões periódicas do nível de risco das operações em andamento, em função do comportamento de crédito do tomador.

A decisão do Conselho Monetário Nacional tem sido a de não convergência às normas internacionais de contabilidade do IASB, quanto à metodologia de provisão para créditos de liquidação duvidosa, por considerar que as atuais regras de provisão seguidas pelos bancos brasileiros, emanadas na Resolução $\mathrm{CMN} \mathrm{N}^{\circ} 2.682 / 99$, têm sido eficientes na garantia de medidas anticíclicas para manutenção do nível de créditos bancários brasileiros em períodos recessivos, não contribuindo, dessa forma, para o agravamento de crises financeiras no país. 
Apesar de a Resolução CMN N 2.682/99 conter regras bem definidas, a serem seguidas pelas instituições financeiras, para a constituição da provisão para créditos de liquidação duvidosa pelos bancos, a própria Resolução também recomenda que os bancos brasileiros constituam provisões adicionais para perdas com créditos, caso julguem prudente. Além disso, determina que cada banco tenha seu próprio modelo de gerenciamento e avaliação de riscos de créditos. Cria-se, portanto, ambiente favorável a práticas discricionárias que, em certo estágio, poderiam desvirtuar a finalidade principal das regras da Resolução CMN No 2.682/99, que é a de proteger o sistema bancário contra de perdas com créditos de liquidação duvidosa e, de forma adjacente, contribuir para medidas anticíclicas de manutenção dos níveis de crédito em períodos recessivos.

Toda essa discussão a respeito da existência de um método mais adequado para constituição de provisões para perdas com empréstimos e o seu papel no auxílio da contenção de crises, bem como o posicionamento do regulador bancário brasileiro quanto à eficiência das suas regras de provisão para créditos de liquidação duvidosa emanadas da Resolução CMN No 2.682/99, motivou esta pesquisa, cujo problema central foi investigar a relação entre os ciclos econômicos do Brasil e a despesa com créditos de liquidação duvidosa dos bancos brasileiros. A proxy representativa dos ciclos econômicos utilizada neste trabalho foi a variação trimestral do PIB, amplamente utilizada em trabalhos acadêmicos com essa finalidade. De forma adjacente, foi examinada a característica dominante da metodologia brasileira de provisão para créditos de liquidação duvidosa, considerando-se as regras mínimas de provisão da Resolução CMN No 2.682/99, ou seja, livre de elementos discricionários.

De forma complementar, foi investigado o comportamento da despesa com créditos de liquidação duvidosa dos bancos brasileiros caso fossem adotadas metodologias de provisão para perdas com créditos exclusivamente pelo método da perda esperada ou pelo método da perda incorrida. Para tanto, foram aplicados, aos dados dos bancos brasileiros, os modelos teóricos desenvolvidos por Bouvatier e Lepetit (2012a), descritos no decorrer desta pesquisa.

Para responder o problema central da pesquisa, foi formulado um conjunto de três hipóteses, cuja operacionalização demandou a dedução de fórmulas, aplicação e estimação de modelos econométricos de dados em painel, conforme o procedimento a seguir:

a) dedução de uma fórmula para cálculo do saldo da provisão para créditos de liquidação duvidosa, a partir dos saldos da carteira de empréstimos, segregados por níveis de risco; 
b) dedução de uma fórmula para cálculo da despesa com provisão para créditos de liquidação duvidosa dos bancos brasileiros, considerando as regras mínimas de provisão da Resolução CMN No 2.682/99;

c) elaboração de premissas e estimação dos valores da despesa com créditos de liquidação duvidosa dos bancos brasileiros, a partir da aplicação dos modelos teóricos propostos por Bouvatier e Lepetit (2012a), segundo os métodos da perda esperada e da perda incorrida;

d) estimação de um modelo teórico para investigar a relação entre os ciclos econômicos do Brasil, representados pela variação percentual do PIB real, e a despesa com créditos de liquidação duvidosa dos bancos brasileiros.

Os valores referentes aos saldos da provisão para créditos de liquidação duvidosa, calculados a partir dos saldos das carteiras de créditos dos bancos da amostra, segregados por níveis de risco, foram divididos em dois grandes grupos:

a) níveis de risco de "A" a "D", adotados com proxies para as operações de créditos em curso normal;

b) níveis de risco de "E" a " $\mathrm{H}$ ", adotados como proxies para as operações de créditos em curso anormal.

Efetuados os testes de médias entre esses dois grupos, observou-se que os saldos das provisões para créditos de liquidação duvidosa em curso anormal são, em média, maiores do que os saldos relativos às operações em curso normal, o que denota uma característica predominante de perda incorrida da provisão para créditos de liquidação duvidosa dos bancos brasileiros, calculada segundo as regras da Resolução CMN N ${ }^{\circ}$ 2.682/99. Esses achados permitiram inferir sobre a característica predominante de perda incorrida da DPCLD registrada pelos bancos brasileiros, fato que foi confirmado no teste do modelo construído para análise da relação entre os ciclos econômicos do Brasil e a DPCLD registrada pelos bancos brasileiros. Esses resultados indicaram a rejeição da Hipótese 1 desta pesquisa, ou seja, o componente de perda esperada da despesa com provisão para créditos de liquidação duvidosa dos bancos brasileiros não é preponderante na composição dessa provisão.

Os valores da despesa com provisão para créditos de liquidação duvidosa, calculados segundo as regras mínimas de provisão contidas na Resolução CMN No 2.682/99, foram comparados aos valores efetivamente registrados pelos bancos brasileiros. Os testes de médias não 
apontaram diferenças estatisticamente significantes entre a DPCLD calculada e a DPCLD efetivamente registrada pelos bancos brasileiros. Entretanto, verificaram-se diferenças estatisticamente significantes em suas variâncias (sig. $<1 \%$ ) e, adicionalmente, um fraco grau de correlação entre a DPCLD calculada e a DPCLD informada. Com base nesses achados, não se pode descartar a presença de elementos discricionários nas DPCLD efetivamente registradas pelos bancos brasileiros.

Os resultados obtidos a partir dos testes do modelo de análise da relação entre os ciclos econômicos e a DPCLD registrada pelos bancos brasileiros sugeriram a existência de relação negativa entre as variações do PIB real (proxy representativa dos ciclos econômicos) e a DPCLD registrada pelos brancos brasileiros, fato que denota a característica pró-cíclica dos empréstimos bancários, uma vez que esses achados indicam de que os bancos tendem a constituir menos provisões em períodos de expansão e provisionam mais em períodos recessivos. Os resultados ainda sugerem que a motivação predominante dos bancos brasileiros para constituição da DPCLD está mais relacionada a práticas de gerenciamento de resultados e aos movimentos macroeconômicos, seguidos de mecanismos de gerenciamento de capital e, paradoxalmente, em último lugar, à variação da inadimplência, e, ainda assim, com retardo de um trimestre. Esses achados implicam a rejeição da Hipótese 2A da pesquisa, ou seja, a despesa com provisão para créditos de liquidação duvidosa registrada pelos bancos brasileiros não é anticíclica.

Por outro lado, os resultados obtidos através da análise entre os ciclos econômicos do Brasil e a DPCLD calculada com base nas regras mínimas de provisão da Resolução $\mathrm{CMN}^{\mathrm{o}}$ 2.682/99 possibilitaram a confirmação da característica mista da DPCLD calculada nos moldes da referida Resolução, com preponderância do método da perda incorrida. Adicionalmente, apesar de os resultados não evidenciarem a existência de relação estatisticamente significante (sig. $=10,1 \%$ ) entre a variação do PIB real e a DPCLD calculada de acordo com as regras mínimas de provisão da Resolução CMN No 2.682/99, há a sugestão de uma tendência anticíclica da DPCLD calculada, fato que confirma a ponderação do Regulador Bancário Brasileiro, de que as regras de provisão da Resolução CMN No 2.682/99 seriam capazes de contribuir para medidas anticíclicas de manutenção dos níveis de crédito em períodos recessivos.

Os achados também permitiram observar que as práticas discricionárias dos bancos brasileiros na constituição de provisões adicionais são consideráveis, ao ponto de quase anular o objetivo 
primordial das regras de constituição de provisões para créditos de liquidação duvidosa, de proteger os bancos contra perdas com empréstimos e, de forma adjacente, contribuir para medidas anticíclicas. Apesar de sugerir uma tendência anticíclica, esses achados rejeitam a Hipótese 2B da pesquisa, isto é, a DPCLD dos bancos brasileiros, calculada com base na Resolução CMN No 2.682/99, desconsiderando-se os elementos discricionários, não é anticíclica.

Os resultados dos testes do modelo de análise da a relação entre os ciclos econômicos do Brasil e a DPCLD pelo método da perda esperada, estimada segundo o respectivo modelo teórico de Bouvatier e Lepetit (2012a), proporcionaram a confirmação da Hipótese 3A, de que a despesa com provisão para créditos de liquidação duvidosa, estimada a partir do modelo teórico de Bouvatier e Lepetit (2012a), pelo método da perda esperada, não tem relação com os ciclos econômicos. Entretanto, para um modelo de perda esperada, eram esperadas relações estatisticamente significantes entre a variação futura da inadimplência, que caracteriza a antecipação de perdas, bem como a variação da inadimplência no período corrente, o que não se confirmou no modelo testado. Portanto, dadas as premissas adotadas para a calibragem do modelo de Bouvatier e Lepetit (2012a) e os resultados alcançados com o modelo de regressão, não se pode afirmar que o modelo teórico proposto pelos pesquisadores para a DPCLD, pela perda esperada, consiga de fato atingir seus objetivos.

Já os achados a partir dos testes do modelo de análise da relação entre os ciclos econômicos do Brasil e a DPCLD pelo método da perda incorrida, estimada segundo o respectivo modelo teórico de Bouvatier e Lepetit (2012a), confirmaram a Hipótese 3B, de que a despesa com provisão para créditos de liquidação duvidosa para os bancos brasileiros, estimada a partir do modelo teórico de Bouvatier e Lepetit (2012a), pelo método da perda incorrida, é pró-cíclica. Entretanto, os demais achados, resultantes dos testes do modelo de análise da relação entre os ciclos econômicos do Brasil e a DPCLD pela perda incorrida de Bouvatier e Lepetit (2012a), não permitem validar o respectivo modelo teórico proposto pelos pesquisadores, uma vez que não se constataram relações com significância estatística entre as variáveis características de um modelo de perda incorrida ( $\triangle I N A D i i, \triangle I N A D i$ e $\triangle I N A D a)$ e a DPCLD.

Portanto, os resultados encontrados nesta pesquisa permitiram concluir que, mais importante do que a discussão do modelo ideal de provisão, capaz de proporcionar medidas anticíclicas para o nível de empréstimos bancários, é controlar a motivação da constituição das perdas com créditos de liquidação duvidosa. 
Os achados do presente estudo ainda demonstraram que o modelo de provisão para créditos de liquidação duvidosa adotado para os bancos brasileiros, advindo da Resolução $\mathrm{CMN}^{\circ}$ 2.682/99, apesar de misto, tem características predominantes de um modelo de perda incorrida e, mesmo assim, consegue atingir os objetivos de proteção contra perdas com créditos e aponta para uma tendência de contribuir com a adoção de medidas anticíclicas na concessão de créditos. Entretanto, o uso de práticas discricionárias pelos bancos brasileiros, na constituição da DPCLD por eles efetivamente registrada, chega ao ponto de quase anular o objetivo primordial da referida Resolução $\mathrm{CMN}^{\mathrm{o}}$ 2.682/99, que é o de proteger contra perdas com empréstimos pelos bancos brasileiros.

Portanto, a resposta ao problema central desta pesquisa é a existência de uma relação negativa entre os ciclos econômicos e a despesa com créditos de liquidação duvidosa registrada pelos bancos brasileiros. Entretanto, tal situação ocorre não porque as regras de provisão emanadas do Regulador Bancário sejam inadequadas, mas devido ao exagerado uso de práticas discricionárias pelos bancos brasileiros, as quais podem originar-se tanto do uso de provisões adicionais como de seus modelos internos de gerenciamento e análise de risco de créditos.

Dentre as contribuições de trabalho para a teoria contábil, enumeram-se as seguintes:

a) a dedução de uma fórmula, e o cálculo, da despesa com créditos de liquidação duvidosa com base nas regras mínimas de provisão contidas na Resolução CMN No 2.682/99, portanto livre de elementos discricionários, exceto aqueles inevitáveis, contidos nos modelos internos de modelagem e análise de riscos de créditos dos bancos brasileiros;

b) a confirmação, de forma empírica, da característica predominante do método da perda incorrida no modelo de cálculo da DPCLD advindo da Resolução CMN No 2.682/99;

c) a verificação que, mesmo um modelo de provisão com característica predominantemente ex-post pode ser eficiente na proteção contra perdas de créditos e guardar de uma relação positiva com os ciclos econômicos, capaz de contribuir com a adoção de medidas anticíclicas do mercado de empréstimos, evitando o agravamento de crises;

d) a constatação que, por mais que um sistema bancário possua mecanismos capazes de protegê-lo contra perdas com créditos de liquidação duvidosa e de garantir medidas anticíclicas, o uso de práticas discricionárias por parte dos participantes do sistema 
bancário, se não controlado de alguma forma, pode desvirtuar os mecanismos de proteção criados pelo Regulador.

Uma das principais limitações deste trabalho está associada à dificuldade da coleta dos dados. Cita-se, por exemplo, a informação referente aos saldos das carteiras de créditos, segregados por níveis de risco e situação de atraso (normal ou anormal); essas informações deveriam constar nas notas explicativas dos bancos, entretanto, nem todos divulgam tais dados e, quando isso acontece, partem de premissas totalmente distintas. Alguns bancos consideram em atraso as operações vencidas a partir do primeiro dia; outros seguem os conceitos de situação normal e anormal e consideram atrasos as operações vencidas por mais de 15 dias. Alguns bancos segregam suas operações por segmento (pessoa física, pessoa jurídica e governos), outros as dividem por tipos de operação (empréstimos, financiamentos, etc.); enfim, não há uma uniformidade dos dados. Tal situação levou à adição de proxies representativas de operações crédito em curso normal e anormal. Outro limitador refere-se à falta de transparência dos bancos brasileiros acerca das provisões adicionais para créditos de liquidação duvidosa. Os motivos das provisões, quando constituídas, em geral não são evidenciados.

Uma limitação adicional deve-se ao fato de os modelos estimados não terem sido adequados para análise segregada da relação entre os ciclos econômicos do Brasil e a DPCLD dos bancos privados e públicos. Ao analisar a relação entre os ciclos econômicos do Brasil e a DPCLD registrada apenas pelos bancos privados, os resultados foram praticamente os mesmos obtidos na análise da amostra completa (com bancos privados e públicos). Entretanto, o modelo estimado mostrou-se inadequado para a análise da relação entre os ciclos econômicos do Brasil e a DPCLD registrada pelos bancos públicos, provavelmente por não terem sido consideradas, nos modelos, variáveis relacionadas a certas peculiaridades desses bancos, devido ao seu caráter de empresa pública.

Sugere-se, para trabalhos futuros, a estimação de modelos de investiguem a relação entre os ciclos econômicos do Brasil e a DPCLD registrada pelos bancos públicos, de forma a estabelecer uma comparação com os resultados encontrados na presente pesquisa.

Recomenda-se, também, a realização de estudos sobre os efeitos da crise financeira internacional de 2008 sobre a economia brasileira e as consequências da política expansionista adotada pelo Brasil na tentativa de contenção da crise de 2008. 
Por fim, para trabalho futuros, propõem-se estudos relacionados aos efeitos causados pela adoção das normas internacionais de contabilidade, alteradas em decorrência da crise financeira internacional de 2008, sobretudo em relação à IFRS 9 - Financial Instruments (IASB, 2015). 


\section{REFERÊNCIAS}

AHMED, A.; TAKEDA, C.; THOMAS, S. Bank loan loss provisions: a reexamination of capital management, earnings management and signaling effects. Journal of Accounting and Economics. New York: v. 28, n. 1, p. 1-25, Nov. 1999.

ALALI, F.; JAGGI, B. Earnings versus capital ratios management: role of bank types and SFAS 114. Original Research. v. 36, p. 105-132, 2011.

ARAÚJO, A. M. H. B. A ciclicidade da provisão para créditos de liquidação duvidosa em bancos comerciais. 2014. 175 p. Tese (Doutorado em Ciências Contábeis) - Programa Multiinstitucional e Inter-regional de Pós-graduação em Ciências Contábeis - UnB/UFPB/UFRN, Brasília.

BANCO CENTRAL DO BRASIL (BACEN). Circular 1.273, de 29 de dezembro de 1987: Institui, para adoção obrigatória a partir do Balanço de 30.06.88, o Plano Contábil das Instituições do Sistema Financeiro Nacional - COSIF. Brasília: DF, 1987.

Circular 3.630, de 18 de fevereiro de 2013: Dispensa as instituições financeiras e demais instituições autorizadas a funcionar pelo Banco Central do Brasil da elaboração e remessa do documento Informações Financeiras Trimestrais (IFT). Brasília: DF, 2013.

Diagnóstico da convergência às normas internacionais: IAS 39 - Financial Instruments: Recognition and Measurement. Disponível em:<http://www.bcb.gov.br/nor/convergencia/IAS_39_Instrumentos_Financeiros_Escopo_e_ Definicoes.pdf $>$. Acesso em 06 jul. 2008.

IFT - Informações Financeiras Trimestrais. Disponível em:

$\overline{<h t t p: / / w w w . b c b . g o v . b r / ? I F T>. ~ A c e s s o ~ e m: ~} 30$ dez. 2014.

BARBOSA FILHO, N. H. Estimando e revisando o produto potencial do Brasil: uma análise do filtro Hodrick-Prescott com função de produção. In: GENTIL, D. L.; MESSENBERG, R. $\mathrm{P}$. (Org.). Crescimento econômico: produto potencial e investimento. Rio de Janeiro: IPEA, 2009, p. 33-57.

BALTAGI, B. H. Econometric Analysis of panel data. 3.ed. England: John Wiley \& Sons Ltd., 2005. 

2008.

Econometric Analysis of panel data. 4. ed. England: John Wiley \& Sons Ltd.,

BAUM, C. F. An Introduction to Modern Econometrics Using Stata. United States of America: Stata Press, 2006.

BEATTY, A.; LIAO, S. Do delays in expected loss recognition affect banks' willingness to lend? Journal of Accounting and Economics. New York: v. 52, n. 1, p. 1-20, June 2011.

BEAVER, W. H.; ENGEL, E. E. Discretionary behavior with respect to allowance for loan losses and the behavior of securities prices. Journal of Accounting and Economics. New York: v. 22, n. 1-3, p. 177-206, Oct.-Dec. 1996.

BECK, T.; LEVINE, R.; LOAYZA, N. Finance and sources of growth. Journal of Financial Economics. New York: v. 58, p. 261-300, 2000.

BERGER, A. N.; BOUWMAN C. H. S. How does capital affect bank performance during financial crises? Journal of Financial Economics. v. 109, p. 146-176, 2013.

BETANCOURT, L.; BARIL, C.P. Accounting for loan losses: is dynamic provisioning the answer? Bank, Accounting and Finance. Nov-Dec, 2009.

BIKKER, J. A.; METZEMAKERS, P. A. J. Bank provisioning behavior and procyclicality. Journal of International Financial Markets, Institutions and Money. Michigan: v. 15, n. 2, p. 141-157, April 2005.

BORIO, C.; FURFINE C.; LOWE, P. Procyclicality of the financial system and financial stability issues and policy options. BIS Papers n.1, March. 2001.

BOUVATIER, V.; LEPETIT, L. Banks' procyclical behavior: Does provisioning matter? Journal of International Financial Markets, Institutions and Money. Michigan: v. 18, n. 5, p. 513-526, Dec. 2008.

BOUVATIER, V.; LEPETIT, L. Provisioning rules and bank lending: a theoretical model. Journal of Financial Stability. New York: v. 8, n. 1, p. 25-31, Jan. 2012a.

BOUVATIER, V.; LEPETIT, L. Effects of loan loss provisions on growth in bank lending: some international comparisons. International Economics. Paris: v. 132, p. 91-116, April. $2012 b$. 
BOUVATIER, V.; LEPETIT, L.; STROBEL, F. Bank income smoothing, ownership concentration and the regulatory environment. Journal of Banking and Finance. Vol. 41, p. 253-270, Feb. 2014. Disponível em: <http://gdre2013.conference.univ-poitiers.fr/wpcontent/uploads/sites/21/2014/05/Bouvatier_Lepetit_Strobel.pdf $\geq$. Acesso em 01 jul. 2014.

BRASIL. Lei $\mathrm{n}^{\circ}$ 4.595, de 31 de dezembro de 1964. Dispõe sobre a política e as instituições monetárias, bancárias e creditícias, cria o Conselho Monetário Nacional e dá outras providências. Diário Oficial da União, 31 de janeiro de 1965. Disponível em: $<$ http://www.planalto.gov.br/ccivil_03/leis/L4595.htm>. Acesso em 16 mai. 2012.

BROOKS, C. Introductory Econometric for Finance. London: Cambridge University Press, 2008.

BUSHMAN, R. M.; WILLIAMS, C. D. Accounting discretion, loan loss provisioning, and discipline of Banks'risk-taking. Journal of Accounting and Economics. New York: v. 54, p. 1-18, 2012.

CAMERON, A. C; TRIVEDI, P. K. Microeconometrics: methods and applications. New York: Cambridge University Press, 2009.

Microeconometrics using Stata. 2. ed. Texas: Stata Press, 2010.

CAVALLO, M.; MAJNONI, G. Do banks provision for bad loans in good times? World Bank Policy Research Working Paper N. 2.619. Disponível em: $<$ http://wwwwds.worldbank.org/servlet/WDSContentServer/WDSP/IB/2001/07/27/000094946_01071204 123124/Rendered/PDF/multi0page.pdf> Acesso em 30 jun. 2013.

CHENG, Q.; WARFIELD, T.; YE, M. Equity incentives and earnings management: evidence from the banking industry. Journal of Accounting, Auditing and Finance. New York: v. 26, n. 2, p. 317-349, April 2011.

COMPTON, R.; SILVA, J.R. Finance and Business Cycle: A Kalman filter approach with Markov Switching. Working Paper Series. Brasília, n. 97, Aug. 2005. Disponível em: $<$ http://www.bcb.gov.br/pec/wps/ingl/wps97.pdf >. Acesso em 14 out. 2013.

COMITÊ DE PRONUNCIAMENTOS CONTÁBEIS (CPC). Pronunciamento técnico CPC 25: provisões, passivos contingentes e ativos contingentes. Correlação às normas internacionais de contabilidade - IAS 27. Brasília: DF, 2009. Disponível em: $<$ http://www.cpc.org.br/CPC/Documentos-Emitidos/Pronunciamentos>. Acesso em 16 mai. 2012. 
CONSELHO MONETÁRIO NACIONAL (CMN). Resolução 2.682, de 21 de dezembro de 1999. Dispõe sobre critérios de classificação das operações de crédito e regras para constituição de provisão para créditos de liquidação duvidosa. Brasília: DF, 1999. Disponível em: $<$ http://www.cosif.com.br/mostra.asp?arquivo=r2682>. Acesso em 16 mai. 2012.

Resolução 3.786, de 24 de setembro de 2009. Dispõe sobre a elaboração e a divulgação de demonstrações contábeis consolidadas com base no padrão contábil internacional emitido pelo International Accounting Standards Board (IASB). Brasília: DF, 2009. Disponível em:

$<$ http://www.bcb.gov.br/pre/normativos/busca/downloadNormativo.asp?arquivo=/Lists/Norm ativos/Attachments/47513/Res_3786_v1_O.pdf>. Acesso em 16 mai. 2012.

CRESWELL, J. W. Research design: qualitative, quantitative, and mixed methods approaches. Califórnia: SAGE, 2009.

CUSINATO, R. T.; MINELLA, A.; PÔRTO JÚNIOR, S. S. Hiato do produto e PIB no Brasil: uma análise de dados em tempo real. Trabalhos para Discussão. Brasília, n. 203, abril, 2010. Disponível em: <http://www.bcb.gov.br/pec/wps/port/wps203.pdf>. Acesso em 30 jun. 2013.

DANTAS, J. A. Auditoria em instituições financeiras: determinantes de qualidade no mercado brasileiro. 2012. 173 p. Tese (Doutorado em Ciências Contábeis) - Programa Multi-institucional e Inter-regional de Pós-graduação em Ciências Contábeis UnB/UFPB/UFRN, Brasília.

DANTAS, J. A; LUSTOSA, P. R. B.; MEDEIROS, O. R. Validação de modelo ampliado para avaliação da discricionariedade da PCLD em bancos. In: CONGRESSO USP DE CONTROLADORIA E CONTABILIDADE, 12, 2012, São Paulo. Anais... São Paulo: USP.

DRUMOND, I. Bank capital requirements, business cycle fluctuations and the Basel accords: a synthesis. Journal of Economic Surveys. Oxford: v. 23, n. 5, p. 798-830, 2009.

EL SOOD, H. A. Loan loss provisioning and income smoothing in US banks pre and post the financial crisis. International Review of Financial Analysis. Hattiesburg: v. 25, p. 64-72, 2012.

FAVERO, L. P. Métodos quantitativos com Stata. Rio de Janeiro: Elsevier, 2014.

Análise de dados: modelos de regressão com Excel ${ }^{\circledR}$, Stata ${ }^{\circledR}$ e SPSS ${ }^{\circledR}$. Rio de Janeiro: Elsevier, 2015. 
FINANCIAL STABILITY BOARD (FSB). Report of the financial stability forum on addressing pro-cyclicality in the financial system. Basel: Apr. 2009. Disponível em: $<$ http://www.financialstabilityboard.org/publications/r_0904a.pdf $>$. Acesso em: 04 jul. 2011.

FONSECA, A.R.; GONZALES, F. Cross country determinants of bank income smoothing by managing loan loss provisions. Journal of Banking and Finance. Brighton: v. 32, n. 2, p. 217-228, Feb. 2008.

GREENAWALT, M.B; SINKEY, J.F. Bank loan-loss provisions and the income smoothing hypothesis: an empirical analysis, 1976-1984. Journal of Financial Services Research. Stockholm: v. 1, p. 301-318, 1988.

GUJARATI, D. N. Econometria Básica. Tradução: Maria José Cyhlar Monteiro. 4. ed. Rio de Janeiro: Elsevier, 2006.

INSTITUTO DE PESQUISA ECONÔMICA APLICADA (IPEA). Base de dados macroeconômicos. Disponível em: <http:// www.ipeadata.gov.br>. Acesso em: 29 set. 2014.

INTERNATIONAL ACCOUNTING STANDARDS BOARD (IASB). International Accounting Standard n. 37 - Provisions, Contingent Liabilities and Contingent Assets. IASB: London, 2009.

International Accounting Standard n. 39 - Financial Instruments: Recognition and Measurement. IASB: London, 2008.

International Financial Accounting Standard no 9 - Financial Instruments:

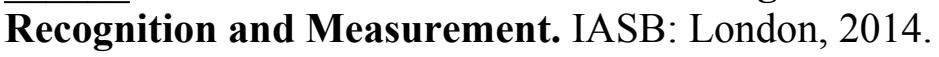

IUDÍCIBUS, S. de; MARTINS, E.; GELBCKE, E. R.; SANTOS, A. dos. Manual de contabilidade societária: aplicável a todas as sociedades. 2. ed. São Paulo: Atlas, 2013.

KANARAGETNAM, K; LIM, C. Y.; LOBO, G. J. Auditor reputation and earnings management: international evidence from bank industry. Journal of Banking and Finance. v. 34 , p. 2328-2327, 2010.

KANAGARETNAM, K.; LOBO, G. J.; MATHIEU, R. Managerial incentives for income smoothing through bank loan loss provisions. Review of Quantitative Finance and Accounting. New Jersey: v. 20, n.1, p. 63-80, 2003. 
KIM, M-S; KROSS, W. The impact of the 1989 change in bank capital standards on loan loss provisions and loan write-offs. Journal of Accounting and Economics. New York: v. 25, n. 1, p. 69-99, Feb.1998.

KING, R.; LEVINE, R. Financial Intermediation and Economic Development, In: MAYER, C.; VIVES, X. Financial Intermediation in the Construction of Europe. London: Center for Economic Policy Research, p. 156-189, 1993 a.

Finance and Growth: Schumpeter might be right. Quarterly Journal of Economics. Oxford: v. 108, n. 3, p. 717-737, Aug. 1993b.

Finance, entrepreneurship and growth: theory and evidence. Journal of Monetary Economics. North Holland: v. 32, n. 3, p. 513-542, 1993c.

LAEVEN, L.; MAJNONI, G. Loan loss provisioning and economic slowdowns: too much, too late? Journal of Financial Intermediation. New York: v. 12, n. 2, p. 178-197, Apr. 2003.

LEVINE, R. Law, finance, and economic growth. Journal of Financial Intermediation. New York: v. 8, n. 1-2, p. 8-35, Jan. 1999.

LIU, C. C.; RYAN, S. G.; WAHLEN, J. M. Differential valuation implications of loan loss provisions across bank and fiscal quarters. The Accounting Review. Sarasota: v. 72, n. 1, p.133-146. Jan. 1997.

LOPES, F. L. A dimensão da crise. In: BACHA, E.; GOLDFAJN, I. (Orgs.) Como reagir à crise: políticas econômicas para o Brasil. Rio de Janeiro: Imago, 2009, p. 13-16.

MARCONDES, D. A. Disciplina de mercado e as acumulações contábeis discricionárias. 2008. 142p. Tese (Doutorado em Ciências Contábeis) - Faculdade de Economia, Administração e Contabilidade, Universidade de São Paulo, São Paulo.

MARTINS, G. de A.; THEÓPHILO, C. Metodologia da investigação científica para ciências sociais aplicadas. São Paulo: Atlas, 2007.

MATOS, O. C. Desenvolvimento do Sistema Financeiro e crescimento econômico no Brasil: evidências de causalidade. Texto para discussão n. 49. Brasília: BACEN, 2002. 
MESQUITA, M.; TORÓS, M. Considerações sobre a atuação do Banco Central na crise de 2008. Trabalho para discussão n. 202. Brasília: BACEN, 2010

MIRANDA, L. C. The role of interfirm information exchange and choice of coordination mechanism on performance in the U.S. pork supply chain. 1997. 246p. Tese (Doutorado em Economia Agrícola) - Universidade de Illinois, Urbana.

MISSIO, F. J.; JAYME JR., F. G.; OLIVEIRA, A. M. H. C. Desenvolvimento financeiro e crescimento econômico: teoria e evidência empírica para os estados brasileiros (1995-2004)

Texto para discussão n. 379. Belo Horizonte: UFMG/Cedeplar, 2009.

MOREIRA, T. B. S.; SOARES, F. A. R. A crise financeira e as políticas anticíclicas do Brasil. Monografia. (Finanças Públicas - XV Prêmio Tesouro Nacional). Tema III - Política fiscal e a crise econômica internacional. Brasília: Tesouro Nacional, 2010.

PAULO, E. Manipulação das informações contábeis: uma análise teórica e empírica sobre os modelos operacionais de deteç̧ão de gerenciamento de resultados. 2007, v. 1. 260p. Tese (Doutorado em Ciências Contábeis) - Faculdade de Economia, Administração e Contabilidade, Universidade de São Paulo, São Paulo.

RAVITCH, S. M.; RIGGAN, M. Reason \& rigor: how conceptual frameworks guide research. California: SAGE, 2011.

REPULLO, R., SUAREZ, J. The procyclical effects of Basel II. In: 9th JACQUES POLAK ANNUAL RESEARCH CONFERENCE, 2008, Washington, DC. Anais eletrônicos... Washington: International Monetary Fund, 2008. Disponível em:

$<$ http://www.imf.org/external/np/res/seminars/2008/arc/pdf/rs1.pdf $>$. Acesso em 13 jul. 2013.

ROCHA, B. P.; NAKANE, M. I. Sistema Financeiro e desenvolvimento econômico: evidências de causalidade em um painel para o Brasil. In: ENCONTRO NACIONAL DE ECONOMIA, n. 35, 2007. Anais... São Paulo: ANPEC, 2007.

ROUBINI, N.; MIHN, S. Crisis economics: a crash in the future of finance. Estados Unidos: Penguin Books, 2011.

ROUSSEAU, P. L.; WACHTEL, P. Financial intermediation and economic performance: historical evidence from five industrialized countries. Journal of Money, Credit, and Banking. Ohio: v. 30, n. 4, p.657-678, 1998. 
SANCHES, F. A. M.; ROCHA, B. P.; SILVA, J. C. D. Estimating a theoretical model of state banking competition using a dynamic panel: the Brazilian case. Revista Brasileira de Economia. Rio de Janeiro: v. 63, n. 1, p. 23-34, jan-mar. 2009.

SCOTT, W. R. Financial accounting theory. 6.ed. Toronto: Pearson Canada, 2009.

SILVA, A. C. R. da. Metodologia da pesquisa aplicada à contabilidade: orientações de estudos, projetos, relatórios, monografias, dissertações, teses. São Paulo: Atlas, 2003.

SILVA, E. N.; PORTO JÚNIOR, S. S. Sistema financeiro e crescimento econômico: uma aplicação de regressão quantílica. Economia aplicada. São Paulo: v. 10, n. 3, p. 425-442, julset. 2006.

SOUZA JÚNIOR, J. R. C. Produto potencial: conceitos e metodologia. In: GENTIL, D. L.; MESSENBERG, R. P. (Org.). Crescimento econômico: produto potencial e investimento. Rio de Janeiro: IPEA, 2009.

Produto Potencial como Ferramenta de Análise da Política Monetária e da Capacidade de Crescimento da Economia Brasileira. Revista da Anpec. 2013 (Prelo).

STATACORP. Stata, version 14.1: data analisys statistical software. Texas, USA: StataCorp, 2015. Eletronic download.

LUCAS, G. Estimativas de produto potencial para a economia brasileira: algumas observações críticas. In: ENCONTRO DA ASSOCIAÇÃO KEYNESIANA BRASILEIRA, 3, 2010, São Paulo. Anais... São Paulo: FGV, 2010.

TAKTAK, N. B.; ZOUARI, S. B. S.; BOUDRIGA, A. Do Islamic banks use loan loss provisions to smooth their results? Journal of Islamic Accounting and Business Research. Tunisia: v. 1, n. 2, p.114-127, 2010.

TORRES FILHO, E. T. Entendendo a crise no subprime. Rio de Janeiro: Banco Nacional de Desenvolvimento Econômico e social, 2008 (Visão do Desenvolvimento, n. 44).

WHITE, L. H. How did we get into this financial mess? Cato Institute Briefing Papers. Washington, DC: n. 110, 2008.

WOOLGRIDGE, J. M. Introdução à econometria: uma abordagem moderna. São Paulo: Cengage Learning, 2014. 
WOOLGRIDGE, J. M. Econometric analysis of cross section and panel data. 2. ed. Massachussets: Massachussets Institute of Tecnology, 2010.

ZICCHINO, L. A model of bank capital, lending and the macroeconomy: Basel I versus Basel II. Papers in Money, Macroeconomics and Finance. Manchester, 2006. Disponível em: $<$ http://bankofengland.co.uk/publications/Documents/workingpapers/wp270.pdf $>$. Acesso em 26 jul. 2013. 


\section{GLOSSÁRIO}

Bancos at risk: Bancos cujas carteiras de empréstimos apresentam considerável risco de inadimplir.

Bankscope: Banco de dados que contém informações financeiras de instituições bancárias públicas e privadas em escala mundial.

Ciclo Econômico: Flutuações na atividade econômica agregada, caracterizadas pela alternação entre períodos de expansão e de retração generalizada da economia.

Compustat: Bancos de dados com informações estatísticas, financeiras e de mercado de companhias, ativas e inativas, em escala mundial.

Derivativo: Instrumento financeiro com as seguintes características: (a) seu valor muda em resposta a alterações em uma taxa de juros específica, no preço do instrumento, no risco de crédito etc.; (b) não requer investimento inicial ou este seria menor do que o requerido por outros tipos de contratos com respostas esperadas semelhantes a mudanças do mercado; (c) é liquidável em uma data futura.

Federal Housing Administration (FHA): Agência do governo dos Estados Unidos criada como parte do National Housing Act de 1934, estabelecendo normas para a construção e garantia firme de empréstimos feitos por bancos e por credores privados para construção de residências.

Federal Open Market Committee (FOMC): Comitê interno do Federal Reserve System, responsável por decisões relacionadas a taxas de juros e à oferta monetária da economia norte-americana.

Federal Reserve System: Sistema de Reserva Federal do Estados Unidos da América, composto por um conselho de governadores (Federal Reserve Board), pelo Federal Open Market Committee (FOMC) e pelos doze presidentes de Federal Reserve Banks regionais, 
além dos representantes de bancos privados dos Estados Unidos e diversos conselhos consultivos.

G10: Organização que, apesar do nome, atualmente reúne as treze economias mais desenvolvidas, formadas pelos governos centrais da Alemanha, Austrália, Bélgica, Canadá, Espanha, Estados Unidos, França, Itália, Japão, Países Baixos, Reino Unido, Suécia e Suíça.

G20: Grupo formado pelos ministros de economia e chefes de bancos centrais das 19 maiores economias do mundo e da União Europeia, com o objetivo de promover o debate entre países industrializados e emergentes sobre assuntos relacionados à estabilidade econômica mundial.

Gerenciamento de resultados: Manipulação dos resultados com a intenção de evidenciar uma imagem diferente da entidade.

Hiato do Produto: Indicador que mede a diferença entre o PIB efetivo e o PIB potencial.

Instrumento Financeiro: Qualquer contrato que gere um ativo financeiro para uma entidade e um passivo financeiro ou instrumento patrimonial para outra entidade.

London Interbank Offered Rate (LIBOR): Taxa de juros preferencial, do mercado internacional, utilizada entre bancos de primeira linha no mercado monetário.

Modelo de provisão ex-post: Provisão para créditos de liquidação duvidosa pelo método da perda incorrida.

Modelo de provisão ex-ante: Provisão para créditos de liquidação duvidosa pelo método da perda esperada.

Modelos de risco de crédito: Modelos que visam a atribuir uma medida de risco a um devedor (ou grupo de devedores) ou a uma operação de crédito (ou carteira de crédito) específica.

NASDAQ: Mercado de ações automatizado norte-americano, com a finalidade de cotar empresas de alta tecnologia. 
PIB Efetivo: Valor total dos bens e serviços finais produzidos no país durante um determinado período de tempo.

PIB Nominal: PIB calculado a preços correntes.

PIB Potencial: Nível do produto a ser obtido com a plena utilização dos recursos disponíveis na economia, sem gerar pressões sobre a taxa de inflação.

PIB Real: PIB calculado a preços constantes.

Processo estocástico: Processo cujo comportamento é não determinístico, ou seja, varia aleatoriamente.

Pró-ciclicidade: Movimento que acompanha os ciclos econômicos, acentuando períodos de expansão e agravando períodos de crise.

Risco de crédito: Probabilidade de um tomador de crédito tornar-se inadimplente.

Securitização: Prática financeira que consiste em agrupar vários tipos de ativos financeiros (títulos de crédito, dívidas referentes a empréstimos etc.), convertendo-os em títulos negociáveis no mercado de capitais.

Suavização de resultados: Utilização de práticas contábeis para redução de flutuações no resultado de um período para o outro sem, no entanto, desobedecer às regras contábeis vigentes.

Tranche: Desdobramentos de contratos em parcelas, ou lotes, geralmente para obtenção de empréstimos ou operações de securitização. 


\section{APÊNDICE A - BANCOS PARTICIPANTES DA AMOSTRA}

Tabela A1 - Relação de bancos da amostra

(continua)

\begin{tabular}{|c|c|c|c|}
\hline Código & CNPJ & Nome & Segmento \\
\hline B001 & 00000000 & Banco do Brasil S.A. & Banco Múltiplo \\
\hline B002 & 00000208 & BRB - Banco de Brasília S.A. & Banco Múltiplo \\
\hline B003 & 00253448 & Banco Pottencial S.A. & Banco Comercial \\
\hline B004 & 00360305 & Caixa Econômica Federal & Caixa Econômica \\
\hline B005 & 00416968 & Banco Intermedium S/A & Banco Múltiplo \\
\hline B006 & 00517645 & Banco Ribeirão Preto S.A. & Banco Múltiplo \\
\hline B007 & 00558456 & Banco BGN S.A. & Banco Múltiplo \\
\hline B008 & 00795423 & Banco Semear S.A. & Banco Múltiplo \\
\hline B009 & 01023570 & Banco Rabobank International Brasil S.A. & Banco Múltiplo \\
\hline B010 & 01181521 & Banco Cooperativo SICREDI S.A. & Banco Múltiplo* \\
\hline B011 & 01522368 & BANCO BNP Paribas Brasil S.A. & Banco Múltiplo \\
\hline B012 & 01701201 & HSBC Bank Brasil S.A. - Banco Múltiplo & Banco Múltiplo \\
\hline B013 & 02038232 & Banco Cooperativo do Brasil S.A. - BANCOOB & Banco Comercial* \\
\hline B014 & 02318507 & Banco KEB do Brasil S.A. & Banco Comercial \\
\hline B015 & 02658435 & Banco Caterpillar S.A. & Banco Múltiplo \\
\hline B016 & 02977348 & Banco Toyota do Brasil S.A. & Banco Múltiplo \\
\hline B017 & 02992446 & Banco CNH Capital S.A. & Banco Múltiplo \\
\hline B018 & 03012230 & Hipercard Banco Múltiplo S.A. & Banco Múltiplo \\
\hline B019 & 03017677 & Banco J. Safra S.A. & Banco Múltiplo \\
\hline B020 & 03323840 & Banco Alfa S.A. & Banco Comercial \\
\hline B021 & 03502961 & Banco PSA Finance Brasil S.A. & Banco Múltiplo \\
\hline B022 & 03532415 & Banco CR2 S/A & Banco Comercial \\
\hline B023 & 03609817 & Banco Cargill S.A. & Banco Múltiplo \\
\hline B024 & 03634220 & Banco Honda S.A. & Banco Múltiplo \\
\hline B025 & 04184779 & Banco BRADESCARD S.A. & Banco Múltiplo \\
\hline B026 & 04902979 & Banco da Amazônia S.A. & Banco Comercial \\
\hline B027 & 04913711 & Banco do Estado do Pará S.A. & Banco Múltiplo \\
\hline B028 & 05040481 & Banco de Lage Landen Brasil S.A. & Banco Múltiplo \\
\hline B029 & 06271464 & Banco BRADESCO BBI S.A. & Banco Múltiplo \\
\hline B030 & 07207996 & Banco BRADESCO Financiamentos S.A. & Banco Múltiplo \\
\hline B031 & 07237373 & Banco do Nordeste do Brasil S.A. & Banco Múltiplo \\
\hline B032 & 07441209 & Banco Moneo S.A. & Banco Múltiplo \\
\hline B033 & 07450604 & Banco Industrial e Comercial S.A. & Banco Múltiplo \\
\hline B034 & 07656500 & Banco KDB do Brasil S.A. & Banco Múltiplo \\
\hline B035 & 07679404 & Banco Topázio S.A. & Banco Múltiplo \\
\hline B036 & 08357240 & Banco CSF S.A. & Banco Múltiplo \\
\hline
\end{tabular}


(continuação)

\begin{tabular}{|c|c|c|c|}
\hline Código & CNPJ & Nome & Segmento \\
\hline B037 & 09391857 & Banco Azteca do Brasil S.A. & Banco Múltiplo \\
\hline B038 & 09516419 & Banco Original do Agronegócio S.A. & Banco Múltiplo \\
\hline B039 & 09526594 & Banco VIPAL S.A. & Banco Múltiplo \\
\hline B040 & 10264663 & BBN Banco Brasileiro de Negócios S.A. & Banco Múltiplo \\
\hline B041 & 10371492 & Banco Yamaha Motor do Brasil S.A. & Banco Múltiplo \\
\hline B042 & 10664513 & Banco Gerador S.A. & Banco Múltiplo \\
\hline B043 & 10690848 & Banco da China Brasil S.A. & Banco Múltiplo \\
\hline B044 & 10866788 & Banco BANDEPE S.A. & Banco Múltiplo \\
\hline B045 & 10995587 & Banco Simples S.A. & Banco Múltiplo \\
\hline B046 & 11417016 & Scania Banco S.A. & Banco Múltiplo \\
\hline B047 & 11476673 & Banco Randon S.A. & Banco Múltiplo \\
\hline B048 & 13009717 & Banco do Estado de Sergipe S.A. & Banco Múltiplo \\
\hline B049 & 14388334 & Paraná Banco S.A. & Banco Múltiplo \\
\hline B050 & 15114366 & Banco BBM S/A & Banco Múltiplo \\
\hline B051 & 15173776 & Banco Capital S.A. & Banco Múltiplo \\
\hline B052 & 15357060 & Banco Woori Bank do Brasil S.A. & Banco Múltiplo \\
\hline B053 & 17184037 & Banco Mercantil do Brasil S.A. & Banco Múltiplo \\
\hline B054 & 17192451 & Banco Itaucard S.A. & Banco Múltiplo \\
\hline B055 & 17298092 & Banco Itaú BBA S.A. & Banco Múltiplo \\
\hline B056 & 17351180 & Banco Triângulo S.A. & Banco Múltiplo \\
\hline B057 & 27937333 & Banco BRJ S.A. & Banco Múltiplo \\
\hline B058 & 28127603 & BANESTES S.A. Banco do Estado do Espírito Santo & Banco Múltiplo \\
\hline B059 & 28195667 & Banco ABC Brasil S.A. & Banco Múltiplo \\
\hline B060 & 29030467 & Scotiabank Brasil S.A. Banco Múltiplo & Banco Múltiplo \\
\hline B061 & 30306294 & Banco BTG Pactual S.A. & Banco Múltiplo \\
\hline B062 & 30723886 & Banco Modal S.A. & Banco Múltiplo \\
\hline B063 & 31597552 & Banco Clássico S.A. & Banco Múltiplo \\
\hline B064 & 31880826 & Banco Guanabara S.A. & Banco Múltiplo \\
\hline B065 & 31895683 & Banco Industrial do Brasil S.A. & Banco Múltiplo \\
\hline B066 & 32062580 & Banco Credit Suisse (Brasil) S.A. & Banco Múltiplo \\
\hline B067 & 33042151 & Banco de La Nacion Argentina & Banco Comercial** \\
\hline B068 & 33042953 & Citibank N.A. & Banco Comercial** \\
\hline B069 & 33074683 & Banco Rural Mais S.A. & Banco Múltiplo \\
\hline B070 & 33124959 & Banco Rural S.A. & Banco Múltiplo \\
\hline B071 & 33132044 & Banco Cédula S.A. & Banco Múltiplo \\
\hline B072 & 33172537 & Banco J.P. Morgan S.A. & Banco Múltiplo \\
\hline B073 & 33254319 & HSBC Finance (Brasil) S.A. - Banco Múltiplo & Banco Múltiplo \\
\hline B076 & 33479023 & Banco Citibank S.A. & Banco Múltiplo \\
\hline
\end{tabular}


(continuação)

\begin{tabular}{|c|c|c|c|}
\hline Código & CNPJ & Nome & Segmento \\
\hline B077 & 33485541 & Banco Boavista Interatlântico S.A. & Banco Múltiplo \\
\hline B078 & 33603457 & Banco Rodobens S.A. & Banco Múltiplo \\
\hline B079 & 33644196 & Banco Fator S.A. & Banco Múltiplo \\
\hline B080 & 33700394 & UNIBANCO - União de Bancos Brasileiros S.A. & Banco Múltiplo \\
\hline B081 & 33870163 & Banco Alvorada S.A. & Banco Múltiplo \\
\hline B082 & 33884941 & BANIF - Banco Internacional do Funchal (Brasil), S.A. & Banco Múltiplo \\
\hline B083 & 33885724 & Banco Itaú Consignado S.A. & Banco Múltiplo \\
\hline B084 & 33923111 & Banco BRASCAN S.A. & Banco Múltiplo \\
\hline B085 & 33923798 & Banco Máxima S.A. & Banco Comercial \\
\hline B086 & 34098442 & Banco Citicard S.A. & Banco Múltiplo \\
\hline B087 & 34270520 & Banco IBM S.A. & Banco Múltiplo \\
\hline B088 & 43818780 & Banco Commercial Investment Trust do Brasil S.A. & Banco Múltiplo \\
\hline B089 & 44189447 & Banco de La Provincia de Buenos Aires & Banco Comercial $^{* *}$ \\
\hline B090 & 48795256 & Banco Bracce S.A. & Banco Múltiplo \\
\hline B091 & 49336860 & Ing Bank N.V. & Banco Comercial ${ }^{* *}$ \\
\hline B092 & 49925225 & Banco Itauleasing S.A. & Banco Múltiplo \\
\hline B093 & 50585090 & BCV - Banco de Crédito e Varejo S/A & Banco Múltiplo \\
\hline B094 & 51938876 & Banco de La Republica Oriental Del Uruguay & Banco Comercial $^{* *}$ \\
\hline B095 & 54403563 & Banco ARBI S.A. & Banco Comercial \\
\hline B096 & 57839805 & BancoTricury S.A. & Banco Múltiplo \\
\hline B097 & 58017179 & Banco Volvo Brasil S.A. & Banco Múltiplo \\
\hline B098 & 58160789 & Banco Safra S.A. & Banco Múltiplo \\
\hline B099 & 58497702 & Banco INTERCAP S.A. & Banco Múltiplo \\
\hline B100 & 58616418 & Banco Fibra S.A. & Banco Múltiplo \\
\hline B101 & 59109165 & Banco Volkswagen S.A. & Banco Múltiplo \\
\hline B102 & 59118133 & Banco Luso Brasileiro S.A. & Banco Múltiplo \\
\hline B103 & 59274605 & Banco GMAC S.A. & Banco Múltiplo \\
\hline B104 & 59285411 & Banco Panamericano S.A. & Banco Múltiplo \\
\hline B105 & 59438325 & Banco BRADESCO Cartões S.A. & Banco Múltiplo \\
\hline B106 & 59461152 & Banco ITAUCRED Financiamentos S.A. & Banco Múltiplo \\
\hline B107 & 59588111 & Banco Votorantin S.A. & Banco Múltiplo \\
\hline B108 & 60394079 & Banco Itaubank S.A. & Banco Múltiplo \\
\hline B109 & 60419645 & Banco Bankpar S.A. & Banco Múltiplo \\
\hline B110 & 60498557 & Banco de Tokyo-Mitsubishi UFJ Brasil S.A. & Banco Múltiplo \\
\hline B111 & 60518222 & Banco Sumimoto Mitsui Brasileiro S.A. & Banco Múltiplo \\
\hline B112 & 60701190 & Itaú UNIBANCO S.A. & Banco Múltiplo \\
\hline B113 & 60746948 & Banco BRADESCO S.A. & Banco Múltiplo \\
\hline
\end{tabular}


(conclusão)

\begin{tabular}{|c|c|c|c|}
\hline Código & CNPJ & Nome & Segmento \\
\hline B114 & 60814191 & Banco Mercedes-Benz do Brasil S.A. & Banco Múltiplo \\
\hline B115 & 60850229 & Banco Pecunia S.A. & Banco Múltiplo \\
\hline B116 & 60872504 & Itaú UNIBANCO Holding S.A. & Banco Múltiplo \\
\hline B117 & 60889128 & Banco SOFISA S.A. & Banco Múltiplo \\
\hline B118 & 61024352 & Banco Indusval S.A. & Banco Comercial \\
\hline B119 & 61033106 & BPN Brasil Banco Múltiplo S.A. & Banco Múltiplo \\
\hline B120 & 61071387 & Unicard Banco Múltiplo S.A. & Banco Múltiplo \\
\hline B121 & 61088183 & Banco Westlb do Brasil S.A. & Banco Múltiplo \\
\hline B122 & 61146577 & Banco Barclays S.A. & Banco Múltiplo \\
\hline B123 & 61182408 & Banco Investcred Unibanco S.A. & Banco Comercial \\
\hline B124 & 61186680 & Banco BMG S.A. & Banco Múltiplo \\
\hline B125 & 61190658 & Banco FIAT S.A. & Banco Múltiplo \\
\hline B126 & 61199881 & Banco Dibens S.A. & Banco Múltiplo \\
\hline B127 & 61348538 & Banco FICSA S.A. & Banco Múltiplo \\
\hline B128 & 61533584 & Banco Societe Generale Brasil S.A. & Banco Múltiplo \\
\hline B129 & 61820817 & Banco Paulista S.A. & Banco Comercial \\
\hline B130 & 62073200 & Bank of America Merrill Lynch Banco Múltiplo S.A. & Banco Múltiplo \\
\hline B131 & 62144175 & Banco Pine S.A. & Banco Múltiplo \\
\hline B132 & 62232889 & Banco Daycoval S.A. & Banco Múltiplo \\
\hline B133 & 62237425 & Banco Fidis S/A & Banco Múltiplo \\
\hline B134 & 62331228 & Deutsche Bank S.A. - Banco Alemão & Banco Múltiplo \\
\hline B135 & 62421979 & Banco Cifra S/A & Banco Múltiplo \\
\hline B136 & 68900810 & Banco Rendimento S.A. & Banco Comercial \\
\hline B137 & 71027866 & Banco Bonsucesso S.A. & Banco Múltiplo \\
\hline B138 & 74828799 & NBC Bank Brasil S. A. - Banco Múltiplo & Banco Múltiplo \\
\hline B139 & 75647891 & Banco Credit Agricole Brasil S.A. & Banco Múltiplo \\
\hline B140 & 78626983 & Banco VR S.A. & Banco Múltiplo \\
\hline B141 & 78632767 & Banco Ourinvest S.A. & Banco Múltiplo \\
\hline B142 & 80271455 & Banco Maxinvest S.A. & Banco Múltiplo \\
\hline B143 & 90400888 & Banco Santander (Brasil) S.A. & Banco Múltiplo \\
\hline B144 & 90731688 & Banco Ford S.A. & Banco Múltiplo \\
\hline B145 & 91884981 & Banco John Deere S.A. & Banco Múltiplo \\
\hline B146 & 92702067 & Banco do Estado do Rio Grande do Sul S.A. & Banco Múltiplo \\
\hline B147 & 92874270 & Banco A.J. Renner S.A. & Banco Múltiplo \\
\hline B148 & 92894922 & Banco Original S/A & Banco Múltiplo \\
\hline
\end{tabular}

Notas: *Banco Cooperativo; **Banco Estrangeiro - Filial no país 


\section{APÊNDICE B -VARIÁVEIS PARA O CÁLCULO DA DPCLD PELO MÉTODO DA PERDA INCORRIDA DE BOUVATIER E LEPETIT (2012a)}

Os valores das despesas com créditos de liquidação duvidosa pelo método da perda incorrida, a partir da aplicação do modelo teórico proposto por Bouvatier e Lepetit (2012a), requereram a determinação dos valores trimestrais do hiato do produto e da elasticidade dos empréstimos.

Os valores trimestrais do hiato do produto foram calculados e gentilmente cedidos pelo Professor José Ronaldo de Castro Souza Junior, PhD.

Segundo Bouvatier e Lepetit (2012a), a elasticidade dos empréstimos ( $\omega$ ) é determinada pela aplicação da formula evidenciada na equação 12 (ver capítulo 3), abaixo transcrita:

$$
\lambda_{1}=\left(1-\rho_{1}\right) \cdot \omega \therefore \omega=\frac{\lambda_{1}}{1-\rho_{1}}
$$

em que $\lambda_{1}$ e $\rho_{1}$ são obtidos através do modelo evidenciado na equação 11, abaixo transcrito:

$$
I_{0(i, t)}=c+\rho_{1} I_{0(i, t-1)}+\lambda_{1}\left(y_{t} / y\right)+\varepsilon_{i, t}
$$

Onde: $I_{0(i, t)}$ é a razão entre a média de empréstimos em atraso em relação ao total de empréstimos, calculado conforme a equação 9 (ver capítulo 3 ); $I_{0(i, t-1)}$ equivale a $I_{0(i, t)}$ com um trimestre de defasagem; $\left(y_{t} / y\right)$ denota o hiato do produto; $\rho_{1}$ e $\lambda_{1}$ são os parâmetros das variáveis do modelo.

Estimada a regressão de dados em painel dinâmico (tabela B1), foi possível determinar o valor da elasticidade dos empréstimos:

$$
\omega=\frac{\lambda_{1}}{1-\rho_{1}}=\frac{-0,3392264}{(1-0,5534662)}=-0,7596881
$$


Tabela B1 - Regressão de dados em painel dinâmico

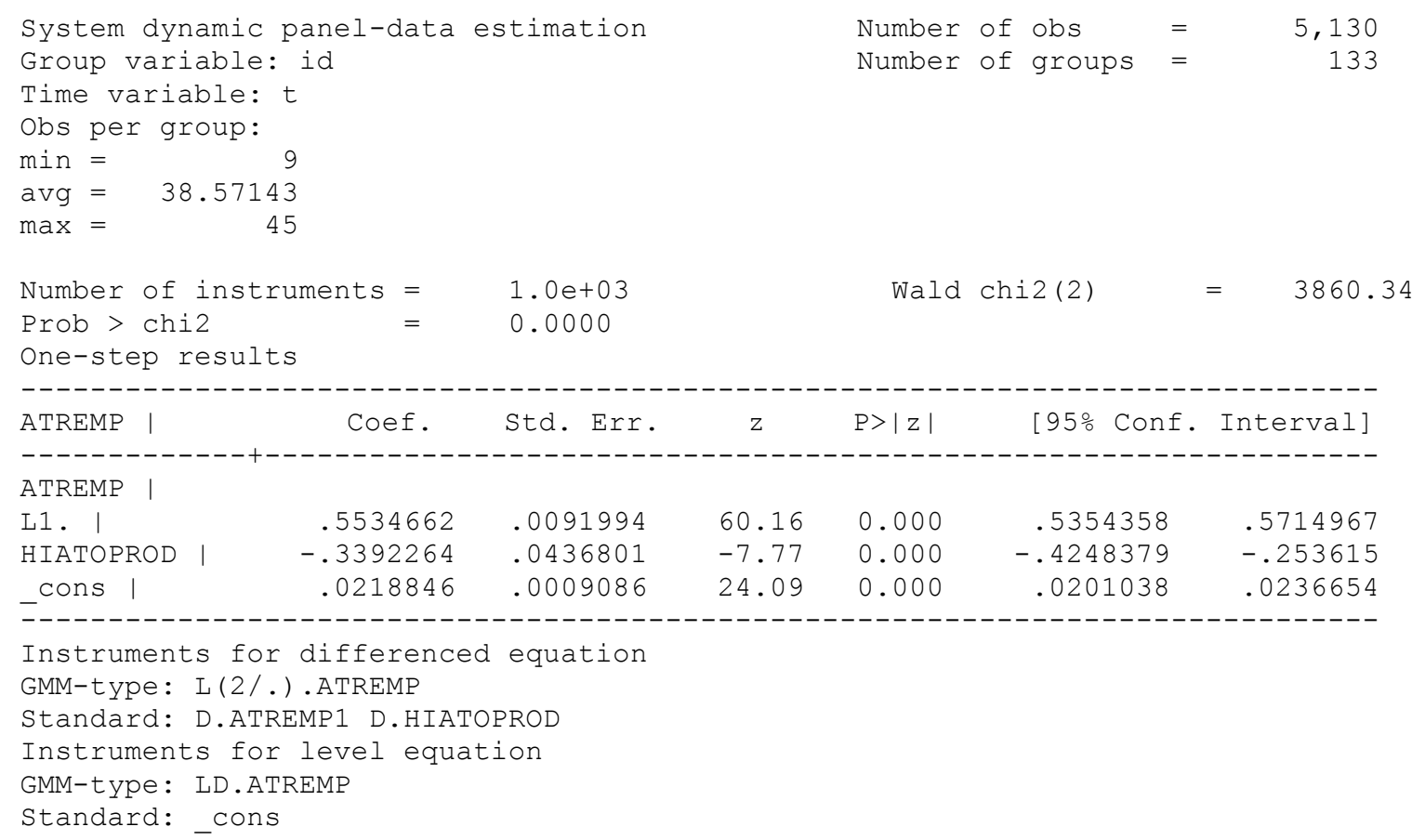

- - - - - - -

Fonte: Dados da pesquisa; output do software Stata 14 (STATACORP, 2015).

Notas: ATREMP $=$ valor médio dos empréstimos com atraso superior a 15 dias; HIATOPROD $=$ hiato do produto;_cons = intercepto 